\title{
Local and large scale determinants of biodiversity in winter wheat fields
}

\author{
Dissertation \\ zur Erlangung des Doktorgrades \\ an der Fakultät für Agrarwissenschaften \\ der Georg-August-Universität Göttingen
}

vorgelegt von

Yann Clough

geboren in Saint-Germain-en-Laye

Göttingen, Februar 2006 
D 7

1. Referent: Prof. Dr. Teja Tscharntke

2. Korreferent: Prof. Dr. Stefan Vidal

Tag der mündlichen Prüfung: 02.02.2006 


\section{Table of contents}

1 Local and large scale determinants of biodiversity in winter wheat fields: 5 General introduction

Introduction $\quad 5$

$\begin{array}{ll}\text { Study area and organisms } & 6\end{array}$

$\begin{array}{ll}\text { Main questions } & 9\end{array}$

Results and conclusions $\quad 9$

$\begin{array}{ll}\text { References } & 10\end{array}$

$2 \quad$ Spider diversity in cereal fields: comparing factors at local, landscape 13 and regional scales

$\begin{array}{ll}\text { Abstract } & 13\end{array}$

$\begin{array}{ll}\text { Introduction } & 14\end{array}$

$\begin{array}{ll}\text { Material and methods } & 16\end{array}$

$\begin{array}{lc}\text { Results } & 18\end{array}$

$\begin{array}{ll}\text { Discussion } & 20\end{array}$

$\begin{array}{ll}\text { References } & 24\end{array}$

$3 \quad$ Functional grouping helps understand staphylinid response to 29 farming system

$\begin{array}{ll}\text { Abstract } & 29\end{array}$

$\begin{array}{ll}\text { Introduction } & 29\end{array}$

$\begin{array}{ll}\text { Material and methods } & 31\end{array}$

Results 33

Discussion $\quad 34$

$\begin{array}{ll}\text { References } & 37\end{array}$

$\begin{array}{ll}\text { Appendix } & 40\end{array}$

$4 \quad$ Untangling local and landscape factors affecting the insect herbivore 44 community of non-crop plants in arable fields

$\begin{array}{ll}\text { Abstract } & 44\end{array}$

$\begin{array}{ll}\text { Introduction } & 45\end{array}$

$\begin{array}{ll}\text { Material and methods } & 46\end{array}$ 
$\begin{array}{lr}\text { Results } & 50\end{array}$

Discussion $\quad 53$

$\begin{array}{ll}\text { References } & 56\end{array}$

$5 \quad \alpha$ and $\beta$ diversity responses to crop management differ between $\quad 60$ species groups

$\begin{array}{ll}\text { Abstract } & 60\end{array}$

$\begin{array}{ll}\text { Introduction } & 60\end{array}$

$\begin{array}{ll}\text { Material and methods } & 63\end{array}$

Results $\quad 66$

$\begin{array}{ll}\text { Discussion } & 68\end{array}$

$\begin{array}{ll}\text { Conclusion } & 71\end{array}$

$\begin{array}{ll}\text { References } & 71\end{array}$

$\begin{array}{ll}\text { Summary } & 75\end{array}$

$\begin{array}{ll}\text { Zusammenfassung } & 77\end{array}$

$\begin{array}{lr}\text { Acknowledgments } & \mathbf{8 0}\end{array}$

$\begin{array}{ll}\text { Publications } & \mathbf{8 2}\end{array}$

$\begin{array}{lr}\text { Curriculum vitae } & 84\end{array}$ 


\section{Chapter 1}

\section{Local and large scale determinants of biodiversity in winter wheat fields: General introduction}

\section{Introduction}

Local agricultural practices as well as large scale land-use have changed considerably during the last decades. While at the field scale management has become more intensive through mechanisation and a dramatic rise in pesticide and fertiliser input, landscapes and whole regions have become less diverse as a consequence of farm specialisation (Matson et al., 1997; Krebs et al., 1999). This has lead to many areas being dominated by annual crops, with only few small highly fragmented remnants of perennial structures, such as grassland or nearnatural habitats.

The ecological consequences of these profound changes have been traditionally studied at the scale of fields or farms, where agricultural activities have been shown to drastically reduce species diversity and disrupt important interactions among species (for a review see Robinson $\&$ Sutherland, 1999). More recently, researchers have expanded their focus to the landscape scale. A number of studies have shown fragmentation of near-natural habitats to be a major threat to biodiversity (Tscharntke et al., 2002; Tscharntke \& Brandl, 2004). Furthermore, it has been recognised that the occurrence of species within agricultural habitats is dependent on the composition of the surrounding landscape. For instance, it has been shown that parasitism of aphids in wheat fields increases with increasing fraction of perennial area within the surroundings, and that landscape factors may override local habitat quality (Thies \& Tscharntke, 1999). Perennial areas may serve as overwintering habitats or contain alternative resources for arthropods (e.g. Russell, 1989), and serve as a source for propagules of non-crop plants.

Understanding biodiversity within agricultural areas thus demands a multi-scale approach: both local habitat factors and the composition of the landscape are likely to be determining factors for the abundance and diversity of the organisms associated with ephemeral habitats such as annual crops.

In this study, we investigate whether certified organic agriculture can contribute to improve biodiversity in winter wheat fields, and how these potential local improvements relate to the 
landscape context. In Germany, organic agriculture is being supported in the framework of European agri-environment schemes (Grafen \& Schramek, 2000). Within this alternative form of management, pesticide as well as synthetic fertiliser applications are not allowed. Weeds are managed mechanically and farmers rely on animal and green manure, typically the inclusion of one or two years of legumes in the crop rotation, for replenishing the soil resources. It is still unclear how organic farming affects biodiversity in Germany. This is due partly to the lack of replication of many comparative studies (Hole et al., 2005), partly to the fact that studies abroad are not applicable to the German conditions: indeed, in Germany fields of different farmers are interspersed in the countryside, and not grouped around farms in estates as is the case in the UK for example (e.g. Fuller et al., 2005). We conducted a largescale biodiversity comparison on fields belonging to commercial farms which are representative of a large part of the agricultural enterprises in Germany and part of the neighbouring countries.

Specifically, we focused on the responses of two groups of ground-dwelling arthropods, spiders, which are predatory, and staphylinid beetles, which cover a range of feeding groups, as well as a taxonomically heterogeneous group of herbivorous insects feeding on the weed Cirsium arvense. We completed this study by determining the relative importance of the different spatial components of diversity in a larger selection of taxa also including plants, bees and carabid beetles sampled from the same study fields, and how this partitioning depends on management.

\section{Study areas and organisms}

The study was conducted in three regions of Germany (Table 1, Fig. 1). The first region, which we termed Leine Bergland, is situated in an upland area in the vicinity of Göttingen in Niedersachsen. Landscapes are dominated by arable crops in the flatter parts situated in the valleys, whereas in the more hilly parts land use is more diversified, with a higher density of grasslands and semi-natural habitat such as forests, fallows and hedges. The second region, the Soester Boerde, is situated on a fertile loess soil strip around the town of Soest in Nordrhein-Westfalen. The land-use is dominated by arable fields, grasslands and forests are scarcer. The third region, the Lahn-Dill Bergland, is situated near the towns of Marburg and Giessen in Hessen. The landscapes consist of a small-scale mosaic of forests, grassland and arable fields.

Within each region we selected seven field pairs consisting of one organic and one conventional winter wheat field. The fields within a pair were never more than $600 \mathrm{~m}$ apart. 
We selected an extra six pairs of fields in the Leine Bergland for the survey of the thistle herbivores to increase the sample size. The surveys for ground-dwelling arthropods, as well as the plant and bee surveys, carried out by colleagues, which enter the analysis presented in chapter 5, were made in the centre as well as in the edge of the field, between the first and the second row of cereal. Patches of Cirsium arvense were planted out into the centre of each field.

The ground-dwelling arthropod fauna of cereal fields is mainly composed of spiders (Aranea) and beetles (Coleoptera). The beetle community is dominated by carabids (Coleoptera: Carabidae) and staphylinids (Coleoptera: Staphylinidae). These three taxa are thought to play an important role as generalist predators and have been show to significantly lower populations of aphids (Winder, 1990; Schmidt et al., 2004), the most important pest insects in cereals. While all the spider species are predatory (Roberts, 1995), this is not true for the two beetle families (Thiele, 1977; Good \& Giller, 1991). Several carabid species, mainly in the genus Harpalus Latreille, are known to feed mainly on seeds, and many staphylinid species are known to be detritivorous, fungivorous or phytophagous. Epigeic arthropods may be influenced by landscape context in addition to local factors, as perennial habitats are needed for successful overwintering (Petersen, 1999; Lemke \& Poehling, 2002).

The creeping thistle Cirsium arvense (L.) Scop., also known as Canada thistle, is a noxious dioecious perennial. Although it is native in Europe, it is now widely distributed throughout the northern hemisphere, as well as in Australia and New Zealand. It is a problem weed in pasture and arable areas mainly due to its ability to spread vegetatively through its root system

Table 1: Elevation, climate, land-use and crop data for the three regions Leine Bergland, Soester Boerde, Lahn-Dill Bergland in 2003. Large-scale land-use was calculated on the areas defined by $10 \mathrm{~km}$ buffers around the study sites

\begin{tabular}{llll}
\hline & Leine Bergland & Soester Boerde & Lahn-Dill Bergland \\
\hline \% arable land & 52.1 & 61.8 & 23.5 \\
$\%$ grassland & 5.3 & 8.9 & 16.8 \\
$\%$ forest & 31.3 & 16.2 & 42.8 \\
$\%$ settlements & 6.9 & 7.5 & 7.1 \\
Elevation, range in m & $155-340$ & $70-320$ & $100-496$ \\
Mean temperature & 8.70 & 9.30 & 9.40 \\
Precipitation in mm & 550 & 693 & 704 \\
Mean winter wheat yield in dT & 62.0 & 62.8 & 58.1 \\
Mean winter wheat cover in \% & 64.8 & 68.5 & 64.9 \\
\hline
\end{tabular}




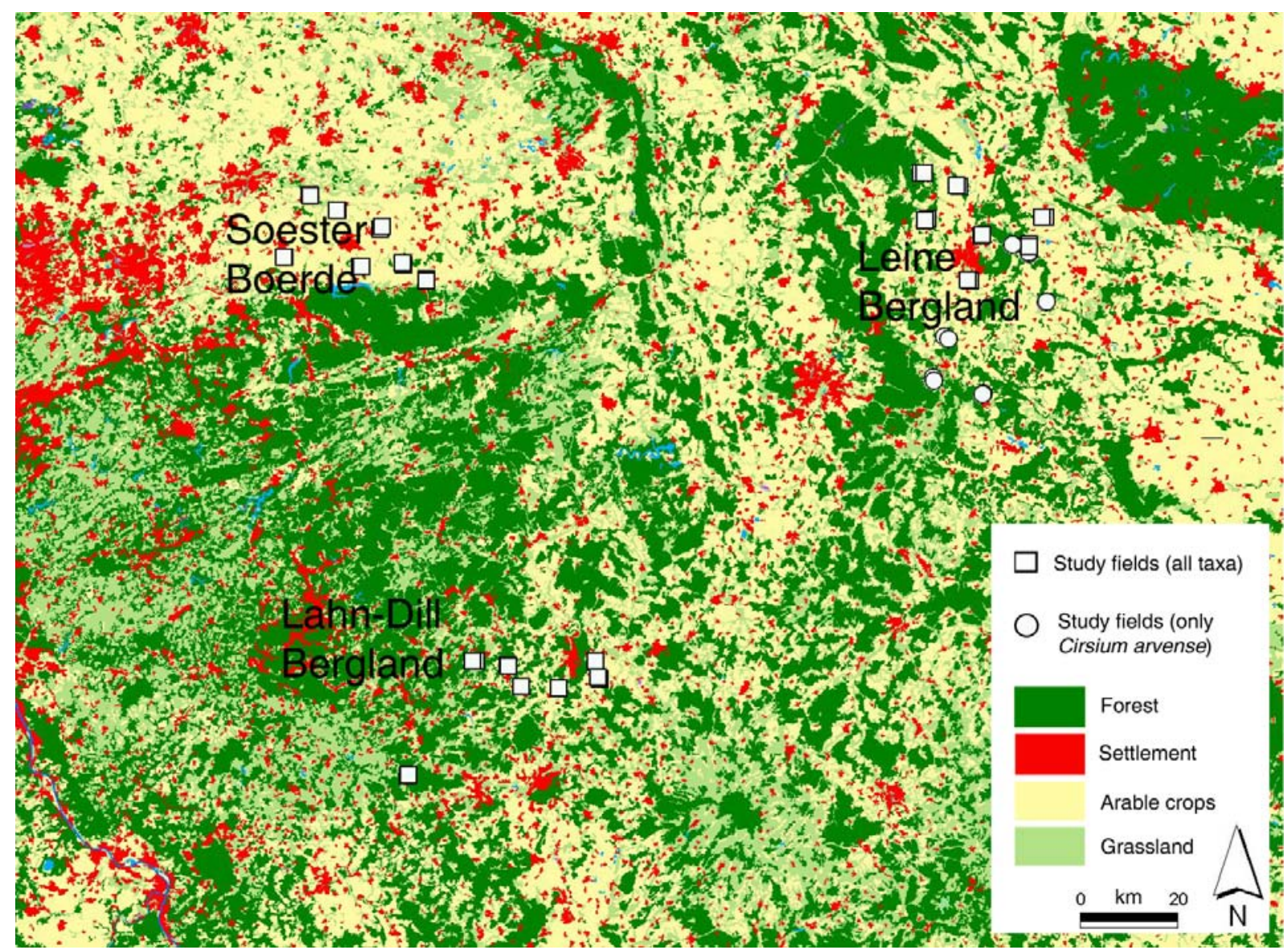

Fig. 1. Map of the study sites

in addition to sexual reproduction, which makes it difficult to control. Chemical control is possible but not satisfactory since it requires repeated applications of non-broad spectrum herbicides. Management options such as the use of smother crops are effective in a rather short term. Biology, control and detrimental effects of $C$. arvense have been reviewed extensively by Donald (1990, 1994).

Creeping thistle may harbour a large number of different species of insect herbivores and the parasitoids associated with them: flowerhead, stem, leaf, root and sap provide food for insect species spanning the whole range from generalist to specialist (Zwölfer, 1965). Some of these are well known, since they have been studied as potential biocontrol agents (Bacher, 1998). Indeed, although it seems that herbivory per se is not harmful enough to ensure control of this plant species, there are some indications that herbivorous insects facilitate infection by fungal pathogens (Friedli \& Bacher, 2001) and may thus play an important role in the natural control of this weed. 


\section{Main questions}

How do organic management and landscape context affect the activity-density and species richness of spiders? Are the patterns similar in the edge and in the centre of the fields? (Chapter 2)

Do staphylinids respond to organic management and landscape context? Does the response depend on the ecological group? What effect do local factors have on activity-density and species richness? (Chapter 3)

Does the richness and composition of the community of herbivorous insects on the thistle Cirsium arvense depend on management type, local factors such as weediness and the landscape context? Do these factors affect parasitism rates? (Chapter 4)

What is the importance of $\beta$ diversity compared to $\alpha$ diversity for bees, plants, carabids, staphylinids and spiders? Do patterns of $\beta$ diversity in the differently managed habitats follow the same trends as the patterns of $\alpha$ diversity? What is the importance of dispersal in determining the relative importance of $\beta$ diversity? (Chapter 5)

\section{Results and Conclusions}

Spider species richness was best predicted by the within-field location of the traps and landscape heterogeneity: while region and local management had no effect on species richness, more species were found in field edges and in heterogeneous landscapes. Activitydensity was higher in field edges and differed between regions. Diversity of farmland spiders was influenced by differences at two spatial scales (edge vs. centre, simple vs. complex landscapes), but not at the two others (field management, region), emphasising the importance of analyses at different spatial scales for adequately explaining patterns in biodiversity. Our study suggests that one of the keys to enhance spider diversity in agroecosystems is to promote heterogeneity in land use at landscape scales. (Chapter 2)

Management effects on staphylinid beetles were found to strongly depend on feeding group, to the extent that they were not to be detected within an analysis over all species. Patterns for predators and detritivores differed: while the activity-density of predators was higher in the conventional fields, both activity-density and species richness of the detritivores was higher in the organic fields. Activity-density and species richness of detritivores were positively correlated with yield in the conventional fields but not in the organic fields, suggesting that the role of crop productivity is especially important in intensive systems. One of the most abundant predatory species showed a higher activity-density in landscapes with a high percentage of non-crop habitat early in the season, but no significant effects of landscape 
context could be found on activity-density or species richness of the different feeding groups. More species were caught near the field edge than in the middle of the field, underlining the importance of spill-over from perennial field boundaries into arable crops. Thus we show that the absence of a clear pattern in previous comparisons of organic and conventional fields with regard to staphylinids is partly due to the contrast in responses between different feeding groups, and argue that a functional approach can deliver more robust hypotheses with regard to the observed patterns. (Chapter 3)

Herbivore species richness on the creeping thistle Cirsium arvense was enhanced by both organic farming and landscape heterogeneity, but not by higher amounts of thistles in the landscape. The analysis of presence/absence data for individual species revealed that for most of the herbivore species host-plant patches in organic fields were more likely to be colonised than those in the conventional fields. The enhancement of diversity in organic fields is most likely due to a slightly higher natural cover of the host plant $C$. arvense. High levels of weed cover (above 35\%) seem to cause a decrease in herbivore species richness. Enhancing herbivore insect richness on non-crop plants is an important prerequisite for the reestablishment of complex aboveground food webs in arable systems. Our results show that both diversification of landscapes (less arable crops, more perennial habitats) and diversification of crop fields (moderate - but not high - weed cover) through organic management are effective measures in this respect. Again, we suggest that the impact of fieldscale agri-environment schemes on biodiversity should be supplemented by including landscape-scale diversification programmes. (Chapter 4)

Diversity partitioning in $\alpha$ and $\beta$ diversity depended on taxon. $\beta$ diversity was very high (65$85 \%$ ), and was larger in the edge than in the centre of fields for all taxa, emphasising the importance of the species pool in the surrounding landscape. Patterns of $\beta$ diversity were found to closely track those found for $\alpha$ diversity, with significantly higher values in organic than in conventional fields only for plants and bees. Dispersal acts as a homogenizing force: flightless carabids exhibited small $\alpha$ and high $\beta$ diversity, which contrasted with flying and dimorphic carabids. $\beta$ diversity is thus an important biodiversity component in agroecosystems. Organic management results in significant benefits for both $\alpha$ and $\beta$ diversity of plants and their main pollinator group, but this does not hold for arthropod taxa less dependent on vegetation. (Chapter 5)

\section{References}

Bacher, S. (1998): Das Potential einheimischer Insekten zur biologischen Bekämpfung der Ackerkratzdistel (Cirsium arvense (L.) Scop.) in Mitteleuropa. Mitteilungen der deutschen Gesellschaft für allgemeine und 
angewandte Entomologie, 11, 277-280.

Benton, T.G., Vickery, J.A. \& Wilson, J.D. (2003) Farmland biodiversity: is habitat heterogeneity the key? Trends in Ecology and Evolution, 18, 182-188.

Donald, W.W. (1994) The biology of Canada Thistle (Cirsium arvense). Reviews of Weed Science, 6, 77-101.

Donald, W.W. (1990) Management and control of Canada thistle (Cirsium arvense). Reviews of Weed Science, 5, 193-250.

Friedli, J. \& Bacher, S. (2001) Mutualistic interaction between a weevil and a rust fungus, two parasites of the weed Cirsium arvense. Oecologia, 129, 571-76.

Fuller, R.J., Norton, L.R., Feber, R.E., Johnson, P.J., Chamberlain, D.E., Joys, A.C., Mathews, F., Stuart, R.C., Townsend, M.C., Manley, W.J., Wolfe, M.S., Macdonald, D.W. \& Firbank, L.G. (2005) Benefits of organic farming to biodiversity vary among taxa. Biology Letters.

Good, J.A. \& Giller, P.S. (1991) The diet of predatory staphylinid beetles - a review of records. Entomologist's Monthly Magazine, 127, 77-89.

Grafen, A. \& Schramek, J. (2000) Germany: complex agri-environmental policy in a federal system. AgriEnvironmental Policy in the European Union (ed. by Buller. H., G.A. Wilson and A. Höll), Ashgate, Aldershot, UK.

Hole, D.G., Perkins, A.J., Wilson, J.D., Alexander, I.H., Grice, P.V. \& Evans, A.D. (2005) Does organic farming benefit biodiversity? Biological Conservation, 122, 113-130.

Krebs, J.R., Wilson, J.D., Bradbury R.B. \& Siriwardena, G.M. (1999) The second Silent Spring? Nature, 400, 611-612.

Lemke, A. \& Poehling, H.-M. (2002) Sown weed strips in cereal fields: overwintering site and "source" habitat for Oedothorax apicatus (Blackwall) and Erigone atra (Blackwall) (Araneae: Erigonidae). Agriculture, Ecosystems and Environment, 90, 67-80.

Matson, P.A., Parton, P.J., Power, A.G. \& Swift, M.J. (1997) Agricultural intensification and ecosystem properties. Science, 277, 504-509.

Petersen, M.K. (1999) The timing of dispersal of the predatory beetles Bembidion lampros and Tachyporus hypnorum from hibernating sites into arable fields. Entomologia Experimentalis et Applicata, 90, 221-224.

Roberts, M.J. (1995) Spiders of Britain and Northern Europe. HarperCollins, London.

Robinson, R.A. \& Sutherland, W.J. (2002) Post-war changes in arable farming and biodiversity in Great Britain. Journal of Applied Ecology, 39, 157-176.

Russell, E.P. (1989) Enemies hypothesis: a review of the effect of vegetational diversity on predatory insects and 
parasitoids. Environmental Entomology, 18, 590-599.

Schmidt, M.H., Thewes, U., Thies, C. \& Tscharntke, T. (2004) Aphid suppression by natural enemies in mulched cereals. Entomologia Experimentalis et Applicata, 113, 87-93.

Thiele, H.U. (1977) Carabid Beetles in Their Environment. Springer, Berlin/Heidelberg.

Thies, C. \& Tscharntke, T. (1999) Landscape structure and biological control in agroecosystems. Science, 285, 893-895.

Tscharntke, T., \& Brandl, R. (2004) Plant-insect interactions in fragmented landscapes. Annual Review of Entomology, 49, 405-430.

Tscharntke, T., Steffan-Dewenter, I., Kruess, A. \& Thies, C. (2002) Contribution of small habitat fragments to conservation of insect communities of grassland-cropland landscapes. Ecological Applications, 12, 354-363.

Winder, L. (1990) Predation of the cereal aphid Sitobion avenae by polyphagous predators on the ground. Ecological Entomology, 15, 105-110.

Zwölfer, H. (1965) Preliminary list of phytophagous insects attacking wild cynareae (Compositae) in Europe. Technical Bulletin of the Commonwealth Institute for Biological Control, 6, 81-154. 


\title{
Chapter 2
}

\section{Spider diversity in cereal fields: comparing factors at local, landscape and regional scales}

\begin{abstract}
Factors acting at various scales may affect biodiversity, demanding analyses at multiple spatial scales to understand how community richness is determined. Here, we adopted a hierarchical approach to test the contribution of region, landscape heterogeneity, local management (organic vs. conventional) and location within-field (edge vs. centre) to the species richness and abundance of spiders in cereals. The study was conducted in three regions of Western and Central Germany: Leine Bergland, Soester Boerde and Lahn-Dill Bergland. Forty-two paired organic and conventional winter wheat fields were compared. Field pairs were located in areas ranging from structurally simple to structurally complex landscapes. In May and June 2003 spiders were sampled using pitfall traps. Linear mixed models were used to determine the relationship between spider diversity and abundance and the spatial factors region, landscape heterogeneity within a $500 \mathrm{~m}$ radius, as well as local management and location within field. Within-field location of the traps and landscape heterogeneity were the best predictors of species richness: more species were found in field edges and in heterogeneous landscapes. Region and local management had no effect on species richness. Activity-density was higher in field edges and differed between regions. Diversity of farmland spiders was influenced by differences at two spatial scales (edge vs. centre, simple vs. complex landscapes), but not at the two others (field management, region), emphasising the importance of analyses at different spatial scales for adequately explaining patterns in biodiversity. Our study suggests that promoting heterogeneity in land use at landscape scales is one of the keys to promote spider diversity in agroecosystems.
\end{abstract}

Keywords Agroecosystem, Araneae, biodiversity, cereals, biological control, landscape composition, organic farming, regional variation, scale effects 


\section{Introduction}

There is a growing concern over the adverse effects of agricultural intensification on biodiversity in agricultural areas (Swift et al., 1996; Krebs et al., 1999). Biodiversity may have been influenced by these changes on different spatial scales ranging from local to regional. At the field scale the introduction of pesticides and the shift from organic to synthetic fertilisers has had a negative impact on fauna and flora (Greig-Smith, 1990; Matson et al., 1997) and resulted in greatly simplified agroecosystems (Swift et al., 1996). At the same time, agricultural specialisation has led to rural landscapes becoming more dominated by arable crops.

The general concerns about the negative impact of modern agriculture on environment and calls for more sustainability have been finding political resonance within European countries for some time (e.g. in Germany, SRU, 1985). Partly in reaction to this, the European Union is financing alternative agricultural practices through agri-environment schemes, in which farmers agree to reduce the management intensity on all or part of their fields. One of the most well-known activities subsidised within this framework in Germany is certified organic agriculture. It explicitly aims at "maintaining and encouraging agricultural and natural biodiversity on the farm and surrounds"(IFOAM, 2002). Organic farmers rely on organic fertilisers such as animal and green manure, extended crop rotation and are not allowed to use biocides for pest control.

It is increasingly recognised that not only local factors but also the spatial surroundings of habitat patches may have a strong influence on local diversity and abundance of organisms (Kareiva \& Wennergren, 1995; Dauber et al., 2003; Duelli \& Obrist, 2003; Jeanneret et al., 2003; Kruess, 2003; Holland et al., 2004). Arable fields are subject to periodical disturbances such as ploughing, harrowing or pesticide applications, and are often left bare in the wintertime. Perennial habitats such as field boundaries or grasslands may act as a refugium for arthropods providing alternative prey, hosts or nectar (Pfiffner \& Wyss, 2004). Arable fields have been found to be regularly recolonised from perennial habitats (Samu et al., 1999; Holland \& Reynolds, 2003; Schmidt \& Tscharntke, 2005b). Consequently, not only local factors but also the landscape context may have significant effects on biodiversity and biological control within arable fields (Schmidt et al., 2004). Although there are cases in which agricultural areas may be comparable in terms of farming practices and landscape composition, regions differ in a number of aspects such as land use or climate. This may have an impact on the size of the species pool and the amount of immigration propagules of 
individual species within regions (Ricklefs, 1987; Caley \& Schluter, 1997), independently of smaller-scale landscape context.

Spiders (Araneae) contribute greatly to biodiversity in agroecosystems and are important as effective components of natural pest control (Symondson et al., 2002; Marc et al., 1999). Mechanisms by which these predators may control pest organisms have been studied extensively and were reviewed by Sunderland (1999). Long-term studies for spiders are scarce, but there is indeed evidence of a density and diversity decline in winter wheat fields in the UK between the years 1970 and 1990 (Aebischer, 1990).

Several small or medium-scale studies comparing the spider fauna in organic and conventional cereal crops reported increases in abundances (Feber et al., 1998; Schmidt et al., 2005a) and species diversity (Feber et al., 1998) in the organic fields, while others did not find any differences (e.g. Weibull et al., 2003; Booij \& Noorlander, 1992). A recent review of studies comparing organic and conventional farming (Hole et al., 2004) highlighted the frequent methodological shortcomings, such as insufficient replication or the lack of comparability between treatment and control fields. Large scale effects of landscape or region may also be a reason for different outcomes in studies testing the effect of management practices on biodiversity in a similar way, as the influence of large-scale features may interact with local factors.

Here we present the results of a study examining the contribution of several spatial scales, from large scale regional effects to small within-field scale effects, to the explanation of diversity and abundance of spiders in agroecosystems. Additionally we tested for effects of local field-scale management and interactions with spatial variables. We greatly extend the spatial scale of previous studies focusing on these themes (e.g. Schmidt \& Tscharntke, 2005a,b) by sampling several regions and including within-field patterns.

We surveyed the spider fauna on 21 organic and conventional field pairs in three contrasting regions of Germany and quantified the landscape heterogeneity surrounding each field pair. Our study was conducted in the single most important arable crop in these regions, winter wheat (Triticum aestivum ssp. vulgare). Focussing on fields rather than farms was necessary because in the study areas, as in many regions of Germany and other European countries, the countryside is a patchwork of interspersed organic and conventional fields belonging to different farmers. 


\section{Material and methods}

Design. In 2003, spider communities were monitored in 21 organic-conventional wheat fieldpairs along a gradient of landscape structure, in three different regions (Soester Boerde, Leine Bergland, Lahn-Dill Bergland, seven pairs per region) situated about $150 \mathrm{~km}$ from each other. The regions are between 400 and 500 square kilometres in size. The Soester Boerde $\left(51^{\circ} 35^{\prime}\right.$ $00^{\prime \prime} \mathrm{N} 008^{\circ} 07^{\prime} 00^{\prime \prime} \mathrm{E}$ ) is a rather flat area of North-Rhine Westfalia known for its very fertile silt-like loess soils and intensive agriculture centred mainly on arable crops such as wheat. The Leine Bergland ( $51^{\circ} 32^{\prime} 00^{\prime \prime} \mathrm{N} 009^{\circ} 56^{\prime} 00^{\prime \prime} \mathrm{E}$ ) is situated in an upland area of Lower Saxony. Landscape sectors are dominated by arable crops in the flatter parts situated in the valleys, whereas in the more hilly parts land use is more diversified. The Lahn-Dill Bergland in Hesse (50 49' 00" N $\left.008^{\circ} 46^{\prime} 00^{\prime \prime} \mathrm{E}\right)$ spans a range from homogeneous arable-dominated, to very heterogeneous, often aforested areas. Field sizes are smaller than in the other two regions. More information about the study regions can be found in Table 1. The local organic and conventional practices in the study were as a whole quite representative for medium-scale farming in western and central Europe.

Table 1: Elevation, climate, land-use and crop data for the three regions Leine Bergland, Soester Boerde, Lahn-Dill Bergland in 2003. Land use was calculated on the areas defined by $500 \mathrm{~m}$ buffers around the study sites.

\begin{tabular}{llll}
\hline & Leine Bergland & Soester Boerde & Lahn-Dill Bergland \\
\hline \% arable land & 73.8 & 68.1 & 59.7 \\
\% grassland & 9.4 & 10.1 & 20.3 \\
\% forest & 1.7 & 5.5 & 6.4 \\
\% settlements & 2.3 & 5.4 & 2.0 \\
Elevation, range in $\mathrm{m}$ & $155-340$ & $70-320$ & $100-496$ \\
Mean temperature $\left({ }^{\circ} \mathrm{C}\right)$ & 8.70 & 9.30 & 9.40 \\
Precipitation in mm & 550 & 693 & 704 \\
Mean winter wheat yield in dT & 62.0 & 62.8 & 58.1 \\
Mean winter wheat cover in \% & 64.8 & 68.5 & 64.9 \\
\hline
\end{tabular}

Landscape metrics. Land use was mapped from a field survey in a radius of $500 \mathrm{~m}$ around each field, and digitalised to a vector-based GIS map using ArcView 3.1 (ESRI Geoinformatik, Hannover, Germany). Previous studies indicate that this radius is large enough to describe the landscape relevant to spider dispersal (e.g. Schmidt \& Tscharntke 2005a). We used \% non-crop as an indicator of amount and diversity of perennial habitats (grasslands, fallows, woodlands, hedges) in the landscape. This landscape factor was 
positively correlated to elevation $\left(\mathrm{R}^{2}=0.29, \mathrm{P}<0.001\right)$. However, pre-analysis showed that elevation could not account for any variation of the dependant variables under study $(\mathrm{P}>0.90)$. Sampling. Two pitfall traps $(\varnothing 11 \mathrm{~cm})$ were placed in the centre (distance from edge: $50 \pm 15 \mathrm{~m}$ ) and at the edge (between the first and the second wheat row) of each field, and opened for three two-week sampling periods during spring and early summer (1-15, 15-28 May; 11-26 June, \pm two days depending on the region). The decision when to start trapping in each region was based on a phenological indicator: The traps were opened one week after the beginning of the mass flowering of Taraxacum officinale. This sampling scheme was designed following Duelli (1997). The trapping fluid was ethylene glycol (cooling fluid) diluted with water (1/3 v/v) (Schmidt et al. 2005c). Pitfall traps generate activity-density measures and not absolute abundance measures. However, this method is suitable for comparisons within the same habitat (Topping \& Sunderland, 1992). The data (species richness, total activity-density species numbers, activity-densities of the more common species) were tested for effects of management type, region, location in the field (edge or centre) as well as landscape metrics, which have been shown to play a role in explaining spider densities.

Statistical analysis. We fitted linear mixed models using restricted maximum likelihood (REML) (Pinheiro and Bates, 2000), incorporating the following error structure (number of levels indicated in parentheses):

\section{“region"(3)/“pair" (7)/"management" (2)/"in-field location" (2)/"sampling period" (3)/"sample" (2)}

Landscape was included as a fixed factor, with each field pair as an independent replicate. This method enabled us to retain full information while avoiding pseudoreplication. Wald tests (Aitkin et al. 1989) were used to test for significance of fixed effects (Region, Landscape heterogeneity, Management, Location in field) and two-way interactions. Normality of the distribution of the raw dependant variables was assessed using QQ-plots and data were logtransformed when necessary. Non-significant interactions $(\alpha>0.05)$ were discarded using a manual stepwise backward selection procedure.

Differences between regions, whenever significant in the mixed model, were further investigated using one-way ANOVA and Tukey HSD post-hoc tests on the data averaged over pairs. All analyses were performed using $R$ (R Development Core Team, 2004).

Sampling effort proved to be sufficient with observed species richness being between 80 and 90\% of the first-order jacknife estimate of species richness (Heltshe \& Forrester, 1983), depending on management and location within field. However, to check for possible bias of sample size in our analysis of species richness we performed the analysis not only on raw 
species richness but also on the rarefied numbers of species (Hurlbert, 1971), using the rarefy procedure of the package vegan for $R$ (version 1.6.9, Oksanen, 2005). We rarefied to 110 individuals per within-field location, which was the size of the smallest sample.

\section{Results}

A total of 24759 spider individuals from 98 species were sampled and identified. A further 1644 individuals, comprising juveniles and badly damaged specimens, could not be identified and had to be discarded from the analysis. Activity-density of spiders was significantly influenced by the study region, and by the location in the field (Table 2). Activity-densities were on average 3.5 times higher at the edge of the fields than in the centre. The Leine Bergland showed higher activity-densities than the other two regions (Fig. 1). Raw and rarefied species richness was influenced by the location in the field, and by landscape heterogeneity (Table 2). It was $15 \%$ higher in the edge of the fields compared to the centre. The number of species found in the most heterogenous landscapes was $25 \%$ higher compared to the simple ones (Fig.2). There was a non-significant trend towards more species in the Leine Bergland with the raw species richness data. No differences in activity-density and diversity were found between organic and conventional fields.

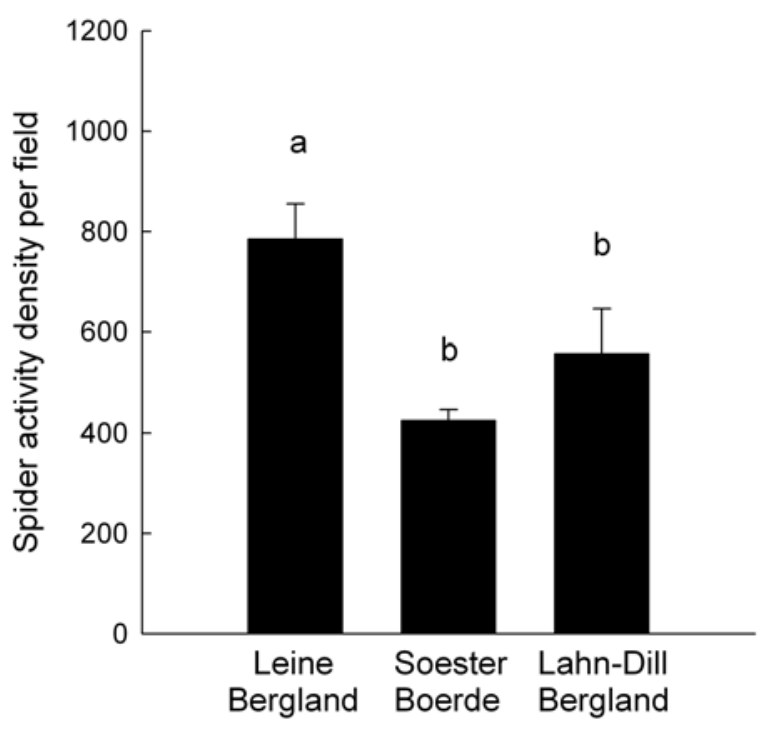

Fig. 1. Spider activity-density per field in three regions of Germany. Different letters represent significant differences (Means \pm SEM). 


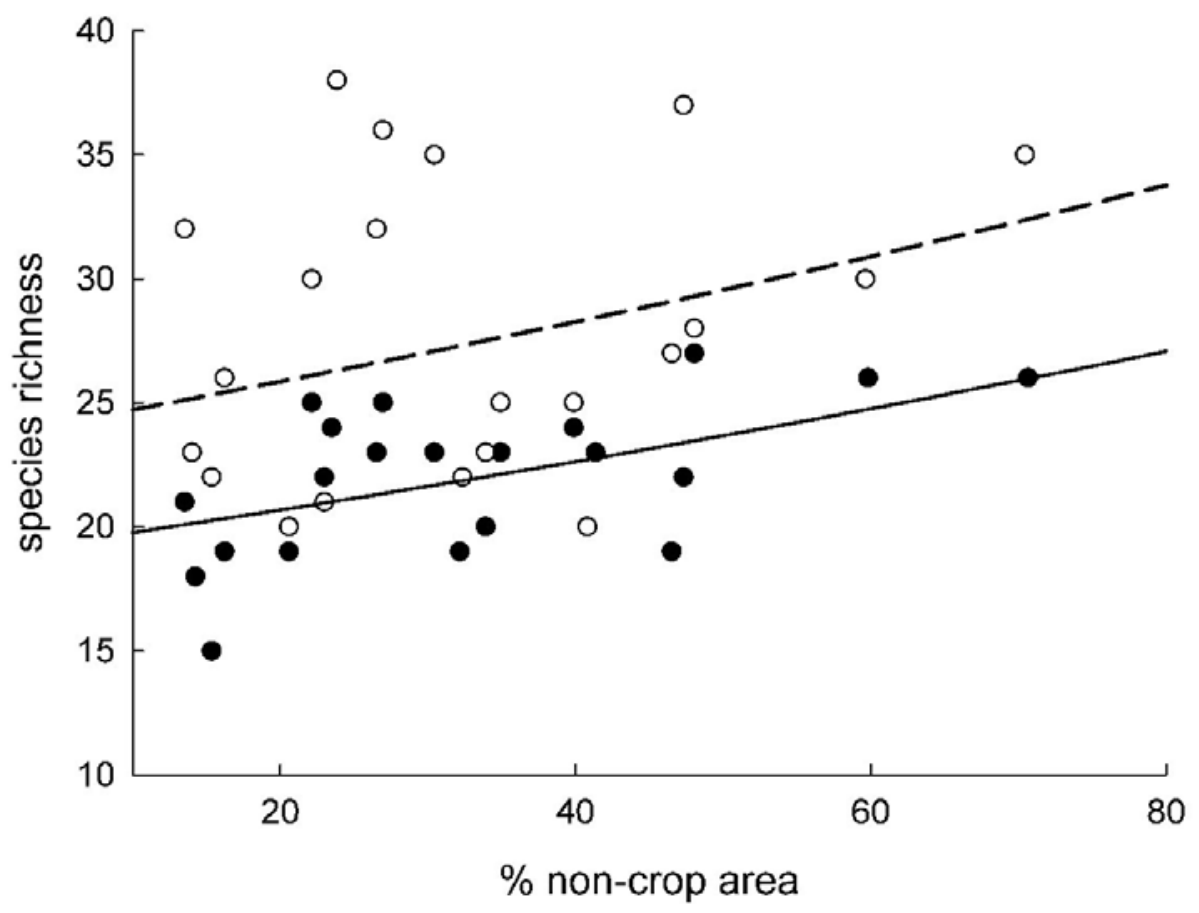

Fig. 2. Spider species richness in wheat fields depends on within-field location and \% non-crop area in a radius of $500 \mathrm{~m}$; Traps in paired fields (conventional and organic) have been pooled, with filled circles indicating values for field centres, and empty circles indicating values for field edges. The solid line represents the fitted model for field centres and the broken line the fitted model for the field edges. The effects of both within-field location and \% non-crop area are significant $\left(\mathrm{N}=21, \mathrm{P}<0.05\right.$, Cox-Snell pseudo- $\left.\mathrm{R}^{2}=0.44\right)$.

At the species level, analyses were performed for the ten most abundant species, each totalling more than 400 caught individuals: the erigonids Oedothorax apicatus (Blackwall), O. retusus (Westring), Erigone atra (Blackwall), E. dentipalpis (Wider), the lycosids Pardosa agrestis (Westring), P. amentata (Clerck), P. pullata (Clerck), P. palustris (Linnaeus), Trochosa ruricola (de Geer), and the tetragnathid Pachygnatha degeeri (Sundevall). Together these species accounted for more than $80 \%$ of individuals in the whole sample. Results of mixed-effect models are summarised in Table 3. Much higher activitydensity levels were found in the edge for three out of the four large-sized Pardosa species, P.palustris, P. amentata and P.pullata, whereas the smaller Erigoninae E. dentipalpis, Oedothorax apicatus and $O$. retusus had higher activity-densities in the centre of the fields less abundant in the Lahn-Dill Bergland, P. pullata, P. palustris and P. agrestis were found in significantly lower numbers in the Soester Boerde. O. apicatus activity-density was significantly lower in the Soester Boerde and Lahn-Dill Bergland than in the Leine Bergland. No regional differences were found for $P$. degeeri, $P$. amentata, T. ruricola. 
Table 2: Effects of region, landscape heterogeneity, organic versus conventional management and edge versus centre of the field on activity density and species richness of spiders (Wald tests for linear mixed-model fits).

\begin{tabular}{lllll}
\hline & Factor & d.f. & W & P \\
\hline Activity-density & Region & 18 & 9.960 & $\mathbf{0 . 0 0 1 2}$ \\
& Landscape & 19 & 1.506 & 0.2347 \\
& Management & 19 & 0.106 & 0.7484 \\
& Location in field & 41 & 6.343 & $\mathbf{0 . 0 1 5 8}$ \\
Species richness & Region & 18 & 2.867 & 0.0851 \\
& Landscape & 19 & 5.000 & $\mathbf{0 . 0 3 7 5}$ \\
& Management & 19 & 1.202 & 0.2867 \\
Rarefied species richness & Location in field & 41 & 7.307 & $\mathbf{0 . 0 1 0 0}$ \\
& Region & 18 & 0.430 & 0.6572 \\
& Landscape & 19 & 5.019 & $\mathbf{0 . 0 3 7 2}$ \\
& Management & 19 & 0.970 & 0.3370 \\
& Location in field & 41 & 10.334 & $\mathbf{0 . 0 0 2 5}$ \\
\hline
\end{tabular}

\section{Discussion}

In this study we compared the spider fauna of agroecosystems at different spatial scales, from within-field to between-field differences and up to between-landscape and between-region effects. While management had no effect on the spider fauna, we found the regional characteristics, landscape heterogeneity and the location within fields to be of major importance in determining abundance and diversity of spiders.

More individuals and more species were found in the edge of the fields. Differences in the fauna of the edge and centre of the fields indicate a strong edge effect in the crop immediately adjacent to the perennial field boundary, resulting in a large increase of the activity-density of Pardosa species. The latter tend to prefer grassy habitats and occur only in low densities in the field centre, whereas Erigone and Oedothorax species occur in high densities within cereal fields. The presence of Erigone species in the centre of the field could be partly explained by their aerial mode of dispersal, which enables them to colonise larger areas. However this explanation would not hold for the Oedothorax species, which are predominantly cursorial dispersers, as are the Pardosa species (Lemke and Poehling, 2002). The decrease in activity-density of Erigone and Oedothorax species at the edge of the fields may be due to the habitat being less suitable, or to competitive exclusion and/or intraguild predation by the larger Pardosa wolf spiders (Wise, 1993; Hodge, 1999; Marshall and Rypstra, 1999). 


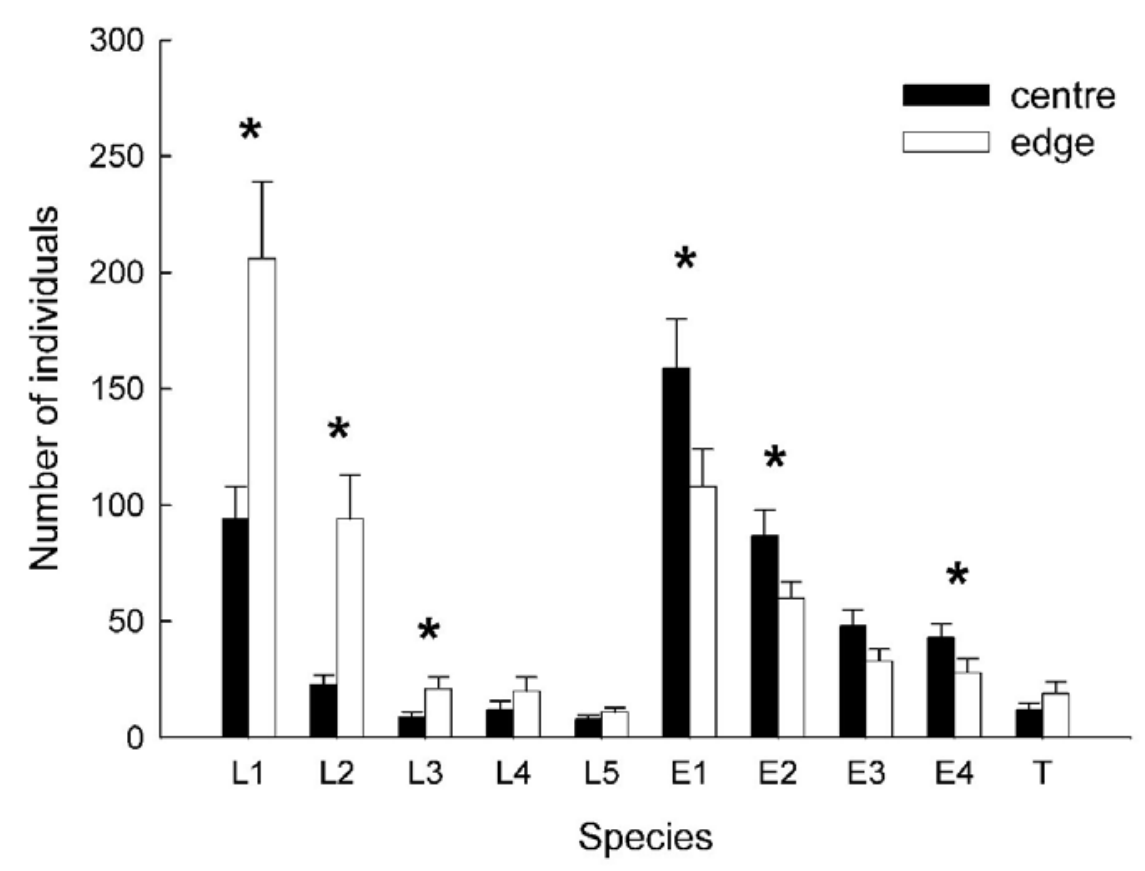

Fig. 3. Spider species captured in edge and centre of German winter wheat fields during 6 weeks in May-June 2003 (values pooled per field pair=4 traps). Stars indicate significant differences (Means \pm SEM) for the ten most abundant species. Lycosidae: L1=Pardosa palustris L2=P. amentata, L3=P. pullata, L4= P. agrestis, L5=Trochosa ruricola; Erigoninae: E1=Oedothorax apicatus, $\mathrm{E} 2=O$. retusus, $\mathrm{E} 3=$ Erigone atra, E4=E. dentipalpis; Tetragnathidae: $\mathrm{T}=$ Pachygnatha degeeri

There were no differences between spider faunas of organically and conventionally farmed fields. It has been hypothesised that arthropod biodiversity within crop fields should be enhanced by weediness because of prey items associated with non-crop plants (Marshall et al., 2003; Sunderland \& Samu, 2000), and corresponding results were found for the spider fauna by Pfiffner \& Luka (2003). The weed cover and diversity were significantly higher in the organic fields studied here (Gabriel et al., submitted), without there being any significant effect on the spider fauna. A possible reason for the absence of differences is the use of combharrowing in organic fields to control weeds mechanically. It has been shown that this may have a detrimental effect on the spider fauna (Everts et al., 1989). A further point may be that spider density, similarly to that of other epigaeic predators, cannot necessarily be predicted by weediness since spiders are also integrated within the decomposition food web (e.g. Wise et al., 1999), the assessment of which was beyond the scope of this study. It is also important to consider that the interspersion of organic and conventional fields in the regions we studied contrasts with the situation described in studies from the UK (Feber et al., 1998) and Sweden (Weibull et al., 2003) where fields belonging to the same farm are usually contiguous, thus creating larger areas under either organic or conventional management, with potential scale 
consequences on management effects. From our results we therefore conclude that the higher densities or species richness reported in organic cereals elsewhere (Feber et al., 1998; Schmidt et al., 2005a) do therefore not necessarily hold across space and time, emphasizing the importance of long-term studies, and/or meta-analyses (Weibull et al., 2003; Bengtsson et al. 2005; Schmidt \& Tscharntke, 2005a).

Species richness was correlated with landscape heterogeneity. Landscapes less dominated by arable fields have more perennial habitats such as grassland, leys, woodland and roadside verges. Not only can these serve as overwintering areas because of reduced disturbance, but are also structurally and vegetationally more diverse, with more predictable food resources. This makes such landscapes viable for a greater number of spider species, especially for those less adapted to arable-dominated environments. The resulting increase in the species pool can

Table 3: Effects of region, landscape heterogeneity, organic versus conventional management and edge versus centre of the field on log-transformed abundances of the most frequent spider species (Wald tests for linear mixed-model fits). Bold P-values indicate significant effects.

\begin{tabular}{lllll}
\hline & Factor & d.f. & W & P \\
\hline Oedothorax apicatus & Region & 18 & 13.410 & $<\mathbf{0 . 0 0 1}$ \\
& Landscape & 19 & 0.343 & 0.565 \\
Management & 19 & 0.0000 & .999 \\
Ledothorax retusus & Location in field & 41 & 7.041 & $\mathbf{0 . 0 1 1}$ \\
& Region & 18 & 4.128 & $\mathbf{0 . 0 3 0}$ \\
Landscape & 19 & 0.701 & 0.413 \\
Erigone dentipalpis & Management & 19 & 0.045 & 0.834 \\
& Location in field & 41 & 3.437 & 0.071 \\
Region & 18 & 9.761 & $\mathbf{0 . 0 0 1}$ \\
Erigone atra & Landscape & 19 & 0.703 & 0.412 \\
& Management & 19 & 1.036 & 0.322 \\
& Location in field & 41 & 5.155 & $\mathbf{0 . 0 2 9}$ \\
& Region & 18 & 11.004 & $<\mathbf{0 . 0 0 1}$ \\
& Landscape & 19 & 0.043 & 0.827 \\
Mardosa palustris & 19 & 2.651 & 0.120 \\
& Location in field & 41 & 2.361 & 0.132 \\
& Region & 18 & 6.972 & $\mathbf{0 . 0 0 6}$ \\
& Landscape & 19 & 3.357 & 0.083 \\
Management & 19 & 0.005 & 0.942 \\
& Location in field & 41 & 11.914 & $\mathbf{0 . 0 0 1}$ \\
\hline
\end{tabular}


Table 3 (continued)

\begin{tabular}{lllll}
\hline Pardosa pullata & Region & 18 & 5.545 & $\mathbf{0 . 0 1 3}$ \\
& Landscape & 19 & 0.030 & 0.863 \\
Management & 19 & 1.683 & 0.210 \\
Pardosa agrestis & Location in field & 41 & 11.198 & $\mathbf{0 . 0 0 2}$ \\
& Region & 18 & 4.111 & $\mathbf{0 . 0 3 4}$ \\
Pardosa amentata & Landscape & 19 & 0.007 & 0.936 \\
& Management & 19 & 0.996 & 0.331 \\
Location in field & 41 & 1.163 & 0.287 \\
Pachygnatha degeeri & Region & 18 & 0.437 & 0.652 \\
& Landscape & 19 & 0.004 & 0.953 \\
& Management & 19 & 0.088 & 0.771 \\
& Location in field & 41 & 29.689 & $<.001$ \\
Region & 18 & 0.143 & 0.490 \\
Trochosa ruricola & Landscape & 18 & 0.547 & 0.469 \\
& Management & 18 & 0.041 & 0.842 \\
& Location in field & 41 & 2.586 & 0.116 \\
& (Management x & & & \\
& Landscape) & 18 & 9.066 & $\mathbf{0 . 0 0 6}$ \\
& Region & 18 & 3.307 & 0.060 \\
& Landscape & 19 & 0.155 & 0.698 \\
Management & 19 & 0.980 & 0.335 \\
& Location in field & 41 & 3.858 & 0.056 \\
\hline
\end{tabular}

then benefit the species richness in nearby arable fields, by movement of individuals from perennial areas to arable fields (see also Thomas et al., 1999; Topping, 1999; Jeanneret et al., 2003; Schmidt et al., 2005a). A recent study carried out at landscape scale near Göttingen, a region also included in this survey, but in different fields, showed that the species richness of spiders in these cereal fields was also positively correlated to the percentage of non-crop habitats around the study sites (Schmidt et al., 2005a), indicating that this pattern is robust across years.

The large effect of regional setting on the overall abundance of spiders in our study fields is interesting because it implies that natural biological control (Symondson et al., 2002) may be more effective in certain regions than in others. Our study design does not enable us to identify the causes for the regional differences, since the three regions we selected obviously differ in more than one aspect (Table 1). Factors such as meteorology, land-use history or large-scale landscape diversity and composition are however likely to play an important role 
here, but we know of no study explicitly addressing the causes for regional differences in spider abundances. The lack of interactions between region and other factors is interesting because it suggests that local and landscape factors do act similarly in different areas.

In conclusion, large-scale features of the environment such as the composition of the surrounding landscape and regional context were very important in determining abundance and diversity of the spider fauna in cereal fields. These larger spatial scales are neglected in most studies. Organic management did not benefit spider diversity, suggesting that organic farming without targeted habitat manipulation (Samu et al., 1999; Sunderland \& Samu, 2000; Landis et al., 2000) may not necessarily benefit the spider fauna. It is apparent that there are limits to the effectiveness of local improvements (Gurr et al., 2004), because important processes such as dispersal take place at larger spatial scales. Conserving and enhancing landscape diversity appears to be one of the keys to conserve spider biodiversity in agroecosystems.

\section{Acknowledgements}

We thank the farmers for their willingness to participate in the project, Angelo Bolzern and Tamás Szüts for the identification of spiders, Stéphanie Domptail and Doreen Gabriel for their help with the land-use data as well as Tobias Purtauf for his participation in the selection of the study sites. We thank Jens Dauber, Martin Schmidt, Jason Tylianakis and two anonymous referees for their constructive comments on the manuscript. This research was carried out within the framework of the EU-funded project 'EASY' (QLK5-CT-2002-01495).

\section{References}

Aebischer, N.J. (1990) Twenty years of monitoring invertebrates and weeds in cereal fields in Sussex. The ecology of temperate cereal fields (ed. by L.G. Firbank, N. Carter, J.F. Darbyshire and G.R. Potts), pp. 305-331. Blackwell Scientific, Oxford.

Aitkin, M., Anderson, D., Francis, B. \& Hinde, J. (1989) Statistical Modelling in GLIM, Oxford Science Publications, Oxford University Press, Oxford.

Bengtsson, J., Ahnström, J. \& Weibull, A.-C. (2005) The effects of organic agriculture on biodiversity and abundance: a meta-analysis. Journal of Applied Ecology, in press.

Booij, C. J. H. \& Noorlander, J. (1992) Farming systems and insect predators. Agriculture, Ecosystems and Environment, 40, 125-135. 
Dauber, J., Hirsch, M., Simmering, D., Waldhardt, R., Otte, A. \& Wolters, V. (2003) Landscape structure as an indicator of biodiversity: matrix effects on species richness. Agriculture, Ecosystems and Environment, 98, 321329.

Duelli, P. (1997) Biodiversity evaluation in agricultural landscapes: an approach at two different scales. Agriculture, Ecosystems and Environment, 62, 81-91.

Duelli, P. \& Obrist, M.K. (2003) Regional biodiversity in an agricultural landscape: the contribution of seminatural habitat. Basic and Applied Ecology, 4, 129-138.

Everts, J.W., Aukema, B., Hengeveld, R. \& Koeman, J.H. (1989) Side-effects of pesticides on ground-dwelling predatory arthropods in arable ecosystems. Environmental Pollution, 59, 203-225.

Feber, R.E., Bell, J., Johnson, P.J., Firbank, L.G. \& Macdonald, D.W. (1998) The effects of organic farming on surface-active spider (Araneae) assemblages in wheat in southern England, UK. The Journal of Arachnology, 26, 190-202.

Gabriel, D., Roschewitz, I., Thies, C. \& Tscharntke T. (submitted) Relative importance of beta diversity at different spatial scales - plant communities in organic and conventional agriculture.

Greig-Smith, P. W. (1990) The Boxworth experience: effects of pesticides on the fauna and flora of cereal fields. The ecology of temperate cereal fields (eds L.G. Firbank, N. Carter, J.F. Darbyshire and G.R. Potts), pp. 333369. Blackwell Scientific, Oxford.

Gurr, G.M., Wratten, S.D. \& Altieri, M.A. (eds.) (2004). Ecological Engineering for Pest Management: Advances in Habitat Manipulation for Arthropods. CSIRO Press, Collingwood.

Heltshe, J.F. \& Forrester, N.E. (1983) Estimating species richness using the Jacknife procedure. Biometrics, 39, $1-11$.

Hodge, M.A. (1999) The implications of intraguild predation for the role of spiders in biological control. The Journal of Arachnology, 27, 351-362.

Hole, D.G., Perkins, A.J., Wilson, J.D., Alexander, I.H., Grice, P.V. \& Evans, A.D. (2005) Does organic farming benefit biodiversity? Biological Conservation, 122, 113-130.

Holland, J.D., Bert, D.G. \& Fahrig, L. (2004) Determining the spatial scale of species' response to habitat. BioScience, 54, 227-233.

Holland, J.M. \& Reynolds, C.J.M. (2003) The impact of soil cultivation on arthropod (Coleoptera and Araneae) emergence on arable land. Pedobiologia, 47, 181-191.

Hurlbert, S.H. (1971) The nonconcept of species diversity: a critique and alternative parameters. Ecological Monographs, 54, 187-211. 
IFOAM (International Federation of Organic Agriculture Movements) (2002) Basic Standards for Organic Production and Processing. IFOAM, Tholey-Theley; URL: http://www.ifoam.org/standard/norms/ibs.pdf

Jeanneret, Ph., Schüpbach, B., Pfiffner, L. \& Walter, Th. (2003) Arthropod reaction to landscape and habitat features in agricultural landscapes. Landscape Ecology, 18, 253-263.

Kareiva, P. \& Wennergren U. (1995) Connecting landscape patterns to ecosystem and population processes. Nature, 373, 299-302.

Krebs, J.R., Wilson, J.D., Bradbury R.B. \& Siriwardena, G.M. (1999) The second Silent Spring? Nature, 400, 611-612.

Kruess, A. (2003) Landscape structure and habitat type affected the diversity and interactions of seed-feeding and stem-boring insects on Cirsium arvense (L.) Scop. Ecography, 26, 283-290.

Landis, D.A., Wratten, S.D. \& Gurr, G.M. (2000) Habitat management to conserve natural enemies of arthropod pests in agriculture. Annual Review of Entomology, 45, 175-201.

Lemke, A. \& Poehling, H.-M. (2002) Sown weed strips in cereal fields: overwintering site and "source" habitat for Oedothorax apicatus (Blackwall) and Erigone atra (Blackwall) (Araneae: Erigonidae). Agriculture, Ecosystems and Environment, 90, 67-70.

Marc, P., Canard, A. \& Ysnel, F. (1999) Spiders (Araneae) useful for pest limitation and bioindication. Agriculture, Ecosystems and Environment, 74, 229-273.

Marshall, S.D. \& Rypstra, A.L. (1999) Spider competition in structurally simple ecosystems. The Journal of Arachnology, 27, 343-350.

Marshall, E.J.P., Brown, V.K., Boatman, N.D., Lutmans, P.J.W., Squire, G.R. \& Ward, L.K. (2003) The role of weeds in supporting biological diversity within crop fields. Weed Research, 43, 77-89.

Matson, P.A., Parton, W.J., Power, A.G. \& Swift, M.J. (1997) Agricultural intensification and ecosystem properties. Science, 277, 504-509

Oksanen, J. (2005) Vegan: $R$ functions for vegetation ecologists; URL: http://cc.oulu.fi/ jarioksa/ softhelp/vegan.html.

Pfiffner, L. \& Luka, H. (2003) Effects of low-input farming systems on carabids and epigeal spiders - a paired farm approach. Basic and Applied Ecology, 4, 117-127.

Pfiffner, L. \& Wyss. E. (2004) Sown wildflower strips to enhance natural enemies of agricultural pests in annual and perennial cropping systems. Ecological Engineering for Pest Management: Advances in Habitat Manipulation for Arthropods (ed. by G.M. Gurr, S.D. Wratten and M.A. Altieri), pp.165-186, CSIRO Press, Collingwood.

Pinheiro, J.C. \& Bates, D.M., (2000) Mixed-effects models in S and S-Plus, Springer, New York. 
R Development Core Team (2004) R: A language and environment for statistical computing, Foundation for Statistical Computing, Vienna; URL: http://www.R-project.org.

Ricklefs, R.E. (1987) Community diversity: relative roles of local and regional processes. Science, 235, 167-171.

Samu, F., Sunderland, K. D. \& Szinetár, C. (1999) Scale-dependent dispersal and distribution patterns of spiders in agricultural systems: a review. The Journal of Arachnology, 27, 325-332.

Schmidt, M.H., Thies, C. \& Tscharntke, T. (2004) Landscape context of arthropod biological control. Ecological Engineering for Pest Management: Advances in Habitat Manipulation for Arthropods (ed. by G.M. Gurr, S.D. Wratten and M.A. Altieri), pp.55-63, CSIRO Press, Collingwood.

Schmidt, M.H. \& Tscharntke, T. (2005a) Landscape context of sheetweb spider (Araneae: Linyphiidae) abundance in cereal fields. Journal of Biogeography, 32, 467-473.

Schmidt, M. H., Roschewitz, I., Thies, C. \& Tscharntke, T. (2005a) Landscape context affects the diversity, and local management the density of farmland spiders. Journal of Applied Ecology, in press.

Schmidt, M.H. \& Tscharntke, T. (2005b) The role of perennial habitats for Central European farmland spiders. Agriculture, Ecosystems and Environment, 105, 235-242.

Schmidt, M. H., Clough, Y., Schulz, W., Westphalen, A. \& Tscharntke T. (2005c) Capture efficiency and preservation attributes of different fluids in pitfall traps. Journal of Arachnology, in press.

SRU (Der Rat von Sachverständigen für Umweltfragen) (1985) Umweltprobleme der Landwirtschaft (Sondergutachten). Kohlhammer Verlag, Stuttgart, Germany

Sunderland, K.D. \& Samu, F. (2000) Effects of agricultural diversification on the abundance, distribution, and pest control potential of spiders: a review. Entomologia Experimentalis et Applicata, 95, 1-13.

Swift, M.J., Vandermeer, J., Ramakrishnan, P.S., Anderson, J.M., Ong, C.K. \& Hawkins, B.A. (1996). Biodiversity and agroecosystem function. Functional Roles of Biodiversity: A Global Perspective (ed. by H.A. Mooney, J.H. Cushman, E. Medina, O.E. Sala and E.D. Schulze), pp. 261-297, Wiley, New York.

Symondson, W.O.C., Sunderland, K.D. \& Greenstone, M. H. (2002) Can generalist predators be effective biocontrol agents? Annual Review of Entomology, 47, 561-594.

Thomas, C.F.G. \& Jepson, P.C. (1999) Different aerial dispersal of linyphiid spiders from a grass and a cereal field. The Journal of Arachnology, 27, 294-300.

Topping, C.J. \& Sunderland, K.D. (1992) Limitations in the use of pitfall traps in ecological studies exemplified by a study of spiders in a field of winter wheat. Journal of Applied Ecology, 29, 485-491

Topping, C.J. (1999) An individual-based model for dispersive spiders in agroecosystems: simulations of the effect of landscape structure. The Journal of Arachnology, 27, 378-386. 
Weibull, A.-C., Östman, Ö. \& Grandqvist, A. (2003) Species richness in agroecosystems: the effect of landscape, habitat and farm management. Biodiversity and Conservation, 12, 1335-1355.

Wise, D.H. (1993) Spiders in ecological webs. Cambridge University Press, Cambridge.

Wise, D.H., Snyder, W.E., Tuntibunpakul, P. \& Halaj, J. (1999) Spiders in decomposition food webs of agroecosystems: theory and evidence. The Journal of Arachnology, 27, 363-370. 


\title{
Chapter 3
}

\section{Functional grouping helps understand staphylinid response to farming system}

\begin{abstract}
We studied the response of different feeding groups of staphylinid beetles to organic management, distance to perennial boundary and landscape context in 42 paired organic and conventional winter wheat fields. Management effects were found to strongly depend on feeding group, and were not detected with an analysis over all species. Contrasting patterns were found for predators and detritivores: while the activity-density of predators was higher in the conventional fields, both activity-density and species richness of the detritivores was higher in the organic fields. Activity-density and species richness of detritivores was positively correlated to crop yield in the conventional but not in the organic fields. Unexpectedly, species richness as high as in the less productive organic fields was thus found in intensified conventional systems. No significant effects of landscape context could be found on activity-density or species richness of the different feeding groups, but the activitydensity of one of the most abundant predatory species was higher in landscapes with a high percentage of non-crop habitat early in the season. More species were caught near the field edge than in the middle of the field, showing the importance of spill-over from perennial field boundaries into arable crops for the diversity of functionally important insect groups. In conclusion, separation of species into feeding groups revealed patterns that have not been shown before. Decomposer diversity (but not that of predators and fungivores) was higher in organic fields, but reached similar levels in high-yielding conventional fields. Thus resource quality (purely organic or organic/synthetic fertiliser) and quantity appear to play a major role for this functional group.
\end{abstract}

Keywords: detritivores, functional diversity, fungivores, landscape heterogeneity, organic farming, predation, productivity, pitfall trap, staphylinidae, Tachyporus hypnorum

\section{Introduction}

Linking ecosystem functioning and biodiversity is one of the major endeavours in ecology (Ehrlich \& Wilson, 1991). While progress has been made in this topic in experimental plant 
ecology (e.g. Hector et al., 1999), larger scale field data as well as studies on diverse and functionally important groups such as insects are rare. This is not only due to the obvious methodological limitations and lack of appropriate ecological knowledge, but also to a traditional focus on species abundance and diversity, irrespective of feeding group (Walker, 1992). As a consequence, many studies test hypotheses on species groups whose members differ in many traits. However, species can be expected to respond differently to the biotic and abiotic environment according to their traits - e.g. feeding group (Bongers \& Bongers, 1998; Purtauf et al., 2005a), dispersal ability (Schmidt et al., 2005), level of specialisation or searching mode (Bukovinszky et al., 2005) - and information about these responses can be accessible only if we analyse our data accordingly (Cole et al., 2002). We suggest that splitting species into functional groups is one step field research can take towards incorporating more ecology into biodiversity and conservation research. While field observations alone may not lead us to mechanistic explanations for ecosystem functions, a functional approach may generate more robust - and more testable - hypotheses.

In this study we assess the impact of organic farming and landscape context on staphylinid beetles in wheat fields. Staphylinids are difficult to identify and have not been the subject of species-level biodiversity research nearly as often as other arthropod groups (Hole et al., 2005). From a functional perspective they are of particular interest, however, because they may act as detritivores, herbivores, fungivore or predators, and some are known to parasitize diptera pupae (Fournet et al., 2000), while a few species are associated with ants (Päivinen et al., 2003). Staphylinids are active at the ground surface but also in the leaf litter and within the soil. They play an important part both aboveground, most notoriously as predators of aphids in agroecosystems (Dennis \& Wratten, 1991; Collins et al., 2002), and belowground, where they prey on collembola, feed on algae, fungi and decaying organic matter (Good \& Giller, 1991). It is perhaps not surprising that a group so functionally diverse does not show consistent responses to organic management (Booij \& Noorlander, 1992; Krooss \& Schaefer, 1998; Shah et al., 2003; Weibull et al., 2003). In addition, the limited replication of past studies is also likely to be a cause for different outcomes (Bengtsson et al., 2005; Hole et al., 2005), which emphasizes the need for a well replicated design.

Most staphylinids can fly and some species have been found to disperse actively between natural habitats and agroecosystems (Coombes \& Sotherton, 1986). It is thus important to consider the landscape context around the study sites because in agricultural landscapes perennial habitats serve as refuges for arthropods which use them for overwintering and reproduction (Sotherton, 1984, 1985). Factors such as the amount of perennial area around 
arable fields may thus influence the species richness and the activity-density, as has been shown for other epigeic arthropod groups such as spiders and carabids (Clough et al., 2005; Purtauf et al., 2005a; Schmidt et al., 2005).

We would like to address the following research questions: How do organic farming, crop productivity and distance to field edge as well as landscape context affect the activity-density and species richness of the staphylinid fauna? Does the separation into functional groups lead to different conclusions than those one would draw with a non-functional approach?

\section{Material and methods}

Design. In 2003, staphylinid beetles were monitored in 21 organic-conventional wheat fieldpairs along a gradient of landscape structure, in three different regions (Soester Boerde, Leine Bergland, Lahn-Dill Bergland, seven pairs per region) situated about $150 \mathrm{~km}$ from each other. The regions are between 400 and 500 square kilometres in size. The Soester Boerde is a rather flat area of North-Rhine Westfalia known for its very fertile silt-like loess soils and intensive agriculture centred mainly on arable crops such as wheat. The Leine Bergland is situated in an upland area of Lower Saxony. Landscape sectors are dominated by arable crops in the flatter parts situated in the valleys, whereas in the more hilly parts land use is more diversified. The Lahn-Dill Bergland in Hesse spans a range from homogeneous arable-dominated, to very heterogeneous, often aforested areas. Field sizes are smaller than in the other two regions.

Field management. All fields were tilled, only about half of the conventional farmers $(n=9)$ used insecticides, and if so only in a single application. The insecticides used by the farmers were Karate (a.i.: lambda-cyhalothrin; $n=8$ ) and Perfekthion (a.i.: dimethoate; $n=1$ ). We recorded yield, weed cover and soil parameters. The local organic and conventional practices in the study were quite representative for medium-scale farming in Western and Central Europe.

Sampling. Two pitfall traps $(\varnothing 11 \mathrm{~cm})$ were placed in the centre (distance from edge: $50 \pm 15 \mathrm{~m})$ and at the edge (between the first and the second wheat row) of each field, and opened for three two-week sampling periods during spring and early summer (1-15, 15-28 May; 11-26 June, \pm two days depending on the region). Starting date of trapping in each region was based on a phenological indicator: the traps were opened one week after the beginning of the mass flowering of Taraxacum officinale L. This sampling scheme was designed following Duelli (1997). The trapping fluid was ethylene glycol (cooling fluid) diluted with water $(1 / 3 v / v)$ (Schmidt et al., 2005). Pitfall traps generate activity-density measures and not absolute 
abundance measures. However, this method is considered suitable for comparisons within the same habitat (Topping \& Sunderland, 1992).

Landscape. We mapped the land use from a field survey in a radius of $500 \mathrm{~m}$ around each field, and digitalised it to a vector-based GIS map using ArcView 3.1 (ESRI Geoinformatik, Hannover, Germany). We used \% non-crop as an indicator of amount and diversity of perennial habitats (grasslands, fallows, woodlands, hedges) in the landscape. This landscape factor was positively correlated to elevation $\left(r^{2}=0.29, P<0.001\right)$. However, pre-analysis showed that elevation could not account for any variation of the dependant variables under study $(P>0.90)$.

Statistical analyses. We analysed activity-densities and species richness of the overall sample as well as for separate functional groups by fitting linear mixed models using restricted maximum likelihood (REML) (Pinheiro \& Bates, 2000), incorporating the following error structure (number of levels indicated in parentheses):

"region"(3)/“pair" (7)/"management" (2)/"in-field location" (2)

Landscape was included as a fixed factor, with each field pair as an independent replicate. This method enabled us to retain full information while avoiding pseudoreplication. Wald tests (Aitkin et al., 1989) were used to test for significance of fixed effects (Region, Landscape heterogeneity, Management, Location in field, Yield) and two-way interactions. Weed cover and soil parameters were found not to significantly explain any variance in our models so were discarded from the final models and not further considered here. Normality of the distribution of the raw dependent variables was assessed using QQ-plots and data were log-transformed when necessary. We first performed the analyses with time and interactions between time and other fixed factors included as explanatory variables. When time did not significantly interact with one of the other fixed factors we repeated the analyses using the sums over the three sampling periods. Non-significant interactions $(\alpha>0.05)$ were discarded using a manual stepwise backward selection procedure. Differences between regions, whenever significant in the mixed model, were further investigated using the contrasts of the models. Sampling effort proved to be sufficient with observed species richness being between 75 and $80 \%$ of the first-order jacknife estimate of species richness (Heltshe \& Forrester, 1983), depending on management and location within field. All analyses were performed using $R$ (R Development Core Team, 2005). Values given in the text are REML estimates of the treatment means \pm SE.

Feeding groups. The species were separated into the following feeding groups: predators, parasites, detritivores, fungivores, myrmecophiles, phytophages, unknown. To assign species 
to these groups we used literature (Good \& Giller, 1991; Frank \& Thomas, 1999) as well as expert advice (Boris Büche, pers. comm.). A list is provided in the appendix. Whenever information was lacking for a certain species, the functional group was either extrapolated from species belonging to the same genus, or classified as unknown.

\section{Results}

A total of 10693 individuals belonging to 174 species were collected. The results of the linear mixed models for overall activity-density and species richness are shown in Table 1. Total activity-density (127.3 \pm 12.2$)$ was similar across the levels of all factors and did not vary with $\%$ non-crop area. Total species richness differed between regions (values for field centre:

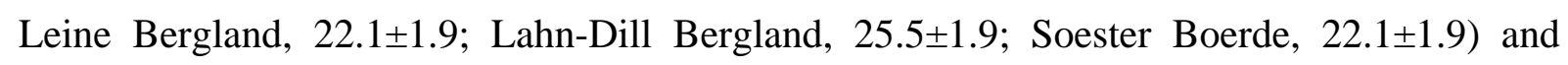

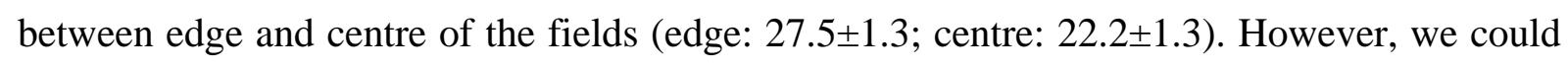
not detect any differences between organic and conventional management. Neither was there any significant correlation between the total species richness and \% non-crop area.

$\%$ non crop area had a significant positive effect on the activity-density of the predator Tachyporus hypnorum (Fab.) $(\mathrm{N}=21 ; \mathrm{F}=5.977 ; P=0.024)$, a pattern which could not be found in the other common species (Philonthus rotundicollis (Menetries), P. cognatus (Stephens), Stenus biguttatus (L.), S. canaliculatus Gyll., Anotylus sculpturatus (Grav.), A. inustus (Grav.), A. rugosus (Fab.), Lathrobium fulvipenne Grav., Aloconota gregaria (Erichson)). A significant interaction with time shows that this is valid only for the first sampling period $(\mathrm{N}=150 ; \mathrm{F}=7.811 ; P<0.001)$.

Of the 174 species, 115 were classified as predators (7780 ind.), 12 as detritivores (1536 ind.), 23 as fungivorous (825 ind.), 4 as myrmecophilous (370 ind.), 4 as parasitic (24 ind.), 7 as

Table 1: Effects of region, landscape heterogeneity, organic versus conventional management and edge versus centre of the field on activity density and species richness of staphylinid beetles (Wald tests for linear mixed models fits).

\begin{tabular}{lllll}
\hline & Factor & d.f. & F & $P$ \\
\hline Activity-density & Region & 18 & 0.996 & 0.388 \\
& Landscape & 19 & 0.811 & 0.379 \\
& Management & 19 & 0.119 & 0.734 \\
Lpecies richness & Location in field & 41 & 0.853 & 0.361 \\
& Region & 18 & 3.845 & $\mathbf{0 . 0 4 1}$ \\
& Landscape & 19 & 0.966 & 0.338 \\
& Management & 19 & 0.629 & 0.438 \\
& Location in field & 41 & 16.250 & $<\mathbf{0 . 0 0 1}$ \\
\hline
\end{tabular}



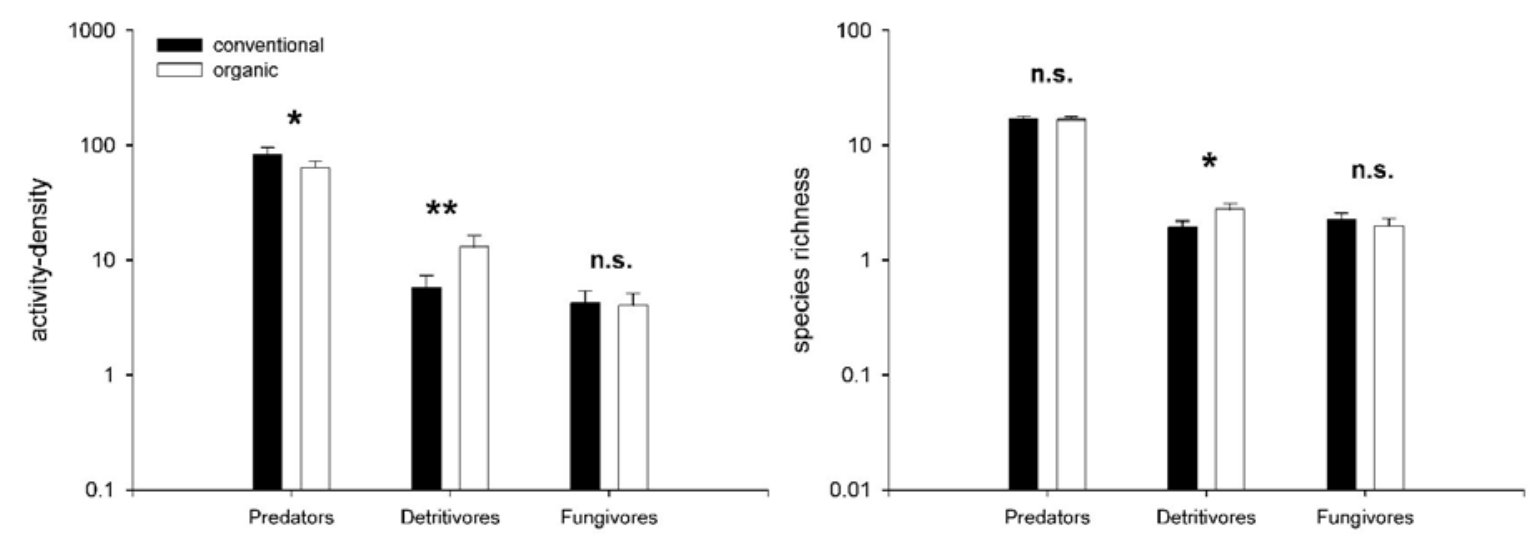

Fig. 1. Effect of farming system on number of trapped individuals and species richness of staphylinid beetles in organic and conventional winter wheat fields. Back-transformed per-field means and significance levels from linear mixed models are shown $(* * *, P<0.001 ; * *, P>0.01 ; *, P<0.05$; n.s., $P>0.05)$.

phytophagous (13 ind.) and 9 as unknown (136 ind.). We restricted our functional-groupspecific analyses to the predators, the detritivores and the fungivores because they were the most well represented groups. The myrmecophiles were not analysed separately because the bulk of the sample was found in a single location.

Management had significant effects on separate feeding groups (Fig. 1). While more predatory staphylinids were found in the conventional fields $(\mathrm{N}=21, \mathrm{~F}=5.966, P=0.024)$, more individuals $(\mathrm{N}=21, \mathrm{~F}=8.608, P=0.009)$ and more species $(\mathrm{N}=21, \mathrm{~F}=8.013, P=0.011)$ of detritivorous staphylinids were caught in organic fields. Management had no significant effect on fungivores $(P>0.500)$.

Both activity-density and species richness of the detritivorous staphylinids were correlated with yield. There was a significant interaction with management (activity-density: $\mathrm{N}=21$, $\mathrm{F}=6.126, P=0.024$; species richness: $\mathrm{N}=21, \mathrm{~F}=6.868, P=0.017)$ : in the conventional fields activity-density and species richness decreased with yield, while in organic fields such an effect could not be found (Fig. 2). Neither activity-density nor species richness of predators and fungivores were correlated with yield.

\section{Discussion}

The indications from this study are that species richness of Staphylinidae is affected by fieldscale management factors, proximity of the perennial boundary and the surrounding landscape. Management effects were found to strongly depend on feeding group. This may partly explain the lack of significant difference of past comparisons of staphylinids in organic 

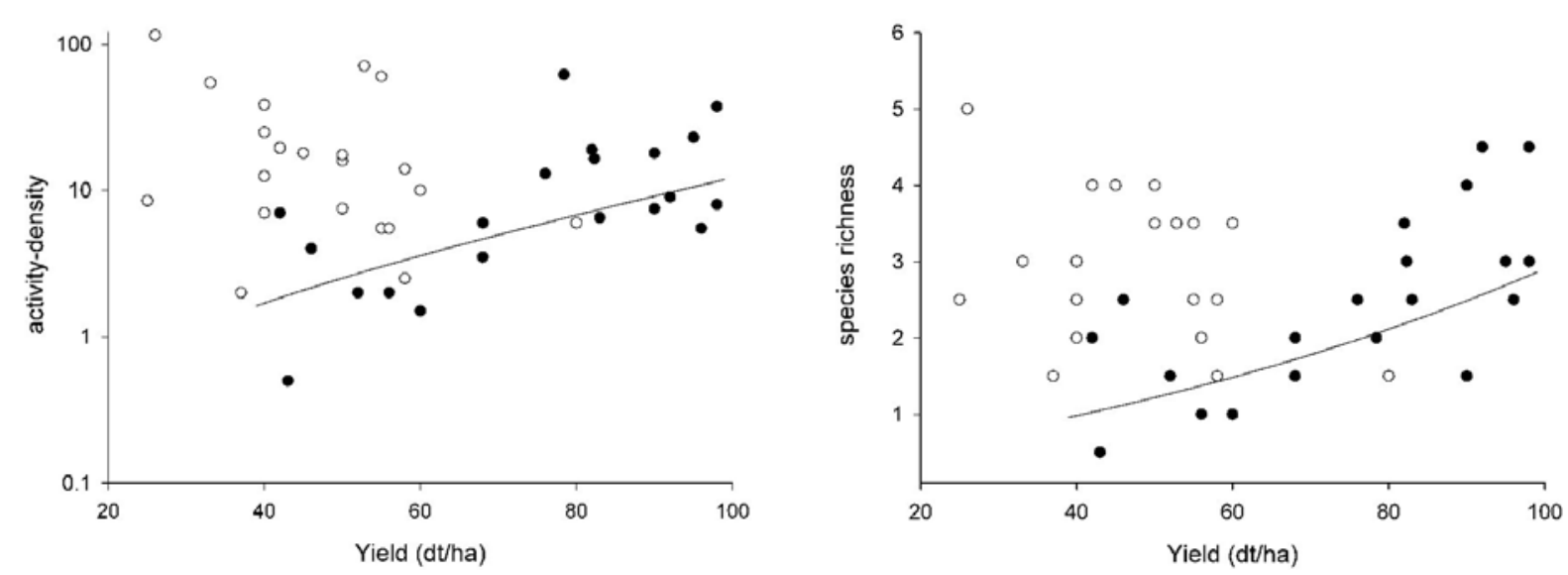

Fig. 2. Detritivorous staphylinid beetle activity-density and species richness in winter wheat fields depend on management and yield; for every field values for traps (centre and edge) have been averaged, with filled circles indicating values for conventional fields, and empty circles indicating values for organic fields. The solid line represents the fitted model for conventional fields, the effect of yield was not significant for organic fields. The effects of management, yield and the interaction are significant $(P<0.05)$.

and conventional fields (Booij \& Noorlander, 1992; Krooss \& Schaefer, 1998; Shah et al., 2003; Weibull et al., 2003).

Detritivorous staphylinids were found to be more diverse and to have higher activity-density levels in organic fields. This is in line with results of other studies showing positive effects of organic agriculture on taxa involved in decomposition (Paoletti et al., 1992; Moreby et al., 1994; Mäder et al., 2001), since detritivores are likely to profit from the organic fertilisation applied to organic fields. Surprisingly, both activity-density and diversity of detritivorous staphylinids was found to significantly increase with yield in conventional fields, but not in organic fields. This complex pattern may have several causes. Yield is just a part of the productivity within arable fields. In conventional fields wheat accounts for nearly the entire biomass, while in organic fields a substantial part of the biomass is represented by weeds. It may thus be that the relationship between productivity and the diversity in detritivorous staphylinids is blurred by the variation in weed biomass between the organic fields.

Interestingly, this pattern could imply that the activity-density and diversity of this detritivorous group can be increased by improving crop productivity in simplified, intensively managed systems, which is contrary to the common assumption that diversity decreases with intensification of land-use. Alternatively it could be that activity-density and diversity of detritivorous staphylinids indicate good soil health and high potential productivity levels. This potential productivity may be limited by other factors such as weed cover in organic fields, but could be fully realised in conventional fields.

Somewhat surprisingly, fungivorous staphylinids were neither caught in higher numbers nor in higher diversity in organic fields. One might have expected a similar trend as in the 
detritivores, or even increased differences due to the applications of fungicides in conventional fields, which should be deleterious to their food source. On the other hand denser crop stands in conventional fields result in higher humidity levels which may benefit fungal development and in turn, fungal feeders. This may balance out the negative effect of fungicide applications. Also, tillage is one of the main limiting factors for fungal food webs in agroecosystems (Hendrix et al., 1986), and in this respect practices did not differ between organic and conventional fields.

An absence of difference between organic and conventional fields could have been explained with an apparent lack of negative side-effects of insecticides on staphylinids (Everts et al., 1989, Holland et al., 2000). However, predatory staphylinids were even caught in slightly higher numbers in the conventional fields, which was rather surprising but has been found before (Shah et al., 2003). Higher staphylinid activity-densities may be expected in fields with higher aphid densities: predatory staphylinids have been shown to aggregate in areas of high prey density (Bryan \& Wratten, 1984). A study conducted in one of the regions included in the present work (Roschewitz et al., 2005) showed that aphid densities were indeed significantly higher in conventional than in organic fields, which supports this explanation.

The landscape context had no significant effect on activity-density and diversity of the overall staphylinid fauna and the separate feeding groups, and only the activity-density of a common predator, T. hypnorum, increased with percent non-crop area early in the season. This species is often cited as its movement between edge and centre of cereal fields has been well studied (Coombes \& Sotherton, 1986), but our results suggest that it is not necessarily representative of other common species, as all other abundant species did not respond to landscape composition. However, the important differences in species richness between centre and edge of the fields suggest that perennial habitats and boundaries do cause a spill-over into the field. They thus highlight the importance of maintaining perennial edge densities in landscapes to conserve this diversity as well as the recolonisation potential, which is important for the arable ecosystem (Landis et al., 2000; Tscharntke et al., 2005).

In conclusion, by combining a well replicated design and a separation of species into feeding groups, we were able to reveal new patterns of response of staphylinid beetles - differential responses depending on feeding groups as well unexpected effects of local factors such as yield. While further work, including more controlled experimental work, would be needed to test the hypotheses presented here and to unravel the causal mechanisms, this functional approach is a useful step towards a better understanding of agroecosystems. 


\section{Acknowledgements}

We thank the farmers for their willingness to participate in the project and Boris Büche for the identification of the Staphylinidae and information about their feeding habits. This research was carried out within the framework of the EU-funded project 'EASY' (QLK5-CT-200201495).

\section{References}

Aitkin, M., Anderson, D., Francis, B. \& Hinde, J. (1989) Statistical Modelling in GLIM, Oxford Science Publications, Oxford University Press, Oxford.

Bengtsson, J., Ahnström, J. \& Weibull, A.-C. (2005) The effects of organic agriculture on biodiversity and abundance: a meta-analysis. Journal of Applied Ecology, 42, 261-269.

Bongers, T. \& Bongers, M. (1998) Functional diversity of nematodes. Applied Soil Ecology, 10, 239-251.

Booij, C. J. H. \& Noorlander, J. (1992) Farming systems and insect predators. Biotic diversity in agroecosystems (ed. by M. G. Paoletti and D. Pimentel), pp. 125-135. Elsevier, Amsterdam.

Bryan, K. M. \& Wratten, S. D. (1984) The responses of polyphagous predators to prey spatial heterogeneity: aggregation by carabid and staphylinid beetles to their cereal aphid prey. Ecological Entomology, 9, 251-259.

Bukovinszky, T., Potting, R. P. J., Clough, Y., van Lenteren, J. C. \& Vet, L. E. M. (2005) The role of foraging behaviour in the responses of herbivore populations to habitat heterogeneity. Oikos, 109, 435-446.

Cole, L. J., McCracken, D. I., Dennis, P., Downie, I. S., Griffin, A. L., Foster, G. N., Murphy, K. J. \& Waterhouse, T. (2002) Relationships between agricultural management and ecological groups of ground beetles (Coleoptera: Carabidae). Agriculture, Ecosystems and Environment, 93, 323-336.

Collins, K. L., Boatman, N. D., Wilcox, A., Holland, J. M. \& Chaney, K. (2002) Influence of beetle banks on cereal aphid predation in winter wheat. Agriculture Ecosystems and Environment, 93, 337-350.

Coombes, D. S. \& Sotherton, N. W. (1986) The dispersal and distribution of polyphagous predatory Coleoptera in cereals. Annals of applied Biology, 108, 461-474.

Dennis, P. \& Wratten, S. D. (1991) Field manipulation of populations of individual staphylinid species in cereals and their impact on aphid populations. Ecological Entomology, 16, 17-24.

Duelli, P. (1997) Biodiversity evaluation in agricultural landscapes: an approach at two different scales. Agriculture, Ecosystems and Environment, 62, 81-91.

Ehrlich, P. R. \& Wilson, E. O. (1991) Biodiversity studies: Science and policy. Science, 253, 758-762.

Everts, J. W., Aukema, B., Hengeveld, R. \& Koeman, J. H. (1989) Side-effects of pesticides on ground-dwelling 
predatory arthropods in arable ecosystems. Environmental Pollution, 59, 203-225.

Fournet, S., Stapel, J. O., Kacem, N., Nenon, J. P. \& Brunel, E. (2000) Life history comparison between two competitive Aleochara species in the cabbage root fly, Delia radicum: implications for their use in biological control. Entomologia Experimentalis et Applicata, 96 , 205-211.

Frank, J. H. \& Thomas, M. C. (1999) Rove beetles of the world. UF/IFAS Featured Creatures. EENY-114. URL: http://creatures.ifas.ufl.edu/misc/beetles/rove_beetles.html.

Good, J. A. \& Giller, P. S. (1991) The diet of predatory staphylinid beetles - a review of records. Entomologist's Monthly Magazine, 127, 77-89.

Hector, A., Schmid, B., Beierkuhnlein, C., Caldeira, M.C., Diemer, M., Dimitrakopoulos, P.G., Finn, J.A., Freitas, H., Giller, P.S., Good, J., Harris, R., Högberg, P., Huiss-Danell, K., Joshi, J., Jumpponen, A.K.C., Leadley, P.W., Loreau, M., Minns, A., Mulder, C.P.H., O'Donovan, G., Otway, S.J., Pereira, J.S., Prinz, A., Read, D.J., Scherer-Lorenzen, M., Schulze, E.-D., Siamantziouras, A.-S. D., Spehn, E.M., Terry, A.C., Troumbis, A.Y., Woodward, F.I., Yachui, S. \& Lawton, J.H. (1999) Plant diversity and productivity experiments in European grasslands. Science, 286, 1123-1127.

Heltshe, J. F. \& Forrester, N. (1983) Estimating species richness using the jacknife procedure. Biometrics, 39, 111.

Hendrix, P. E., Parmelee Jr., R. W., Crossley, D. A., Coleman, D. C., Odum, E. P. \& Groffman, P. M. (1986) Detritus food webs in conventional and no-tillage agroecosystems. BioScience, 36, 374-380.

Hole, D. G., Perkins, A. J., Wilson, J. D., Alexander, I. H., Grice, P. V. \& Evans, A. D. (2005) Does organic farming benefit biodiversity? Biological Conservation, 122, 113-130.

Holland, J. M., Winder, L. \& Perry, J. N. (2000). The impact of dimethoate on the spatial distribution of beneficial arthropods in winter wheat. Annals of Applied Biology, 136, 93-105.

Krooss, S. \& Schaefer, M. (1998) The effect of different farming systems on epigeic arthropods: a five-year study on the rove beetle fauna (Coleoptera; Staphylinidae) of winter wheat. Agriculture, Ecosystems and Environment, 69, 121-133.

Landis, D.A., Wratten, S.D. \& Gurr, G.M. (2000) Habitat management to conserve natural enemies of Arthropod pests in agriculture. Annual Review of Entomology, 45, 175-201.

Mäder, P., Fließbach, A., Dubois, D., Gunst, L., Fried, P. \& Niggli, U. (2002) Soil fertility and biodiversity in organic farming. Science, 296, 1694-1697.

Moreby, S. J., Aebischer, N. J., Southway, S. E. \& Sotherton, N. W. (1994) A comparison of the flora and arthropod fauna of organically and conventionally grown winter wheat in southern England. Annals of Applied Biology, 125, 13-27. 
Päivinen, J., Ahlroth, P., Kaitala, V., Kotiaho, J. S., Suhonen, J. \& Virola, T. (2003) Species richness and regional distribution of myrmecophilous beetles. Oecologia, 134, 587-595.

Paoletti, M.G., Favretto, M.R., Bressan, M., Marchiorato, A. \& Babetto, M. (1992) Biodiversita in pescheti forlivesi. Biodiversita Negli Agroecosystemi (ed. by M. G. Paoletti, M. R. Faretto, T. Nasolini, D. Scaravelli, and G. Zecchi), pp. 30-80. Wafra Litografica, Cesena.

Pinheiro, J. C. \& Bates, D. M. (2000) Mixed-effects models in S and S-Plus. Springer, New York.

Purtauf, T., Dauber, J. \& Wolters, V. (2005). The response of carabids to landscape simplification differs between trophic groups. Oecologia, 142, 458-464.

R Development Core Team (2005) R: A language and environment for statistical computing. Foundation for Statistical Computing, Vienna; URL: http://www.R-project.org.

Roschewitz, I., Hücker, M., Tscharntke, T. \& Thies, C. (2005) The influence of landscape context and farming practices on parasitism of cereal aphids. Agriculture, Ecosystems and Environment, 108, 218-227.

Schmidt, M. H., Clough, Y., Schulz, W., Westphalen, A. \& Tscharntke, T. (in press) Capture efficiency and preservation attributes of different fluids in pitfall traps. Journal of Arachnology.

Schmidt, M. H., Roschewitz, I., Thies, C. and Tscharntke, T. (in press) Landscape context affects the diversity, and local management the density of farmland spiders. Journal of Applied Ecology.

Shah, P. A., Brooks, D. R., Ashby, J. E., Perry, J. N. \& Woiwod, I. P. (2003) Diversity and abundance of the coleopteran fauna from organic and conventional management systems in southern England. Agricultural and Forest Entomology, 5, 51-60.

Sotherton, N. W. (1984) The distribution and abundance of predatory arthropods overwintering on farmland. Annals of Applied Biology, 105, 423-429.

Sotherton, N. W. (1985) The distribution and abundance of predatory Coleoptera overwintering in field boundaries. Annals of Applied Biology, 106, 17-21.

Topping, C. J. \& Sunderland, K. D. (1992) Limitations in the use of pitfall traps in ecological studies exemplified by a study of spiders in a field of winter wheat. Journal of Applied Ecology, 29, 485-491

Tscharntke, T., Rand, T. A. \& Bianchi, F. J. J. A. (2005) The landscape context of trophic interactions: insects spillover across the non-crop interface. Annales Zoologici Fennici, 42, 421-432.

Walker, B. H. (1992) Biodiversity and ecological redundancy. Conservation Biology, 6, 19-23.

Weibull, A.-C., Östman, Ö. \& Grandqvist, Å. (2003) Species richness in agroecosystems: the effect of landscape, habitat and farm management. Biodiversity and Conservation, 12, 1335-1355. 
Appendix: list of Staphylinidae species collected in this study

Staphylinid beetle species

Acrotona aterrima (Gravenhorst, 1802)

A. parvula (Mannerheim, 1831)

Aleochara bilineata Gyllenhal, 1810

A. bipustulata cf. (Linnaeus, 1761)

A. curtula (Goeze, 1777)

A. ruficornis Gravenhorst, 1802

Aleuonota gracilenta (Erichson, 1839)

Aloconota gregaria (Erichson, 1839)

Amarochara forticornis (Lacordaire, 1835)

Amauronyx maerkelii (Aubé, 1844)

Amischa analis cf. (Gravenhorst, 1802)

A. decipiens (Sharp, 1869)

A. forcipata Mulsant \& Rey, 1873

A. nigrofusca (Stephens, 1832)

Anotylus complanatus (Erichson, 1839)

A. insecatus (Gravenhorst, 1806)

A. inustus (Gravenhorst, 1806)

A. rugosus (Fabricius, 1775)

A. sculpturatus cf. (Gravenhorst, 1806)

A. tetracarinatus (Block, 1799)

Anthobium unicolor (Marsham, 1802)

Arpedium quadrum (Gravenhorst, 1806)

Astenus immaculatus Stephens, 1833

A. pulchellus (Heer, 1839)

Atheta aegra (Heer, 1841)

A. britanniae Bernhauer \& Scheerpeltz, 1926

A. cauta (Erichson, 1837)

A. crassicornis (Fabricius, 1792)

A. elongatula (Gravenhorst, 1802)

A. fungi cf. (Gravenhorst, 1806)

A. harwoodi (Thomson, 1852)

A. laticollis (Stephens, 1832)

A. oblita (Erichson, 1839)

A. palustris (Kiesenwetter, 1844)

A. pittionii cf Scheerpeltz, 1950

A. ravilla (Erichson, 1839)

A. triangulum (Kraatz, 1856)

Autalia rivularis (Gravenhorst, 1802)

Bibloplectus minutissimus (Aubé, 1833)

Bledius gallicus (Gravenhorst, 1806)

Bolitobius castaneus (Stephens, 1832)

B. cingulata (Mannerheim, 1830)

Brachygluta fossulata (Reichenbach, 1816)

Bythinus burrelli Denny, 1825

B. macropalpus Aubé, 1833

Callicerus obscurus Gravenhorst, 1802

C. rigidicornis Erichson, 1839

Carpelimus bilineatus cf. Stephens, 1834

C. corticinus.cf. (Gravenhorst, 1806)

C. elongatulus (Erichson, 1839)

C. gracilis (Mannerheim, 1830)

Coprophilus striatulus Fabricius, 1792
$\mathrm{N}$ feeding group

$$
\begin{aligned}
2 & \text { unknown } \\
1 & \text { unknown } \\
4 & \text { parasitic } \\
14 & \text { parasitic } \\
4 & \text { parasitic } \\
2 & \text { parasitic } \\
2 & \text { unknown }
\end{aligned}
$$

356 predatory

22 predatory

4 predatory

61 predatory

3 predatory

1 predatory

5 predatory

1 detritivorous

29 detritivorous

484 detritivorous

361 detritivorous

572 detritivorous

23 detritivorous

2 detritivorous

2 detritivorous

3 unknown

3 unknown

2 fungivorous

2 fungivorous

6 fungivorous

9 fungivorous

12 fungivorous

108 fungivorous

1 fungivorous

1 fungivorous

3 fungivorous

2 fungivorous

84 fungivorous

1 fungivorous

262 fungivorous

1 predatory

11 predatory

1 phytophagous

12 predatory

2 predatory

34 predatory

1 predatory

6 predatory

68 predatory

4 predatory

1 phytophagous

4 phytophagous

8 predatory

2 predatory

2 phytophagous 
Appendix: list of Staphylinidae species collected in this study (continued)

Cordalia obscura (Gravenhorst, 1802)

Cypha longicornis (Paykull, 1800)

Dinaraea angustula (Gyllenhal, 1810)

Drusilla canaliculata (Fabricius, 1787)

Euaesthetus bipunctatus (Ljungh,1804)

Euplectus brunneus (Grimmer, 1841)

Falagrioma thoracica (Stephens, 1832)

Gabrius bishopi Sharp, 1910

G. coxalus (Hochhuth, 1871)

G. osseticus (Kolenati, 1846)

G. subnigritulus (Reitter, 1909)

Geostiba circellaris (Gravenhorst, 1806)

Gyrohypnus angustatus Stephens, 1833

G. liebei Scheerpeltz, 1926

Gyrophaena nana (Paykull, 1800)

Heterothops niger Kraatz, 1868

H. quadripunctulus (Gravenhorst, 1806)

Ilyobates propinquus (Aub', 1850)

I. subopacus Palm, 1935

Ischnosoma splendidus Gravenhorst, 1806

Lathrobium brunnipes (Fabricius, 1792)

L. fulvipenne Gravenhorst, 1806

L. longulum Gravenhorst, 1802

L. multipunctum Gravenhorst, 1802

L. pallidipenne Hochhuth, 1851

L. pallidum Nordmann, 1837

L. quadratum (Paykull, 1789)

L. volgense Hochhuth, 1851

Lesteva longoelytrata (Goeze, 1777)

Liogluta longiuscula (Gravenhorst, 1802)

L. microptera Thomson, 1867

L. pagana (Erichson, 1839)

Megarthrus denticollis (Beck, 1817)

Micropeplus porcatus (Paykull, 1789)

Mycetoporus forticornis Fauvel, 1872

M. lepidus (Gravenhorst, 1806)

M. longulus Mannerheim, 1830

Ocypus brunnipes (Fabricius, 1781)

O. fuscatus (Gravenhorst, 1802)

O. nero Faldermann, 1835

Oligota pusillima cf. (Gravenhorst, 1806)

Olophrum assimile (Paykull, 1800)

Omalium caesum Gravenhorst, 1806

O. rivulare (Paykull, 1789)

Othius punctulatus (Goeze, 1777)

Oxypoda acuminata (Stephens, 1832)

O. bicolor cf. Mulsant \& Rey, 1853

O. brevicornis (Matthews, 1838)

Paederus brevipennis Lacordaire, 1835

P. fuscipes Curtis, 1826

P. littoralis Gravenhorst, 1802

Parocyusa longitarsis (Erichson, 1837)

P. rubicunda (Erichson, 1837)

\section{4 predatory}

4 fungivorous

150 predatory

343 myrmecophilous

107 predatory

1 unknown

143 predatory

8 predatory

10 predatory

2 predatory

2 predatory

26 predatory

28 predatory

3 predatory

1 fungivorous

1 predatory

1 predatory

25 predatory

221 predatory

61 fungivorous

3 predatory

513 predatory

69 predatory

3 predatory

6 predatory

20 predatory

2 predatory

147 predatory

115 unknown

4 predatory

1 predatory

102 predatory

1 detritivorous

185 fungivorous

6 fungivorous

4 fungivorous

32 fungivorous

5 predatory

1 predatory

30 predatory

3 unknown

6 unknown

40 detritivorous

20 detritivorous

2 predatory

13 predatory

258 predatory

1 predatory

1 predatory

1 predatory

12 predatory

9 predatory

3 predatory 
Appendix: list of Staphylinidae species collected in this study (continued)

\begin{tabular}{l}
\hline Philonthus atratus (Gravenhorst, 1802) \\
P. carbonarius (Gravenhorst, 1810) \\
P. cognatus (Stephens, 1832) \\
P. concinnus (Gravenhorst, 1802) \\
P. coruscus (Gravenhorst, 1802) \\
P. debilis cf. (Gravenhorst, 1802) \\
P. decorus (Gravenhorst, 1802) \\
P. intermedius (Lacordaire, 1835) \\
P. laminatus (Creutzer, 1799) \\
P. quisquiliarius (Gyllenhal, 1810) \\
P. rotundicollis (Menetries, 1832) \\
P. succicola Thomson, 1860 \\
P. umbratilis (Gravenhorst, 1802) \\
P. varians (Paykull, 1789) \\
Plutara bit 1798)
\end{tabular}

Plataraea brunnea (Fabricius, 1798)

Platydracus latebricola (Gravenhorst, 1806)

P. stercorarius (Oliver, 1795)

Platystethus arenarius (Fourcroy, 1785)

P. capito Heer, 1839

P. cornutus (Gravenhorst, 1802)

P. nitens (Sahlberg, 1832)

Proteinus macropterus (Gravenhorst, 1806)

Pycnota paradoxa (Mulsant \& Rey, 1861)

Quedius fuliginosus (Gravenhorst, 1802)

Q. ochripennis (Ménétriés, 1832)

Rugilus erichsoni (Fauvel, 1867)

R. orbiculatus (Paykull, 1789)

R. rufipes Germar, 1836

R. subtilis (Erichson, 1840)

Scopaeus laevigatus (Gyllenhal, 1827)

S. minutus Erichson, 1940

S. sulcicollis (Stephens, 1833)

Sepedophilus immaculatus (Stephens, 1832)

S. marshami (Stephens, 1832)

Staphylinus erythropterus Linnaeus, 1758

Stenus assequens Rey, 1884

S. biguttatus (Linnaeus, 1758)

S. bimaculatus Gyllenhal, 1810

S. canaliculatus Gyllenhal, 1827

S. cicindeloides (Schaller, 1783)

S. clavicornis (Scopoli, 1763)

S. flavipes Stephens, 1833

S. fossulatus Erichson, 1840

S. fulvicornis Stephens, 1833

S. juno (Paykull, 1789)

S. nanus Stephen, 1832

S. pusillus Stephens, 1833

S. ruralis Erichson, 1840

S. similis (Herbst, 1784)

S. tarsalis cf. Ljungh, 1804

Sunius melanocephalus (Fabricius, 1792)

Tachinus corticinus Gravenhorst, 1802

T. fimetarius Gravenhorst, 1802

\section{9 predatory}

183 predatory

595 predatory

2 predatory

8 predatory

1 predatory

5 predatory

1 predatory

2 predatory

2 predatory

1362 predatory

6 predatory

1 predatory

1 predatory

6 predatory

4 myrmecophilous

1 myrmecophilous

3 detritivorous

1 phytophagous

1 phytophagous

3 phytophagous

11 fungivorous

7 predatory

13 predatory

1 predatory

6 predatory

2 predatory

20 predatory

18 predatory

9 predatory

4 predatory

3 predatory

1 fungivorous

27 fungivorous

3 predatory

5 predatory

667 predatory

271 predatory

654 predatory

1 predatory

35 predatory

1 predatory

1 predatory

5 predatory

4 predatory

5 predatory

1 predatory

1 predatory

4 predatory

2 predatory

11 predatory

64 predatory

1 predatory 
Appendix: list of Staphylinidae species collected in this study (continued)

\begin{tabular}{lrl}
\hline T. laticollis Gravenhorst, 1802 & 1 predatory \\
T. signatus Gravenhorst, 1802 & 180 predatory \\
Tachyporus atriceps Stephens, 1832 & 5 predatory \\
T. chrysomelinus cf. (Linnaeus, 1758) & 55 predatory \\
T. hypnorum (Fabricius, 1775) & 751 predatory \\
T. nitidulus (Fabricius, 1781) & 17 predatory \\
T. obtusus (Linnaeus, 1767) & 98 predatory \\
T. pusillus Gravenhorst, 1806 & 2 predatory \\
T. solutus Erichson, 1839 & 11 predatory \\
Thinonoma atra (Gravenhorst, 1806) & 2 predatory \\
Tychus niger (Paykull, 1800) & 7 predatory \\
Xantholinus linearis (Olivier, 1795) & 15 predatory \\
X. longiventris Heer, 1839 & 38 predatory \\
X. semirufus auct.nec Reitter 1901 & 18 predatory \\
X. tricolor (Fabricius, 1787) & 19 predatory \\
Zyras limbatus (Paykull, 1789) & 22 myrmecophilous \\
\hline
\end{tabular}




\title{
Chapter 4
}

\section{Untangling local and landscape factors affecting the insect herbivore community of non-crop plants in arable fields}

\begin{abstract}
Species diversity in simplified ecosystems such as intensively managed annual crops is severely limited. Field scale diversification such as weedy crops is considered an option to restore this diversity. Little is known, however, about the determinants at local and larger spatial scales of the non-crop-plant based insect communities within arable fields, an essential component in the relaying of plant diversity benefits to higher trophic levels. We investigated how diversification of agroecosystems at the field and landscape level affects the insect community of a common weed, the creeping thistle Cirsium arvense. Artificial patches of the host plant were established in three regions of Germany in 48 paired organic (diverse) and conventional (simplified) wheat fields across a gradient of landscape heterogeneity, from simple arable-dominated to heterogeneous, diverse landscapes. Leaf-feeding herbivores were monitored during the season, while stem-boring herbivores and their parasitoids were quantified by dissecting the stems of the thistles in the laboratory after harvest. Land-use types and naturally occurring thistle stands were mapped within a radius of one kilometre of each thistle plot. We found that herbivore species richness was enhanced by both organic farming and landscape heterogeneity, but not by higher amounts of thistles in the landscape. When comparing presence/absence data of individual species, it appeared that for most of the herbivore species host-plant patches in organic fields were more likely to be colonised than those in the conventional fields. The enhancement of diversity in organic fields is most likely due to a slightly higher natural cover of the host plant $C$. arvense. High levels of weed cover (above 35\%) seem to cause a decrease in herbivore species richness. Enhancing herbivore insect richness on non-crop plants is an important prerequisite for the reestablishment of complex aboveground food webs in arable systems. Our results show that both diversification of landscapes (less arable crops, more perennial habitats) and diversification of crop fields (moderate - but not high - weed cover) through organic management are effective measures in this respect. The impact of field-scale agri-environment schemes on biodiversity should be supplemented by including landscape-scale diversification programmes.
\end{abstract}




\section{Keywords}

Biodiversity, Cirsium arvense, Germany, herbivory, landscape context, organic farming, weeds

\section{Introduction}

Most ecological studies focusing on the diversity of plant-insect communities are conducted on natural or near-natural habitat types. Comparatively little is known about the determinants of species diversity of the insect fauna of non-crop plants within arable fields. Yet weeds are the main source of biodiversity within the extremely species poor annual crops. As such, they can be considered as ecological goods that may be produced alongside harvestable crops in the framework of multifunctional agriculture (Gerowitt et al., 2003). The benefits provided by weeds are not limited to increased plant diversity: by providing resources for pollinators and specialist herbivorous insects, which may in turn be fed on by predators including birds and mammals, non crop plants are key players in the above-ground food chain within agroecosystems (Swift \& Anderson, 1994; Marshall et al., 2003). Surprisingly little knowledge is available on the most basic linkage: non-crop plants and their insect herbivores. Insects on weeds are usually studied from the narrow perspective of finding out how they influence the integrated pest management of crop pests (see Norris and Kogan, 2005 for a review). Partly as a result of this, many important questions remain unanswered. For instance, it is unclear how accessible the weeds of arable crops are to insects. Indeed, the resource these non-crop plants constitute is unpredictable in space and time due to the effects of tillage, weed control practices and crop rotation (Eber \& Brandl, 2003). Non-crop plants within annual crops support less herbivorous insects than plants of the same species growing in perennial habitats (Kruess, 2003).

The effective isolation of non-crop plants within arable crops is likely to depend on several factors. Modern agricultural activities (fertilisation, pesticide use) drastically reduce species abundance and diversity across taxa (e.g. De Snoo, 1997; for a review see Robinson \& Sutherland, 2002). As a result, non-crop plants are in most cases embedded within a monoculture of the crop species, which may reduce the likelihood of colonisation by insect species. It is to be expected that the extent and diversity of the weed cover will influence the effective isolation of individual weed patches within a field. Otway, Hector \& Lawton (2005) found that specialist herbivores were affected by both host-plant abundance and plant diversity, suggesting that presence and diversity of herbivores depend on several aspects of vegetation. In European agricultural landscapes, a type of management in which weed cover 
and diversity is greatly increased has become more popular over the past decades: by not using any synthetic fertilisers and prohibiting pesticide use, organic agriculture has created numerous weedy arable habitats, providing us with the opportunity to test the effects of fieldscale vegetation diversification on the insect community of weeds.

Although it is interesting to examine how this management aspect may impact the insects feeding on weeds, much may depend on field surroundings (Tscharntke et al., 2005). Arthropods are no different to most other organisms in that many important population processes take place at larger scales than the habitat patch itself (Kareiva \& Wennergren, 1995; Roland \& Taylor, 1997). The occurrence of species and trophic interactions within a given habitat type depends on the surrounding landscape context (the "matrix"). For example, the parasitism of rape pollen beetles rises with increasing fraction of perennial area within the surroundings (Thies \& Tscharntke, 1999). Arable field ecosystems rely on their surroundings more than other types of habitats because they are cleared at harvest and often ploughed every year, so their biodiversity depends on recolonisation from surrounding perennial habitats (Wissinger, 1997; Tscharntke \& Kruess, 1999). Such non-crop areas serve as a source for immigrants, as overwintering habitat and contain alternative resources for arthropods (e.g. Russell, 1989; Kruess 2003; Pfiffner \& Wyss, 2004).

In this study we examine how diversifying arable fields through organic management affects the insect community of a model non-crop plant species in landscapes with different amounts of perennial habitats. To do so we established patches of the creeping thistle Cirsium arvense (L.) Scop. (Asteraceae) as an indicator plant species, or phytometer (Harper, 1977), in paired organic and conventional winter wheat fields across a landscape gradient in three regions of Germany and surveyed both leaf-feeding and stem-boring herbivores. We tested for effects of local management, landscape complexity and regional setting on herbivore species diversity, probability of colonisation by individual insect species, abundances, insect loads and parasitism.

\section{Material and Methods}

Study area. The insect community on (unsprayed) indicator patches of $C$. arvense was surveyed in 48 paired organic and conventional wheat fields and in three different regions of Germany: seven pairs in the Soester Boerde, ten pairs in the Leine Bergland, seven pairs in the Lahn-Dill Bergland). The Soester Boerde (51 35' 00" N $008^{\circ} 07^{\prime} 00^{\prime \prime} \mathrm{E}$ ) is a rather flat area of Nord-Rhein Westfalen known for its very fertile silt-like loess soil and intensive agriculture centred mainly on arable crops such as wheat. The Leine Bergland (51 $32^{\prime} 00^{\prime \prime} \mathrm{N}$ 
$009^{\circ} 56^{\prime} 00^{\prime \prime}$ E) in Niedersachsen is dominated by arable crops in the flatter parts situated in the valleys, while in the more hilly parts land-use is more diversified. The Lahn-Dill Bergland in Hessen (50 49'00" $\left.\mathrm{N} 008^{\circ} 46^{\prime} 00^{\prime \prime} \mathrm{E}\right)$ spans a range from homogeneous, arable-dominated to heterogeneous, often afforested areas. In each region, the field pairs were situated in landscapes with varying composition, along a gradient from simple, arable dominated to more complex landscapes. Conventional fields are fertilised with synthetic fertiliser and manure, and treated with several applications of fungicides and herbicides. One third of the farmers sprayed insecticides (Karate or Perfekthion), in a single application. Organic fields are fertilised with manure only and are not sprayed with any pesticides. Despite mechanical weed control, weed cover and diversity was higher in the organic fields. Natural Creeping thistle cover outside of the experimental plots was higher in organic fields than in conventional fields (organic: 0.92 \pm 0.44 ; conventional: 0.06 \pm 0.04 ). Originally 28 field pairs were selected, but two had to be discarded because of very high thistle infestation, and one of the indicator patches of a third pair was inadvertently sprayed with herbicides, so this pair was also removed from the dataset. Two further pairs could not be used for the stem-boring insect analysis because in one case the patches were harvested together with the cereals by the farmers, and in the second case the damage by Cassida rubiginosa Müll. caused nearly all plants within one field to die.

Phytometer species. C. arvense, known as creeping or Canada thistle is a noxious dioecious perennial. It was chosen as a model system because it is extremely common and very characteristic for arable habitats, although it also occurs in other disturbed, ruderal environments. Although it is native to Europe, this species has been introduced into many regions of the world. It is a problem weed in pasture and arable areas mainly because of its ability to spread vegetatively through its root system in addition to sexual reproduction, which makes it difficult to control. Biology, control and detrimental effects of $C$. arvense have been reviewed in detail by Donald $(1990,1994)$. In addition to its commonness, another advantage of using Creeping thistle as a model system is that it may harbour a large number of different species of insect herbivores and their associated parasitoids: flower head, stem, leaf, root and sap provide food for insect species spanning the whole range from generalist to specialist (Zwölfer, 1965; Redfern, 1995). Some of these are well known, since they have been studied as potential biocontrol agents (Bacher, 1997; Friedli \& Bacher, 2001a,b).

Host-plant patches. Roots of $C$. arvense were dug up from an old fallow near Göttingen. They were cut into small pieces (between 2 and $6 \mathrm{~cm}$ depending on the diameter) and planted in seedling trays. The shoots emerged after 2-3 weeks. A row of three $C$. arvense plots with 
twelve plantules (2-4 leaves, 2-5 cm height) each was established in the centre (distance from edge: $50 \pm 15 \mathrm{~m}$ ) of every wheat field in the first week of May 2003. Each plot had an area of 1 $\mathrm{m}^{2}$ and was situated $0.5 \mathrm{~m}$ from the next plot. These plots were not considered replicates: all data were summed at the field level. Patches were hand-weeded regularly. Conventional farmers were asked not to spray them with pesticides. The thistles were harvested between the $23^{\text {rd }}$ and the $28^{\text {th }}$ of July. Roots were dug up to avoid thistle infestation by propagules originating from the experiment. Finally the shoots were dried at $70^{\circ} \mathrm{C}$ for 48 hours and the biomass was recorded. The number of stems $(53 \pm 4)$ as well as the amount of dry biomass $(144 \pm 14 \mathrm{~g})$ did not differ between the $C$. arvense plots within pairs of organic and conventional fields or between landscapes of different compositions. Biomass was, however, significantly lower in the Leine Bergland region than in the two other regions (ANOVA:

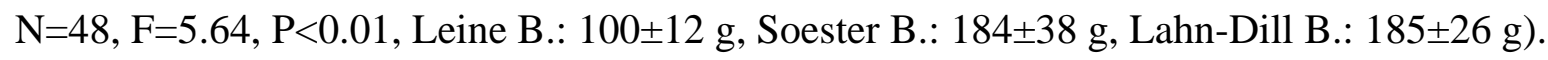

Herbivores. The leaf-feeding herbivores were surveyed on four occasions during spring and summer (end of May, mid-June, end of June, mid-July). All plants were checked for herbivores and signs of herbivory on each survey round. The following herbivore species were found to be feeding on the thistle plants during the survey (see also Fig.1): the shield beetle Cassida rubiginosa Müll. (Coleoptera: Chrysomelidae), caterpillars of the butterfly

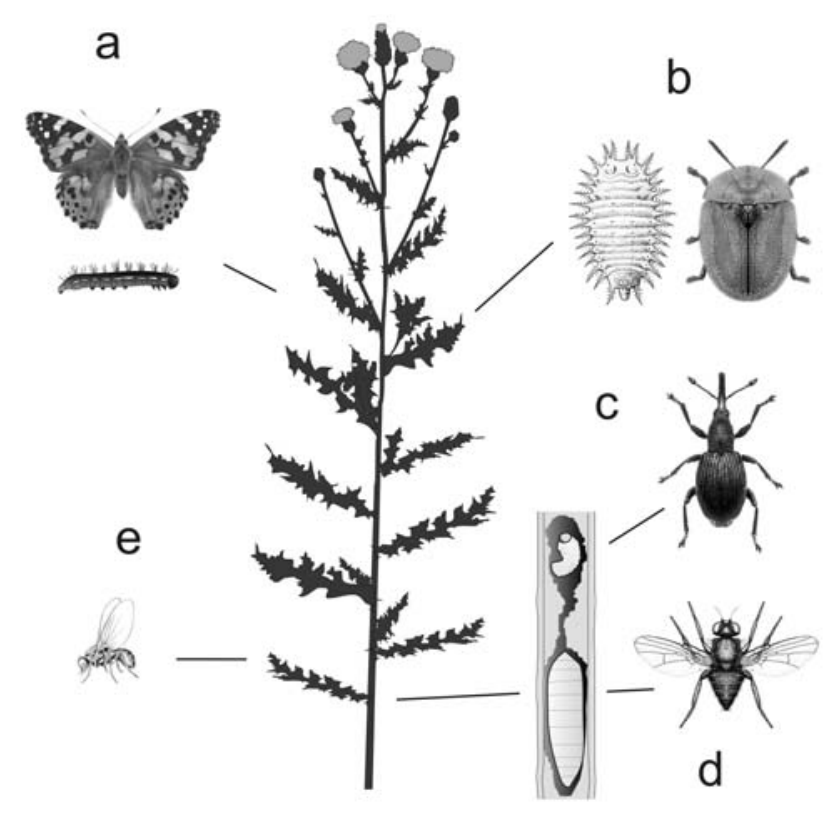

Fig. 1. Herbivore insect taxa commonly found in experimental C. arvense patches in German winter wheat fields in 2003: a) Vanessa cardui L. (Lepidoptera: Nymphalidae), b) Cassida rubiginosa Müll. (Coleoptera: Chrysomelidae), c) Apionidae (Coleoptera), d) Melanagromyza aenoventris Fall. (Diptera: Agromyzidae), e) Leafminers (Diptera: Agromyzidae); drawings not to scale. 
Vanessa cardui L. (Lepidoptera: Nymphalidae), unidentified species of leafminers (Diptera: Agromyzidae) and aphids (Homoptera: Aphidinae). Endophagous herbivores retrieved from a total of 2321 dissected stems included Melanagromzya aenoventris Fall. (Diptera: Agromyzidae), one or two species of weevils (Coleoptera: Apionidae) and Auchenorrhyncha (Hemiptera) eggs. All of the recorded herbivores are monophagous to oligophagous on Cirsium spp. and species of related genera such as Carduus, Arctium and Onopordon, with the exception of the polyphagous Auchenorrhyncha and $V$. cardui which also selects nettles as larval food plants. Leafminers (Diptera: Agromyzidae) were not identified because leafmines occur early in the season and removing leaves for rearing in the laboratory would have harmed the development of the young plants and compromised the rest of the experiment. For this reason the largest mine count from the four rounds was used in the analysis. We used cumulative counts for Vanessa cardui L. caterpillars. This method may overestimate the number of caterpillars feeding during the season, but since the lag between survey rounds approximately equals the larval development time of $V$. cardui (12-18 days) and most caterpillars were found at intermediate larval stages this overestimation is unlikely to have biased the results. Stem-boring herbivores were identified by dissecting the stems in the laboratory. For the apionid weevils (Coleoptera: Apionidae) that had already left the stems, identification to species was not possible but presence could be established by recording the presence of larval head capsules in the stem. Aphids were found only in a single field and were therefore not further analysed. C. rubiginosa was detected by recording the presence/absence of feeding traces on individual plants, resulting in incidence data. For the calculation of species richness we considered higher taxa that were not identified to species level as single species.

Field \& landscape data. Weed cover (\%) and species richness as well as C. arvense cover (\%) was established visually for 42 of the 48 fields. From the farmers we obtained data on number of insecticide applications and amount of nitrogen applied on the fields. At the landscape scale, land-use and naturally occurring thistle populations were mapped based on a field survey in a radius of $1000 \mathrm{~m}$ around each field, and digitised to a vector-based GIS map using ArcView 3.1 (ESRI Geoinformatik, Hannover, Germany). From the land-use maps we calculated \% non-crop area in the landscape sectors (range: 17-83\%). Thistle abundance in the landscapes was estimated by quantifying area and density of each natural patch and calculating total shoot number. We also computed isolation indices following Hanski (1994) using either only the nearest neighbouring patch or all patches within the $1000 \mathrm{~m}$ radius but 
Table 1. Wald tests for best-fit linear mixed models explaining species richness and abundance of Cassida rubiginosa (Coleoptera: Chrysomelidae), Vanessa cardui (Lepidoptera: Nymphalidae), Melanagromyza aenoventris (Diptera: Agromyzidae) and pear-shaped weevils (Coleoptera: Apionidae) feeding in thistle patches in organic and conventional wheat fields in landscapes differing in \% non-crop cover, in three different regions of Germany.

\begin{tabular}{lllccc}
\hline & Factor & d.f. & F & Effect & P \\
\hline Species richness & Management & 19 & 18.899 & + & 0.0003 \\
& \% non-crop & 19 & 5.247 & + & 0.0336 \\
C. rubiginosa & Management & 23 & 2.879 & + & 0.0008 \\
& \% non-crop & 22 & 5.119 & + & 0.0139 \\
V. cardui $^{*}$ & \% non-crop & 23 & 7.486 & - & 0.0118 \\
M. aenoventris & Region & 19 & 6.431 & $\mathrm{a}, \mathrm{b}>\mathrm{c}$ & 0.0074 \\
& Stems per field & 21 & 12.319 & + & 0.0021 \\
Apionidae & Management & 20 & 4.759 & + & 0.0413 \\
& Stems per field & 20 & 6.936 & + & 0.0159 \\
\hline
\end{tabular}

cumulative counts of caterpillars

$\S$ a: Leine Bergland; b: Soester Boerde; c: Lahn-Dill Bergland

since results with these did not differ from the analyses using thistle abundance in the landscapes they are not shown here.

Statistical analysis. We used linear mixed models (Pinheiro \& Bates, 2000), with two error levels added for "Pair" (random factor) and "Management" (fixed factor) nested within "Pair". "Region" and \% non-crop area were considered as fixed factors, for which field pairs were considered as independent replicates, thus taking into account spatial autocorrelation between fields of a pair. We did not assume any special form for the random-effects variancecovariance matrix. Abundances were log-transformed, incidences and percentages arcsinetransformed. Wald tests (Aitkin et al. 1989) were used to test for significance of fixed effects (Region, \% non-crop area, Management) and two-way interactions. Non-significant interactions $(\alpha>0.05)$ were discarded using a manual stepwise backward selection procedure. Number of stems per study field was included as a covariate for the analyses of the incidence of endophagous insects. Differences between regions, whenever significant in the mixed model, were further investigated by inspecting the contrasts in the model. All analyses were performed using R (R Development Core Team, 2004). In the text, data in brackets are mean \pm one standard error.

\section{Results}

Species richness. Overall species richness of herbivores was correlated positively with \% noncrop area and was significantly higher in organic fields than in conventional fields (Fig. 2, Table 1). On average, plots in organic fields were colonised by four herbivore species 
compared to three in the conventional fields, without this effect being attributable to a particular species. Visual inspection of the relationship between weed cover and species richness showed a different pattern for organic and conventional fields, which were then analysed separately with simple linear regressions (Fig. 3). Species richness was found to decrease significantly with weed cover for organic fields $(\mathrm{N}=18, \mathrm{~F}=11.05, \mathrm{P}<0.01)$, but not for conventional fields $(\mathrm{N}=18, \mathrm{~F}=0.67, \mathrm{P}>0.43)$. There was no relationship between species richness and weed cover. Weed cover and weed diversity were not correlated. Neither insecticide application $(\mathrm{N}=18, \mathrm{~F}=2.48, \mathrm{P}=0.13)$ nor amount of fertiliser added $(\mathrm{N}=18, \mathrm{~F}=0.51$, $\mathrm{P}>0.48$ ) contributed significantly to the explanation of species richness in conventional fields. Species richness did not depend on the amount of thistles in the landscape $(\mathrm{N}=24, \mathrm{~F}=0.01$, $\mathrm{P}>0.90)$ and did not differ between regions $(\mathrm{N}=24, \mathrm{~F}=0.48, \mathrm{P}>0.62)$.

Patch colonisation by herbivores. Analysis of the presence/absence data for individual species (Table 2) showed that patches in organic fields were significantly more likely to be colonised by $C$. rubiginosa, $M$. aenoventris, and stem-boring weevils. For the leafminers and $V$. cardui this was not the case. There were no significant landscape effects on individual species colonisation probability. All thistle patches were colonised by $V$. cardui and all but three by leafminers. For the endophagous herbivores, only the presence of $M$. aenoventris was more likely in patches with a greater number of thistle stems.

Herbivore abundances. Analysis of best fit models for the abundance data of individual species are shown in Table 1. The incidence of $C$. rubiginosa was higher in the organic fields

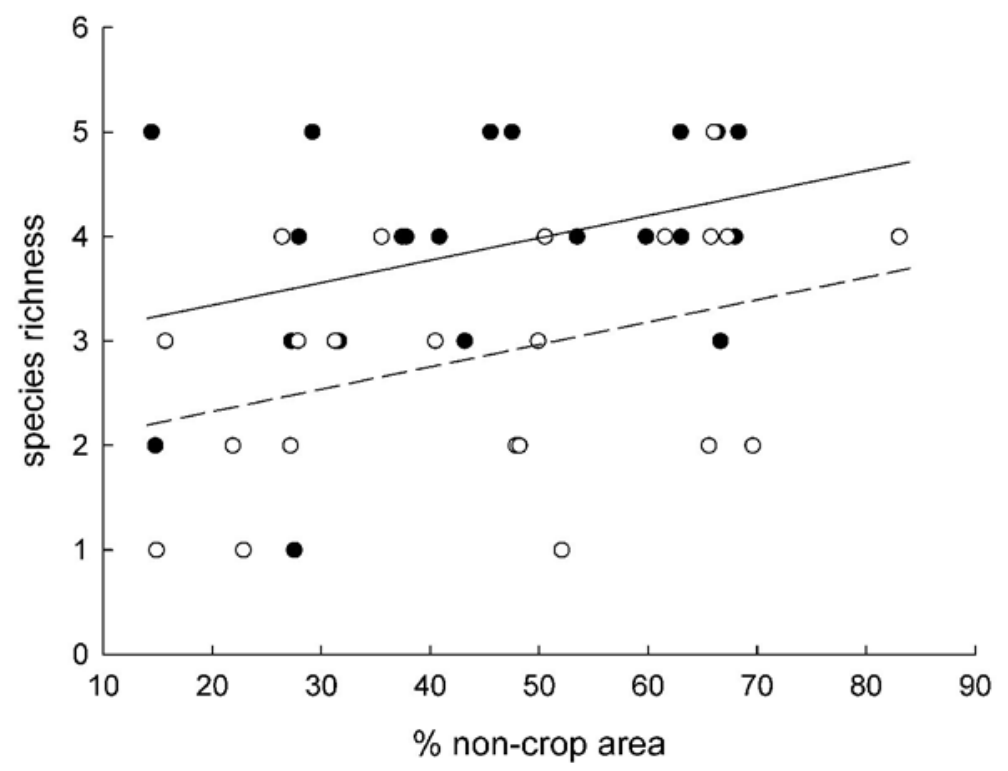

Fig. 2. Species richness of herbivores of Cirsium arvense in wheat fields depends on field management and \% non-crop area; circles indicate the values per field and lines the fitted linear mixed model for organic (filled circles, solid line) and conventional fields (empty circles, broken line). 
than in the conventional fields and increased with \% non-crop area in the landscape (Fig. 4). More individuals of Apionidae, but not of M. aenoventris, were found in organic fields than in conventional fields. Furthermore, the densities of both stem-boring herbivores depended on number of stems per patch. Cumulative densities of $V$. cardui larvae were significantly higher in the Lahn-Dill Bergland and the Leine Bergland than in the Soester Boerde, and decreased with increasing percentage of non-crop area in the landscape. The densities of leafmines (mean density $=0.3$ per thistle shoot) could not be explained by any of the factors included in the model.

Herbivore loads. For the calculation of herbivore loads only fields with species incidence were included in the analysis (following Otway et al., 2005). Herbivore loads (individual numbers/thistle biomass) were higher for $V$. cardui $(\mathrm{N}=21, \mathrm{~F}=4.71, \mathrm{P}<0.05)$ and $M$. aenoventris $(\mathrm{N}=18, \mathrm{~F}=10.29, \mathrm{P}<0.01)$ in organic fields. $V$. cardui loads increased with increasing weed cover in the fields $(\mathrm{N}=21, \mathrm{~F}=29.06, \mathrm{P}<0.0001)$ and was lower in the Soester Boerde than in the other two regions $(\mathrm{N}=21, \mathrm{~F}=4.35, \mathrm{P}<0.05)$. The apionid and leafminer loads could not be explained by any of the factors included in the model.

Parasitism. Because parasitoids of the apionids had emerged before the thistle harvest, the parasitoids found in the stems were all from $M$. aenoventris. They belonged to the geni Stenomalina and Chlorocytus (Hymenoptera: Pteromalidae). Average parasitism rate was $41 \pm 6 \%$. Local and larger scale factors were correlated neither to the parasitism rates, nor to the colonisation success by parasitoids (presence/absence data). Parasitism of $V$. cardui by an unidentified braconid wasp (Hymenoptera: Braconidae) was also observed, but only in four of the study fields.

Table 2. \% presence of five herbivorous insects in patches of Cirsium arvense in organic and conventional wheat fields, with significance levels from Wald-tests for linear mixed models.

\begin{tabular}{lcrl}
\hline & \multicolumn{2}{c}{ Management } & \multirow{2}{*}{ Sig. $^{\S}$} \\
\cline { 2 - 3 } & conventional & organic & \\
\hline Apionidae & 45.5 & 81.8 & $* * *$ \\
C. rubiginosa (Coleoptera: Chrysomelidae) & 62.5 & 83.3 & $*$ \\
M. aenoventris (Diptera: Agromyzidae) & 68.2 & 90.9 & $*$ \\
V. cardui (Lepidoptera: Nymphalidae) & 100 & 100 & $\mathrm{~ns}$ \\
Leafminers (Diptera: Agromyzidae) & 79.2 & 87.5 & $\mathrm{~ns}$ \\
\hline
\end{tabular}

\footnotetext{
${ }^{\S}$ Sample sizes: $\mathrm{n}=22$ field pairs for Apionidae and $M$.aenoventris, $\mathrm{n}=24$ field pairs for $C$. rubiginosa, V. cardui and leafminers; significance levels are ***: $\mathrm{P}<0.001$; **: $\mathrm{P}<0.01$; *: $\mathrm{P}<0.05$; ns: not significant)
} 

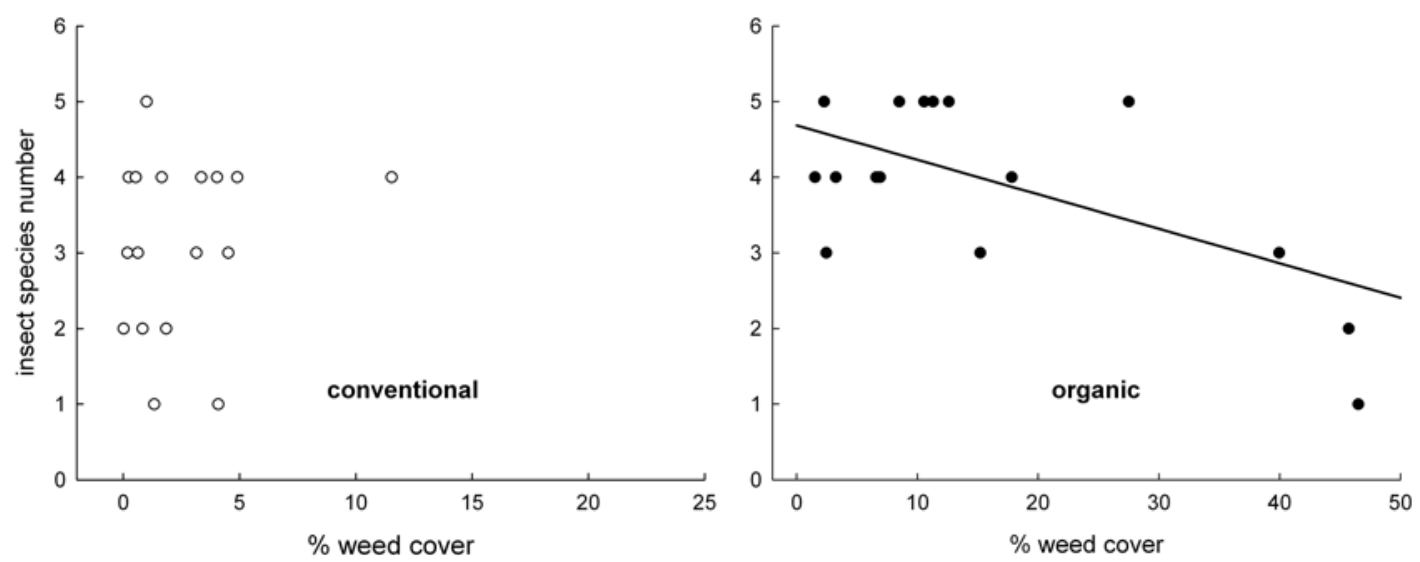

Fig. 3. In organic fields the species richness of herbivores of Cirsium arvense decreases with $\%$ weed cover $\left(\mathrm{R}^{2} \mathrm{adj}=0.30\right)$. In conventional fields, where weed cover is lower, there is no significant relationship between the two variables.

\section{Discussion}

In this study we could separate the effect of enhanced within-field diversity through organic farming and the effect of the landscape-scale complexity around the field on diversity and abundance of thistle herbivores in arable fields. At the local scale, patches of the host plant situated in organic fields were more likely to be colonised by C. rubiginosa, M. aenoventris, and apionid weevils than patches situated in conventional fields. Loads of $V$. cardui and $M$. aenoventris as well as species richness were higher in the organic fields. Host plant acceptance by foraging herbivores is not likely to have been different in organic and

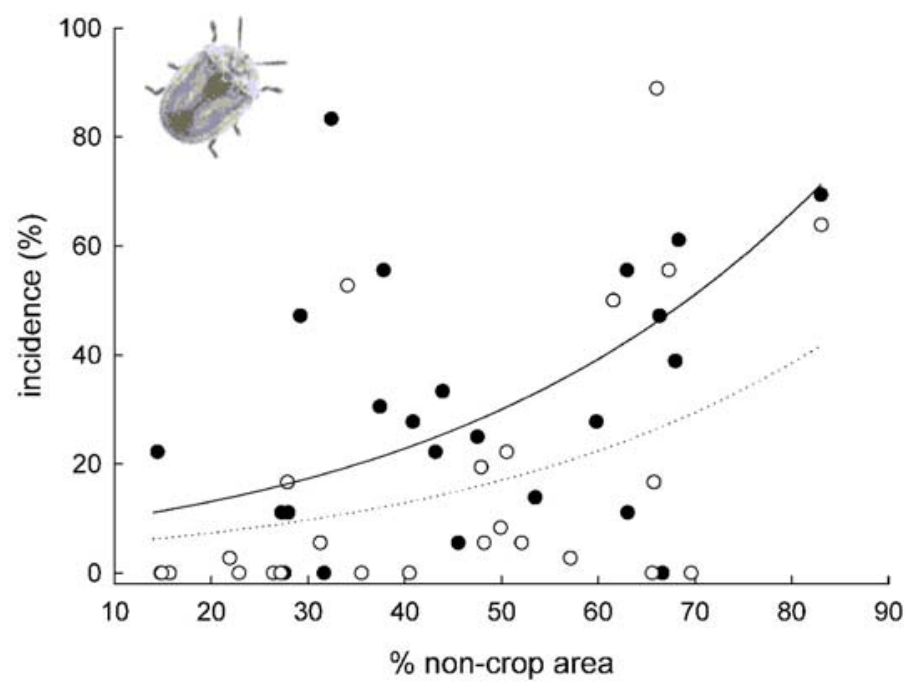

Fig. 4. The percentage of Cirsium arvense plants damaged by Cassida rubiginosa (Coleoptera: Chrysomelidae) per patch depends on management $(\mathrm{N}=22$, Wald-F $=15.03, \mathrm{P}<0.001)$ and \% non-crop area in the landscape $(\mathrm{N}=22$, Wald-F=7.14, $\mathrm{P}<0.05)$; circles indicate the values per field and lines the fitted linear mixed model for organic (filled circles, solid line) and conventional fields (empty circles, broken line). 
conventional fields. A small-scale pot experiment showed no difference in colonisation of $M$. aenoventris between plants grown in organic soil and plants grown in conventional soil but otherwise similar conditions (Y. Clough, unpublished). Insecticide applications seem to have had negligible effects on thistle herbivores as treated fields did have a lower herbivore diversity than untreated conventional fields. The enhanced diversity in organic fields might be due to the higher $C$. arvense cover in the organic fields, although there was no significant correlation between herbivore parameters and \% thistle cover. Overall weed cover was significantly higher in the organic fields than in the conventional fields (D. Gabriel, unpublished data) and affected several herbivores: $V$. cardui cumulative load was positively correlated with weediness. Herbivore species richness decreased with weed cover in organic fields. Since none of the other weed species recorded in the fields were within their host-plant spectrum, weed cover could have been expected to have little or no impact. It has though already been demonstrated experimentally that non-host vegetation surrounding host-plant patches may have large effects on colonisation by herbivore insects (Root, 1973; Banks, 1998; Bukovinszky et al., 2005). Although structural interference can be excluded because of the regular weeding of the experimental thistle patches, visual (Feeny, 1976) and chemical apparency (Stanton, 1983) of the thistles are likely to have been affected by the surrounding vegetation, resulting in associational plant resistance. More research manipulating the diversity and composition of non-host plants surrounding a host-plant patch would be needed, as most past studies use binary "simple vs. diverse" comparisons (Andow, 1991; Tonhasca \& Byrne, 1994). Interestingly, Otway et al. (2005) found similar effects in their study on insect specialists along a gradient of plant diversity in experimental grasslands even though their results were obtained in an undisturbed and less species poor environment. Our results suggest that the identity and the diversity of the vegetation matrix (crop vs. crop and weed plants) play an important role in host-plant finding of arable weed herbivores. More generally we may conclude that organic management does succeed in reverting some of the negative effects of local agricultural intensification on weed herbivore diversity. Surprisingly, such an effect was not found for parasitism of $M$. aenoventris. One might have expected parasitoids to benefit from the larger floral resources in organic fields. Preliminary results for the comparison of bird fauna between the organic and conventional study fields indicate that more birds and more bird species were sighted in the organic fields (Y. Clough, unpublished data), which may indicate that the positive effects of organic management on insect herbivores were relayed to higher trophic levels. 
Not only field-scale factors such as agricultural practices but also large scale land-use has changed considerably during the last decades (e.g. Krebs, 1999). Landscapes and in many cases whole regions have become less diverse in terms of land-use as a result of farm specialisation. This has led to many areas being dominated by annual crops, featuring only few small remnants of perennial structures, such as grassland or near-natural habitats. We found that landscape heterogeneity was important in determining both species richness and individual species densities of thistle herbivores. In monotonous, arable dominated landscapes, less species colonised the thistle patches than in landscapes with a higher percentage of perennial habitats. The latter can provide more colonisers because of their suitability as overwintering areas. For example, for species such as M. aenoventris, which overwinter in the pupal stage within the dried out stems of the host plant, thistle stands on arable fields represent a population sink due to a high mortality by tillage long before the emergence of the adults. Other species overwinter outside of the thistles but still rely on nontilled habitat for survival. One herbivore species, C. rubiginosa, which overwinters as an adult in litter, had a higher incidence in landscapes with high percentage of non-crop habitat. Thus, our results show that the landscape determines the potential diversity which may be realised or not depending on local conditions. The fact that \% non-crop area at landscape scale had no effect on the parasitism rate of $M$. aenoventris does not support the results of Kruess \& Tscharntke (2000), where perennial habitats in the landscape are found to be important for parasitoids. However, parasitism is generally lower in annual crops than in less disturbed habitats (Kruess 2003), so disturbance and isolation within the crop as well as small patch size may be the main limiting factors, leaving other effects undetectable.

The abundance of thistles in the landscape had no measurable impact on the insect community of our indicator patches, despite the large range of different densities covered in the landscapes under study. Presumably no significant effects were found because all the patches in the crop fields were very isolated. It is also possible that the thistle population density in the landscapes does not correlate well either with the thistle population in the previous years or with the overwintering success of the insects, both of which play a central role in the population dynamics of thistle insects.

While local factors and landscape effects were important, large-scale regional setting had surprisingly little influence on species richness, only one herbivore species (M. aenoventris) showing density differences between regions. The absence of interactions between region and local or landscape factors suggests that the results are valid across the agricultural landscapes of Germany. 
In conclusion, we can state that the insect community of Creeping thistles in cereals is more diverse in weedy, organic farmed fields. Our results suggest that diversification of crops through moderate weed cover reduces the effective isolation of single-species weed patches in the field for foraging herbivores. Above a certain threshold, weediness results in concealed host-plant patches and reduces colonisation. More research is needed to find out how the insect community of multi-species weed mixtures would respond to different levels of weediness. We confirm findings reported elsewhere for other taxa (Roschewitz et al., 2004; Clough et al., in press) that nearby perennial habitats are of prime importance for the biodiversity of arthropods within annual crops, and show that for insects on weeds this effect can be complementary to within-field diversification. Though in practice manipulating landscape diversity is difficult, it is a major key to restoring species richness in modern agroecosystems, and should be the focus of future agri-environment programmes.

\section{Acknowledgements}

We thank the farmers for their willingness to participate in the project. We are grateful to Doreen Gabriel and Indra Roschewitz for the vegetation mapping, to Stéphanie Domptail for the landscape digitisation and to Tobias Purtauf for his participation in the field selection. Comments by Tibor Bukovinszky, Sabine Eber and Heiri Wandeler greatly improved earlier versions of the manuscript. This research was carried out within the framework of the EUfunded project 'EASY' (QLK5-CT-2002-01495), coordinated by David Kleijn.

\section{References}

Aitkin, M., Anderson, D., Francis, B. \& Hinde, J. (1989) Statistical Modelling in GLIM. Oxford University Press, Oxford.

Andow, D.A. (1991) Vegetational diversity and arthropod population response. Annual Review of Entomology, 36, $561-586$.

Bacher, S. (1997) The potential of indigenous insects for the biological control of creeping thistle (Cirsium arvense (L.) Scop.) in central Europe. Proceedings of the German Society for General and Applied Entomology, 11, 277-280.

Banks, J.E. (1998) The scale of landscape fragmentation affects herbivore response to vegetation heterogeneity. Oecologia, 117, 239-246.

Bukovinszky, T., Potting, R.P.J., Clough, Y., van Lenteren, J.C. \& Vet, L.E.M. (2005) The role of pre- and postalighting detection mechanisms in the responses to patch size by specialist herbivores. Oikos, 109, 435-446. 
Clough, Y., Kruess, A., Kleijn, D. \& Tscharntke, T. (in press) Spider diversity in cereal fields: comparing local, landscape and regional scales. Journal of Biogeography.

De Snoo, G.R. (1997) Arable flora in sprayed and unsprayed crop edges. Agriculture, Ecosystems and Environment, 66, 223-230.

Donald, W.W. (1994) The biology of Canada thistle (Cirsium arvense). Reviews of Weed Science, 6, 77-101.

Donald, W.W. (1990) Management and control of Canada thistle (Cirsium arvense). Reviews of Weed Science, $\mathbf{5}$, 193-250.

Eber, S. \& Brandl, R. (2003) Regional patch dynamics of Cirsium arvense and possible implications for plantanimal interactions. Journal of Vegetation Science, 14, 259-266.

Feeny, P. (1976) Plant apparency and chemical defense. Recent Advances in Phytochemistry, 10, 1-40.

Friedli, J. \& Bacher, S. (2001a) Mutualistic interaction between a weevil and a rust fungus, two parasites of the weed Cirsium arvense. Oecologia, 129, 571-76.

Friedli, J. \& Bacher, S. (2001b) Direct and indirect effects of a shoot-base boring weevil and plant competition on the performance of creeping thistle, Cirsium arvense. Biological Control, 22, 219-226.

Gerowitt, B., Bertke, E., Hespelt, S.-K., \& Tute, C. (2003) Towards multifunctional agriculture - weeds as ecological goods? Weed Research, 43, 227-235.

Hanski, I. (1994) A practical model of metapopulation dynamics. Journal of Animal Ecology, 63, 151-162.

Harper, J.L. (1977) The Population Biology of Plants. Academic Press, London.

Kareiva, P. \& Wennergren, U. (1995) Connecting landscape patterns to ecosystem and population processes. Nature, 373, 299-302.

Krebs, J.R., Wilson, J.D., Bradbury, R.B. \& Siriwardena, G.M. (1999) The second Silent Spring? Nature, 400, 611-612.

Kruess, A. \& Tscharntke, T. (2000) Effects of habitat fragmentation on plant-insect communities. Interchanges of insects between agricultural and surrounding landscapes (eds B. Ekbom, M.E. Irvin \& Y. Robert), pp. 53-70. Kluwer, Dordrecht.

Kruess, A. (2003) Effects of landscape structure and habitat type on a plant-herbivore-parasitoid community. Ecography, 26, 283-290.

Marshall, E.J.P., Brown, V.K., Boatman, N.D., Lutmans, P.J.W., Squire, G.R., \& Ward, L.K. (2003) The role of weeds in supporting biological diversity within crop fields. Weed Research, 43, 77-89.

Norris, R.F. \& Kogan, M. (2005) Ecology of interactions between weeds and arthropods. Annual Review of 
Entomology, 50, 479-503.

Otway, S.J., Hector, A., \& Lawton, J.H. (2005) Resource dilution effects on specialist insect herbivores in a grassland biodiversity experiment. Journal of Animal Ecology, 74, 234-240.

Pfiffner, L. \& Wyss, E. (2004) Sown wildflower strips to enhance natural enemies of agricultural pests in annual and perennial cropping systems. Ecological Engineering for Pest Management: Advances in Habitat Manipulation for Arthropods (eds G.M. Gurr, S.D. Wratten \& M.A. Altieri), pp. 167-188. CSIRO Publishing, Melbourne.

Pinheiro, J.C. \& Bates, D.M., (2000) Mixed-effects models in S and S-Plus. Springer, New York.

R Development Core Team (2004) R: A language and environment for statistical computing. Foundation for Statistical Computing, Vienna; URL: http://www.R-project.org.

Redfern, M. (1995) Insects and thistles. Richmond, Slough.

Robinson, R.A. \& Sutherland, W.J. (2002) Post-war changes in arable farming and biodiversity in Great Britain. Journal of Applied Ecology, 39, 157-176.

Roland, J. \& Taylor, P.D. (1997) Inesct parasitoid species respond to forest structure at different scales. Nature, 386, $710-713$.

Root, R.B. (1973) Organization of a plant-arthropod association in simple and diverse habitats: The fauna of collards (Brassica oleracea). Ecological Monographs, 43, 95-124.

Roschewitz, I., Hücker, M., Tscharntke, T. \& Thies, C. (2005). The influence of landscape context and farming practices on parasitism of cereal aphids. Agriculture, Ecosystems and Environment, 108, 218-227.

Russell, E.P. (1989) Enemies hypothesis: a review of the effect of vegetational diversity on predatory insects and parasitoids. Environmental Entomology, 18, 590-599.

Stanton, M.L. (1983) Spatial patterns in the plant community and their effects upon insect search. In Ahmad S(ed):Herbivorous Insects: host-seeking behaviour and mechanisms. Academic Press, pp.125-157.

Swift, M.J. \& Anderson, J.M. (1994) Biodiversity and ecosystems in agricultural systems. Biodiversity and ecosystem function (eds E.-D. Schulze \& H.A. Mooney), pp. 15-41. Springer, New York.

Thies, C. \& Tscharntke, T. (1999) Landscape structure and biological control in agroecosystems. Science, 285, 893-895.

Tonhasca Jr., A. \& Byrne, D.N. (1994) The effects of crop diversification on herbivorous insects: a metaanalysis approach. Ecological Entomology, 19, 239-244.

Tscharntke, T. \& Kruess, A. (1999) Habitat fragmentation and biological control. Theoretical approaches to biological control (eds B.A. Hawkins \& H.V. Cornell), pp. 190-205. Cambridge University Press, Cambridge. 
Wissinger, S.A. (1997) Cyclic colonization in predictably ephemeral habitats: a template for biological control in annual crop systems. Biological Control, 10, 4-15.

Zwölfer, H. (1965) Preliminary list of phytophagous insects attacking wild cynareae (Compositae) in Europe. Technical Bulletin of the Commonwealth Institute for Biological Control, 6, 81-154. 


\title{
Chapter 5
}

\section{$\alpha$ and $\beta$ diversity responses to crop management differ between species groups}

\begin{abstract}
$\beta$ diversity need not be correlated with $\alpha$ diversity, raising the concern that contrasting responses of different diversity components may lead to a misrepresentation of the overall pattern with standard analyses of $\alpha$ diversity. We apply a biodiversity-partitioning approach to data from a comparison between paired organic and conventional wheat fields in Germany, where we recorded plants, bees, carabids, staphylinids and spiders. Our results show that diversity partitioning depends on taxon. $\beta$ diversity was very high for all taxa (65-85\%) and was larger in the edge than in the centre of fields for all taxa, emphasising the importance of the species pool of the surrounding landscape. Patterns of $\beta$ diversity were found to closely track those found for $\alpha$ diversity, with significantly higher values in organic than in conventional fields for plants and bees. Dispersal limitation appears to cause changes in spatial partitioning of diversity, as flightless carabids exhibited small $\alpha$ and high $\beta$ diversity, which contrasted with flying and dimorphic carabids, in which dispersal acts as a homogenizing force. We conclude that $\beta$ diversity is an important biodiversity component in agroecosystems. Organic management leads to significant benefits for both $\alpha$ and $\beta$ diversity of plants and their main pollinator group, but this does not hold for arthropod taxa less dependent on vegetation.
\end{abstract}

Key words: agroecosystems, arthropods, beta diversity, dispersal, organic farming, weeds

\section{Introduction}

The decline of biodiversity in agricultural landscapes is of increasing concern (Matson et al. 1997, Krebs et al. 1999), and alternative management forms such as conversion to organic farming are often considered to be a step towards reversing this trend (e.g. Soil Association 2000). However studies assessing the effectiveness of organic agriculture in conserving biodiversity have been plagued by methodological shortcomings such as lack of replication (Hole et al. 2005, Bengtsson et al. 2005). In addition, these studies exclusively address plot scale diversity. This is a very straightforward procedure to quantify biodiversity in plots that 
have been subjected to ecological change. Ecologists are aware, however, that plot scale diversity is but one component of total diversity (Whittaker 1977, Veech et al. 2002, Legendre et al., 2005). In an additive partitioning approach of biodiversity, diversity components are referred to as follows: (1) $\alpha$ diversity, which is the average diversity within a plot, (2) $\gamma$ diversity, which is the total diversity across plots or the regional diversity, and (3) $\beta$ diversity, which is a measure of the difference between $\gamma$ (total) diversity and $\alpha$ (local) diversity. High $\beta$ diversity values indicate large differences in species composition, i.e. differences between patches in the identity of species encountered, while low $\beta$ values are the result of similar species composition between patches.

The partitioning of diversity into its components is of interest to ecologists for several reasons. It is viewed as a useful tool for analysing the spatial patterns of diversity and has recently been used to reveal or reformulate macro-ecological diversity patterns (Blackburn and Gaston 1996, Novotny and Weiblen 2005) and to study the effect of spatial grain on the measurement of biodiversity (Koleff et al. 2003, Arita and Rodriguez 2002). From a more applied perspective, Gering et al. (2003) have pointed out that knowledge about the spatial components of diversity of a community of interest may help in selecting the appropriate spatial scale for species conservation. We suggest that it is important to use spatial partitioning of diversity to compare biodiversity on farmland with different management schemes because $\alpha$ diversity may only reveal part of the differences in biodiversity pattern or may even be misleading. For instance, in hypothetical scenarios, even though $\alpha$ diversity may be higher in sites with a particular management scheme compared to the control, a reduced heterogeneity between sites due to the management schemes may in fact decrease total diversity within the pool of sites (Fig.1A), which may be counterproductive in attaining higher levels of species richness. Such effects have been found by Tylianakis et al. (in press) by temporal partitioning of diversity data. On the other hand, if heterogeneity between sites is increased by management, then it may well be that an increase in $\beta$ diversity complements the increase in $\alpha$ diversity, leading to hidden benefits at larger scales (Fig.1B). In the case when $\alpha$ diversity does not differ between managed sites and the control, $\beta$ diversity may still lead to higher or lower diversity (Fig.1C, 1D)

In this study we apply diversity partitioning to a data set resulting from a biodiversity survey conducted in organic and conventional winter wheat fields in Germany. The main focus of the study, conducted in the framework of the EU-project EASY (Kleijn et al. in press), was to reveal whether organic agriculture provides biodiversity benefits, and if so which species groups profit from the organic management. German organic farmers receive subsidies 


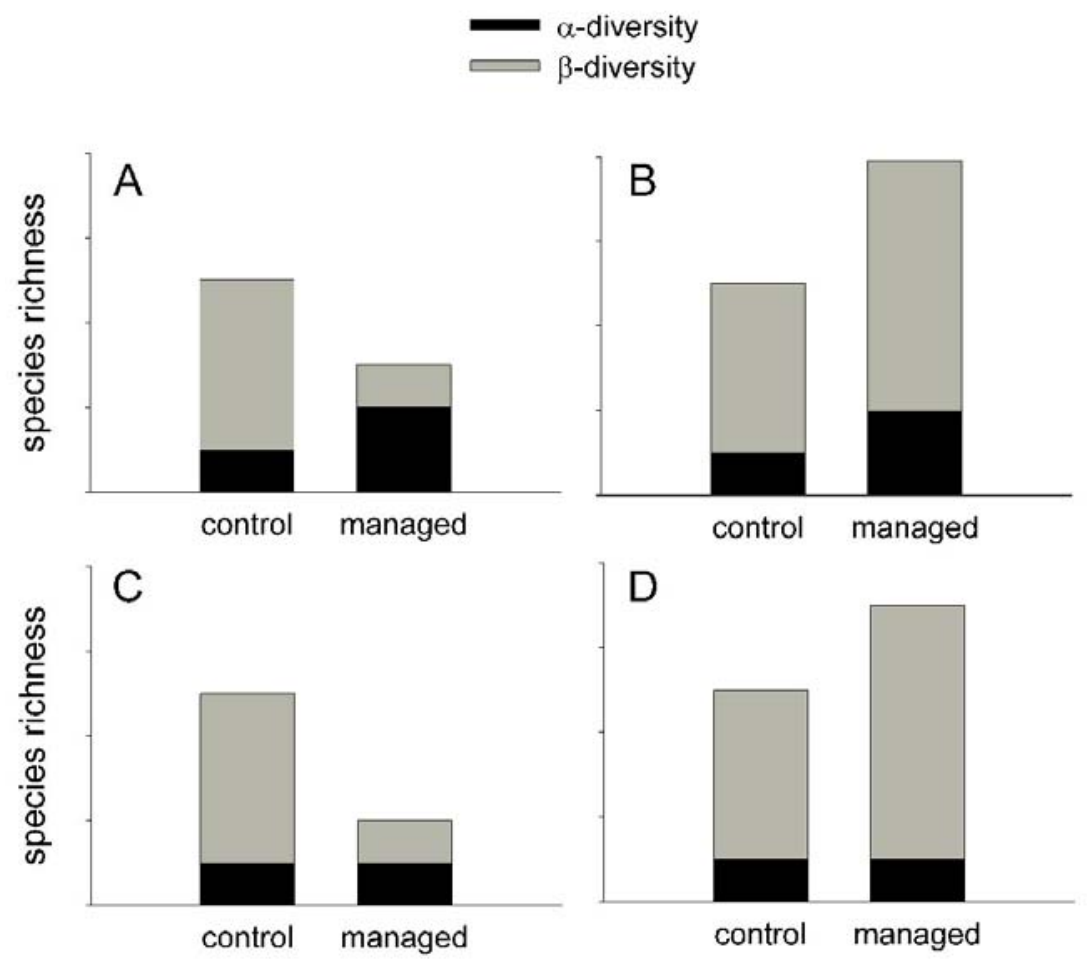

Fig. 1. Four alternative, hypothetical scenarios illustrating the contrasting effects management schemes may have on biodiversity at the field scale ( $\alpha$ diversity) and the between-field scale ( $\beta$ diversity). A: $\alpha$ increases, but $\beta$ decreases; B: $\alpha$ increases, $\beta$ increases; C: $\alpha$ unchanged, $\beta$ decreases; D: $\alpha$ unchanged, $\beta$ increases

through the European agri-environment schemes (Grafen and Schramek 2000) which span a whole range of on-farm measures aimed at reducing the negative ecological side-effects of agricultural activity. We sampled 42 fields for vascular plants, bees (Hymenoptera: Apiformes), carabid beetles (Coleoptera: Carabidae), staphylinid beetles (Coleoptera: Staphylinidae) and spiders (Aranea). The samples were taken in the centre and in the edge of all fields, as management effects can be expected to differ between edge and centre of the arable crop.

We chose to use the additive diversity partitioning method (Allan 1975, Lande 1996), such that $\beta=\gamma-\alpha$. This measure of $\beta$ diversity is intimately related to Whittaker's multiplicative $\beta$, which has been described as "a simple summary statistic of the relation between additive components" (Kiflawi and Spencer 2004). The additive partitioning method is more straightforward and allows direct comparison between $\alpha, \beta$ and $\gamma$ diversity as these components are all expressed in the same unit. We use a recently proposed hypothesis test for comparing $\beta$ diversity measures among groups of sites (Kiflawi and Spencer 2004). Part of the results, especially effect sizes, are expected to depend on elements of the study design, such as the distances between regions and between landscapes in the different regions, but this will not affect the validity of the comparisons between habitat types and species groups. The 
research questions we address in this study are (1) how do the $\alpha$ and $\beta$ diversity differ between organic and conventional fields? (2) do the $\alpha$ and $\beta$ diversity differ between edge and center of the wheat fields? (3) how does the partitioning of diversity differ between taxa, and is it related to dispersal traits? We will then discuss the effectiveness of the organic management and whether the $\beta$ diversity results alter the conclusions one may draw with conventional $\alpha$ diversity analyses.

\section{Methods}

Study area. We surveyed 42 paired organic and conventional wheat fields in three regions of Germany: seven pairs in the Soester Boerde, seven pairs in the Leine Bergland and seven pairs in the Lahn-Dill Bergland). The Soester Boerde (51 $51^{\circ} 00^{\prime \prime} \mathrm{N} 008^{\circ} 07^{\prime} 00^{\prime \prime} \mathrm{E}$ ) is a rather flat area of Nordrhein-Westfalen known for its very fertile silt-like loess soil and intensive agriculture centred mainly on arable crops such as wheat. The Leine Bergland $\left(51^{\circ}\right.$ $32^{\prime} 00^{\prime \prime} \mathrm{N} 009^{\circ} 56^{\prime} 00^{\prime \prime} \mathrm{E}$ ) in Niedersachsen is dominated by arable crops in the flatter parts situated in the valleys, while in the more hilly parts land-use is more diversified. The LahnDill Bergland in Hessen (50 49' 00" N 008 46' 00" E) spans a range from homogeneous, arable-dominated to heterogeneous, often afforested areas. Organic and conventional fields within a pair were never more than $600 \mathrm{~m}$ apart, and were chosen as similar as possible with respect to size and soil conditions.

Organic farming. The organic regulations tend to be specific to the local organic producers associations but are all based on those issued by IFOAM (International Federation of Organic Agriculture Movements). Organic crop production guidelines have been integrated within the EU legislation since 1991: the regulation (EEC) $n^{\circ}$ 2092/91 provides a set of minimum production and processing rules which must be followed in order to label a product as "organic", and specifies an inspection regime which is obligatory for all operators which are involved in placing organic products on the market. Certified organic farmers are not allowed to use synthetic fertilisers or pesticides, and have to rely on organic manure and strategies such as incorporating one or two years of clover in the crop rotation to suppress weeds and increase soil fertility.

Sampling. At the end of May 2003, herb and grass species in each field were recorded using two $95 \mathrm{~m}$ parallel transects. Each transect consisted of ten plots $(5 \mathrm{~m} \mathrm{x} 1 \mathrm{~m})$ at intervals of 5 $\mathrm{m}$. One transect followed the field edge and one was located in the field centre.

Bees (Apiformes) were caught by sweep-netting at four dates between May and July along 95 $\mathrm{m}$ long and $1 \mathrm{~m}$ wide transects in the field centre and the field edge for $15 \mathrm{~min}$ per transect 
and date. All bees were collected and brought to the laboratory for identification. Fields of a pair were sampled directly after another, between 10:00 and 18:00, in appropriate weather conditions (low wind speeds, temperature $>18^{\circ} \mathrm{C}$, cloud cover $<30 \%$ ). The number of bee species is the total number caught within the study period.

Two pitfall traps for surveying spiders, carabids and staphylinids $(\varnothing 11 \mathrm{~cm})$ were placed in the centre (distance from edge: $50 \pm 15 \mathrm{~m}$ ) and two at the edge (between the first and the second wheat row) of each field, and opened for three two-week sampling periods during spring and early summer (1-15, 15-28 May; 11-26 June, \pm two days depending on the region). The decision when to start trapping in each region was based on a phenological indicator: The traps were opened one week after the beginning of the mass flowering of Taraxacum officinale L. This sampling scheme was designed following Duelli (1997). The trapping fluid was ethylene glycol diluted with water (1/3 v/v) (Schmidt et al. 2005). Pitfall traps generate activity-density measures and not absolute abundance measures. However, this method is suitable for comparisons within the same habitat (Topping and Sunderland 1992). Spiders and staphylinids were identified from all samples, carabids only from the first and third sampling period due to the extremely large sample sizes.

Diversity partitioning. We partitioned the total number of observed species in all samples of the study $\left(\gamma_{\text {obs }}\right)$ into three different components:

(1) Following the additive partitioning approach we have: $\gamma_{\mathrm{obs}}=\alpha+\beta$

(2) $\alpha$ diversity: mean species richness at the field level (or field-pair level for comparisons between taxa)

(3) $\beta$ diversity between fields (or field-pairs for comparisons between taxa)

We use the aggregated $\beta$ diversity defined as $\beta=\beta_{L}+\beta_{R}\left(\beta_{L}: \beta\right.$ between field pairs in region, $\beta_{R}$ : $\beta$ between regions), because sample size for regions $(n=3)$ is not large enough to test them separately. For the hypothesis testing of $\beta$ diversity we use an estimate for $\gamma$ diversity (see below).

Statistical models and hypothesis tests for $\alpha$ diversity. We fitted linear mixed models using restricted maximum likelihood (REML) (Pinheiro and Bates 2000), incorporating the following error structure (number of levels indicated in parentheses):

"pair" (21)/"management" (2)/"in-field location" (2)

This method enabled us to retain full information while avoiding pseudoreplication. Wald tests (Aitkin et al. 1989) were used to test for significance of fixed effects (Region, Management, Location in field) and two-way interactions. Normality of the distribution of the 
raw dependant variables was assessed using QQ-plots and data were log-transformed when necessary. We used the package lme, which implements linear mixed models in the open source statistical progam $R$ (R Development Core Team 2005)

Hypothesis test for $\beta$ diversity. It was not possible to use the same approach to test for $\beta$ diversity as for $\alpha$ diversity because of the necessity of estimating total diversity for which the observed values would have been underestimates. We thus conducted several pair-wise tests for the following comparisons: organic vs. conventional for field centre and field edge, field edge vs. centre for conventional and for organic fields, i.e. 4 comparisons in total for each taxon. Given the relatively low power of the test used we did not apply any corrections for multiple testing to the resulting P-values.

We used the following formulas for additive $\beta$ diversity from Kiflawi and Spencer (2004) (corrected versions from Ecology 86(8) p.2252):

$$
Z_{\beta}=\frac{\left(\alpha_{1}-\alpha_{2}\right)}{\left\{\left[\operatorname{Var}\left(\hat{\gamma}_{1}\right)+\operatorname{Var}\left(\alpha_{1}\right)\right]+\left[\left(\operatorname{Var}\left(\hat{\gamma}_{2}\right)+\operatorname{Var}\left(\alpha_{2}\right)\right]\right\}^{0.5}\right.}
$$

Where $Z_{\beta}$ is to be regarded as the standardised normal deviate, with the nominator as effect size, used to test the null hypothesis $H_{0}: \beta_{1}-\beta_{2}=0$.

$\hat{\gamma}$ is the first-order jackknife estimate, used to correct for the underestimation of total species richness by $\gamma_{\text {obs }}$ (Heltshe \& Forrester 1983, Hellmann and Fowler 1999). The estimate and its variance are calculated as follows:

$$
\begin{aligned}
& \hat{\gamma}=\gamma_{o b s}+u\left(\frac{N-1}{N}\right) \\
& \operatorname{Var}(\hat{\gamma})=\frac{N-1}{N}\left(\sum_{s=1}^{\gamma_{o b s}} f_{s}-\frac{u^{2}}{N}\right)
\end{aligned}
$$

where $u$ is the number of unique species and $f_{s}$ is the number of sites that contain exactly $s$ of the $u$ unique species. $N$ is the number of sites. The variance of $\alpha$ diversity is given by

$$
\operatorname{Var}(\alpha)=\left[\sum_{i}^{\text {Yobs }} \hat{p}_{i}\left(1-\hat{p}_{i}\right)+2 \sum_{i}^{\text {Yobs }} \sum_{j>i}^{\text {oobs }} \operatorname{Cov}\left(I_{i}, I_{j}\right)\right] \frac{1}{N}
$$

where $\operatorname{Cov}\left(\mathrm{I}_{\mathrm{i}}, \mathrm{I}_{\mathrm{j}}\right)$ is the covariance of species $\mathrm{i}$ and $\mathrm{j}$ 's' observed presence/absence, $\hat{p}_{i}$ is the observed incidence of species $i$. 
The calculations were performed by a routine programmed in $R$ ( $\mathrm{R}$ Development Core Team 2005). The code is available from the corresponding author upon request.

Comparison of carabid dispersal groups. Carabid species were assorted to dispersal groups (brachypterous, dimorphic and macropterous) according to the literature (Lindroth 1989, Ribera et al. 1999). We calculated diversity components at the level of the field pair for brachypterous, dimorphic and macropterous carabids, and compared the percentage of total diversity $\left(\gamma_{\mathrm{obs}}\right)$ represented by $\alpha$ and $\beta$ diversity. We also performed a 1000-run individualbased randomization (Crist et al. 2003) for each dispersal group to discard the possibility that differences observed between species groups are due to chance.

\section{Results}

Spatial partitioning of diversity in different taxa. Our samples contained 1507 bees from 37 species, 24759 spiders from 98 species, 37322 carabids from 90 species and 10693 staphylinids from 174 species. 110 plant species were recorded.

$\alpha$ diversity was between 18 and $40 \%$ of observed total diversity $\left(\gamma_{\mathrm{obs}}\right)$, depending on the taxa. $\beta$ diversity thus accounted for the bulk of total species richness. Diversity partitioning expressed in percentage of $\gamma_{\text {obs }}$ differed between taxa (Fig. 2). Relative $\alpha$ diversity was highest for the plants $(40 \%)$, followed by carabids (34\%), spiders (27\%), staphylinids (22\%), and finally the bees (16\%). A feature shared by all taxa is the aggregation at the lower scales.

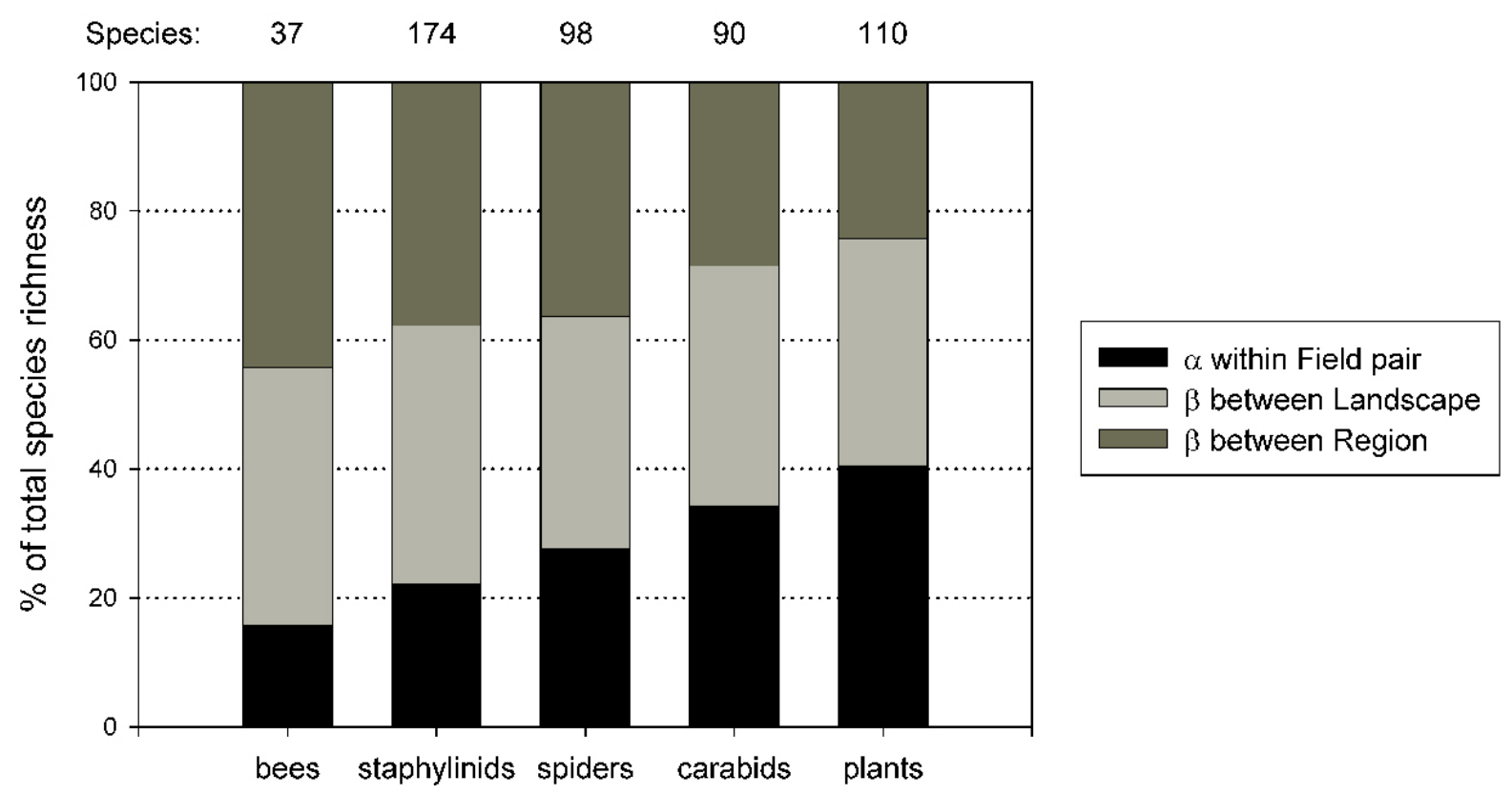

Fig. 2. Relative contributions of field pair, between-field pair and between-region scales to biodiversity of different higher taxa found in German wheat fields 


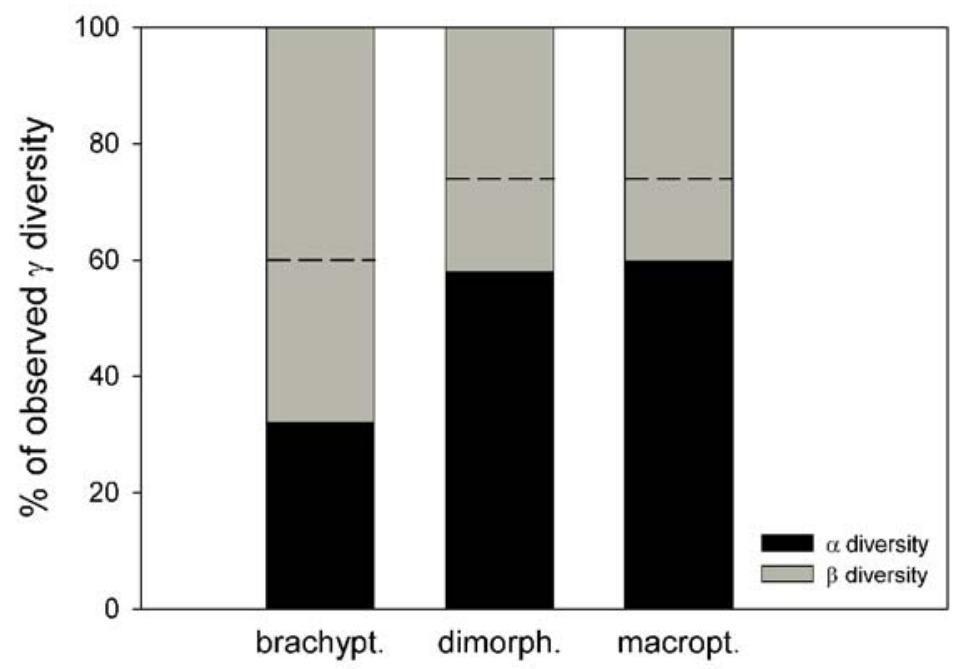

Fig. 3. Relative contributions of field pair and between-region scales to species richness of brachypterous, dimorphic and macropterous carabid beetles. The dashed lines are the expected percentage of $\alpha$ diversity based on an individual based randomisation of the samples.

For all three carabid dispersal groups, observed relative $\alpha$ diversity was smaller than expected by chance $(\mathrm{P}<0.001)$. For brachypterous carabids however this difference was much larger than in the macropterous and dimorphic groups $(\mathrm{P}<0.001$ for both pair-wise comparisons), indicating that dispersal limitation inflates $\beta$ diversity (Fig. 3).

Effects of organic management on $\alpha$ and $\beta$ diversity. The results for the hypothesis tests comparing $\alpha$ and $\beta$ diversities are shown in Table 1 and Table 2 respectively, while the data are summarised in Fig. 4. $\alpha$ diversity was significantly higher in the centre of organic fields than in the center of conventional fields for plants and bees but not for spiders, carabids and staphylinids (Table 1). The pattern was the same in the edge of the fields. $\beta$ diversity of bees

Table 1. Effect of management $(\mathrm{O}=$ organic, $\mathrm{C}=$ conventional) and location in field $(\mathrm{E}=\mathrm{edge}, \mathrm{C}=$ centre $)$ on $\alpha$ diversity of different taxa in German wheat fields (Wald tests for linear mixed-model fits). Interactions were not significant. Significance levels: ***, $\mathrm{P}<0.001 ; * *, \mathrm{P}<0.01 ; * \mathrm{P}<0.05 ;$ n.s., $\mathrm{P}>0.05$

\begin{tabular}{lllllll}
\hline & Management & $\mathrm{N}$ & F-Value & $\begin{array}{l}\text { Location in } \\
\text { field }\end{array}$ & $\mathrm{N}$ & F-Value \\
\hline Plants & $\mathrm{O}>\mathrm{C}$ & 21 & $63.342^{* * *}$ & $\mathrm{E}>\mathrm{C}$ & 42 & $70.00^{* * *}$ \\
Bees & $\mathrm{O}>\mathrm{C}$ & 21 & $32.134^{* * *}$ & $\mathrm{E}>\mathrm{C}$ & 42 & $9.70^{* *}$ \\
Carabids & $\mathrm{O}=\mathrm{C}$ & 21 & $1.037^{\text {n.s. }}$ & $\mathrm{E}>\mathrm{C}$ & 42 & $18.66^{* * *}$ \\
Spiders & $\mathrm{O}=\mathrm{C}$ & 21 & $2.034^{\text {n.s. }}$ & $\mathrm{E}>\mathrm{C}$ & 42 & $26.13^{* * *}$ \\
Staphylinids & $\mathrm{O}=\mathrm{C}$ & 21 & $0.904^{\text {n.s. }}$ & $\mathrm{E}>\mathrm{C}$ & 42 & $17.02^{* * *}$ \\
\hline
\end{tabular}


Table 2. P-values and Z-values (in brackets) for hypothesis tests comparing $\beta$ diversity (Kiflawi \& Spencer 2004) in the centre and edge of organic and conventional wheat fields. Treatments are: OC=Organic-Centre; $\mathrm{OE}=$ Organic-Edge; $\mathrm{CC}=$ Conventional Centre; $\mathrm{CE}=$ Conventional-Edge.

\begin{tabular}{llllll}
\hline & Plants & Bees & Carabids & Staphylinids & Spiders \\
\hline OC-CC & $<\mathbf{0 . 0 0 1}$ & $\mathbf{0 . 0 0 4}$ & 0.118 & 0.941 & 0.406 \\
& $\mathbf{( 4 . 0 9 9 )}$ & $\mathbf{( 2 . 8 6 7 )}$ & $(1.564)$ & $(0.075)$ & $(0.831)$ \\
OE-CE & $\mathbf{0 . 0 6 8}$ & $\mathbf{0 . 0 6 4}$ & 0.243 & 0.615 & 0.230 \\
& $\mathbf{( 1 . 8 2 7 )}$ & $\mathbf{( 1 . 8 5 5 )}$ & $(1.166)$ & $(0.503)$ & $(1.202)$ \\
CE-CC & $\mathbf{0 . 0 4 2}$ & 0.151 & $\mathbf{0 . 0 2 0}$ & $\mathbf{0 . 0 7 7}$ & $\mathbf{0 . 0 0 2}$ \\
& $\mathbf{( 2 . 0 3 4 )}$ & $(1.436)$ & $\mathbf{( 2 . 3 3 6 )}$ & $\mathbf{( 1 . 7 6 8 )}$ & $\mathbf{( 3 . 0 8 2}$ \\
OE-OC & 0.198 & 0.179 & 0.759 & $\mathbf{0 . 0 5 2}$ & $<\mathbf{0 . 0 0 1}$ \\
& $(1.288)$ & $(1.344)$ & $(-0.307)$ & $\mathbf{( 1 . 9 4 2 )}$ & $\mathbf{( 3 . 6 6 2 )}$ \\
\hline
\end{tabular}

and plants was higher in the centre but not at the edge of organic fields compared to conventionally managed fields (Table 2). There were no differences in $\beta$ diversity between both management types for the other taxa (Table 2).

Effects of location in field on $\alpha$ and $\beta$ diversity. Results for $\alpha$ and $\beta$ diversities can be found in Table 1 and Table 2 respectively, and Fig. 4 provides an overview of the data. Both $\alpha$ and $\beta$ diversity of spiders was higher at the edge of the fields. There were more staphylinid species in the edge of the fields as shown by the difference in $\alpha$ diversity. Staphylinid $\beta$ diversity was also higher in the edge, but this result was not significant in the conventional fields. For the plants $\alpha$ diversity was higher in the edge in both organic and conventional fields. Plant $\beta$ diversity was higher in the edge than in the centre of conventional fields, a pattern which did not hold in the organic fields. For bees $\alpha$ diversity was higher in the edge than in the centre of conventional fields, but not in the organic fields.

\section{Discussion}

Spatial partitioning of diversity in different taxa. The aim of this study was to uncover the effects of organic vs. conventional management on the spatial partitioning of diversity within different taxa. The comparison of $\alpha$ and $\beta$ diversities between taxa yielded two important findings. First, $\beta$ diversity accounts for a large part of the total diversity in our set of wheat fields regardless of taxon. This might seem surprising as the fields are rather homogeneous across the sample - they are dense, tilled monocrops. In addition arable fields cover a large part of western and central Europe and are not isolated habitats (FAOSTAT 2005). On the other hand, several studies have shown the large impact that field surroundings may have on species diversity (Dauber et al. 2003, Jeanneret et al. 2003, Gabriel et al. 2005, Clough et al. 

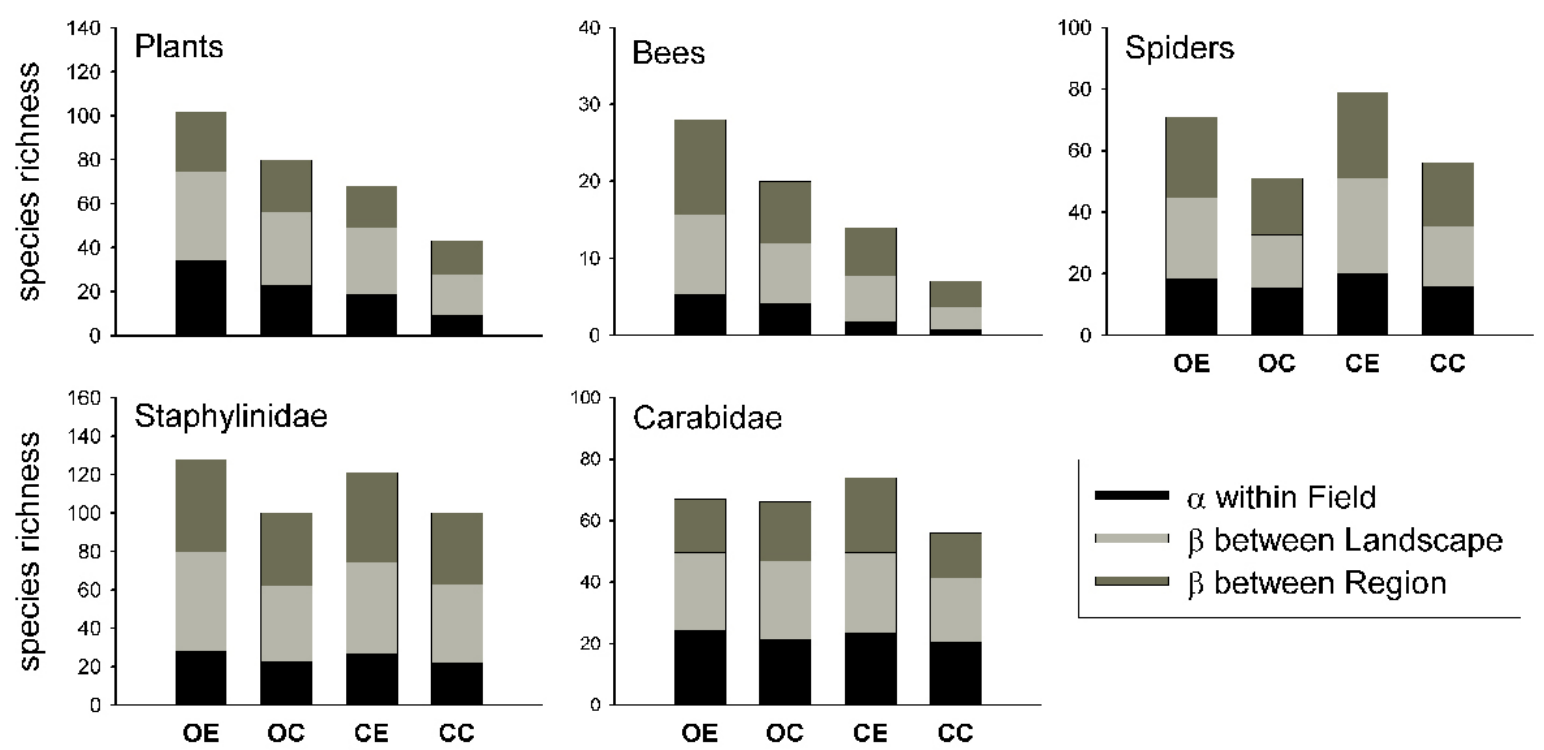

Fig. 4. $\alpha, \beta$ (between-field and between-region) and $\gamma_{\text {obs }}$ diversity for five species groups recorded in the edge and centre of organic and conventional fields in three regions of Germany; Treatments combinations are: $\mathrm{OE}=$ organic-edge $\mathrm{OC}=$ organic-centre $\mathrm{CE}=$ conventional-edge $\mathrm{CC}=$ conventional-centre

2005). Heterogeneity between landscapes may explain the high $\beta$ diversity between fields, just as heterogeneity within landscapes can explain the $\alpha$ diversity at the field level. Secondly, significant differences between taxa indicate that diversity is structured differently in space depending on the type of organism in focus. It is interesting to see that these differences exist between taxonomically related groups, for instance the two coleopteran families, because previous comparisons focused on much more contrasting organisms (Fleishman et al. 2003, for birds vs. butterflies). Our comparison of brachypterous, macropterous and dimorphic carabids show that the spatial partitioning of diversity can be related to dispersal ability: the brachypterous carabids exhibited a smaller $\alpha$ diversity than the other two groups, indicating that dispersal limitation can strongly change spatial partitioning of species richness by reducing $\alpha$ diversity and inflating $\beta$ diversity. Limitation in dispersal has often been stated to be the main cause for spatial patterns in diversity, but this has previously been considered to be more likely for plants than for mobile organisms, which are able to actively select their habitat and are less limited by available space (Loreau and Mouquet 1999). Other factors underlying the observed patterns can be differences in sensitivity to habitat conditions. Indeed, although we implicitly consider all wheat fields as a potential habitat for the species we recorded this is not necessarily a good approximation of the conditions as experienced by the organisms. For example for the bees the small contribution of $\alpha$ diversity to total diversity is not surprising: although bees can be good colonisers, site fidelity as well as the strong reliance on suitable nesting habitats outside of the arable fields (Westrich 1996, Gathmann 
and Tscharntke 2002) is likely to decrease the average amount of bee species found per field and explain the high spatial turnover in species composition.

Effects of organic management on $\alpha$ and $\beta$ diversity. $\alpha$ diversity was higher in organic than in conventional fields for plants and bees, but not for the surface-dwelling arthropods. Studies evaluating biodiversity benefits of organic farming generally find an increase across all taxa considered (Hole et al. 2005, Bengtsson et al. 2005), although variation in response of $\alpha$ diversity between taxa to organic farming has been shown elsewhere (Fuller et al. 2005). Interestingly, the results of our study strongly suggest that the strong positive response of plants to organic management is relayed to the pollinators (wild bees), while organisms that are less strongly associated with non-crop plants such as the epigeic arthropods benefit less (or not at all) from organic farming (Purtauf et al. 2005). Limited use of insecticides in conventional fields (only 9 out of 21 fields were sprayed, with a single application) or the use of comb-harrowing in organic fields (15 out of 21 fields, 10 of those more than once during the season), which may be detrimental to the epigeic fauna, may partly explain the absence of differences. The analysis of $\beta$ diversity in the context of comparing alternative management schemes is a new approach. It has also been shown that more intensive management may result in larger heterogeneity between plots and thus increased $\beta$ diversity, albeit on a temporal and not on a spatial scale (Tylianakis et al. in press). Intuitively, however, we expected $\beta$ diversity to be higher in organic fields than in conventional fields because organic fields tend to be managed more heterogeneously from farm to farm than conventional fields (Y. Clough unpublished results), where systematic use of synthetic fertilisers and pesticides, especially herbicides, are expected to level off the differences between the fields. Our findings matched our expectations for the plants and bees, the two taxonomic groups which showed a higher $\alpha$ diversity in organic fields. The differences were however restricted to the centre of the field, where the management differences are more marked. Edges of organic and conventional fields did not differ when considering $\beta$ diversity, with the exception of the bees. Effects of location in field on $\alpha$ and $\beta$ diversity. Edges of wheat fields contained a higher $\alpha$ diversity for all species groups considered in this study. Edges are less subject to management effect because they are close to the perennial boundary which allows more spillover than in the field centre (Coombes and Sotherton 1986, Bowie et al. 1999). In addition, agro-chemical applications may be less intensive at the edge of the fields than at the centre (Kleijn and van der Voort 1997). A more complex picture emerges from the analysis of the $\beta$ diversity: while for the spiders and the staphylinids the $\beta$ diversity is larger for the field edges than the field centres, this difference is not consistently significant across management types for the other 
taxa, although, with the exception of the bees, it is found for either the organic fields or the conventional fields. We do find an overall trend towards a higher $\beta$ diversity in the edges of the fields than in the centres of the fields. The higher $\beta$ diversity in the ecotone between fields and perennial field edge is most likely due to the high heterogeneity of perennial field edges between fields.

\section{Conclusions}

We found that organic farming contributes to enhanced biodiversity in agricultural habitats for plants and the most important insect group pollinating them, the bees. For arthropods less intimately linked to the non-crop vegetation, this was not the case. Diversity of all taxa was higher at the edge of the fields, presumably due to spillover effects from the adjacent boundary habitats. Our case study clearly demonstrates that the analysis of well-replicated biodiversity data benefits from the inclusion of $\beta$ diversity analyses. Although we did not find that $\beta$ diversity analyses reversed the conclusions on effectiveness of the agri-environment scheme that could be made with $\alpha$ diversity analyses, the $\beta$ diversity was the source of hidden biodiversity benefits in organic fields for two of the taxa. This additional diversity component greatly contributes to overall diversity at larger scales. Recently developed formulas for the statistical testing of $\beta$ diversity differences are a step towards enabling researchers to routinely conduct these analyses. $\beta$ diversity contributes a large part of total diversity regardless of taxon, but the relative importance of $\beta$ diversity, appeared to be especially important for those species groups for which dispersal is limiting and those that rely on multiple habitats.

\section{Acknowledgements}

We thank the farmers for their willingness to participate in the project, Angelo Bolzern and Tamás Szüts for the identification of spiders, Boris Büche for the identification of the Staphylinidae, and Indra Roschewitz for helping with the vegetation survey. This research was carried out within the framework of the EU-funded project 'EASY' (QLK5-CT-200201495).

\section{References}

Aitkin, M., D. Anderson, B. Francis, and J.Hinde. 1989. Statistical Modelling in GLIM, Oxford Science Publications, Oxford University Press, Oxford.

Arita, H. T., and P. Rodríguez. 2004. Local-regional relationships and the geographic distribution of species. Global Ecology and Biogeography 13:15-21. 
Bengtsson, J., J. Ahnström, and A.-C. Weibull. 2005. The effects of organic agriculture on biodiversity and abundance: a meta-analysis. Journal of Applied Ecology 42:261-269.

Blackburn, T. M., and K.J. Gaston. 1996. A sideways look at patterns in species richness, or why there are so few species outside the tropics. Biodiversity Letters 3:44-53.

Bowie M. H., G. M. Gurr, Z. Hossain, L. R. Baggen, and C. M. Frampton. 1999. Effects of distance from field edge on aphidophagous insects in a wheat crop and observations on trap design and placement. International Journal of Pest Management 45:69-73.

Clough Y., A. Kruess, D. Kleijn, and T. Tscharntke. 2005. Spider diversity in cereal fields: comparing factors at local, landscape and regional scales. Journal of Biogeography 32:2007-2014.

Coombes, D.S., and N. W. Sotherton. 1986. The dispersal and distribution of polyphagous predatory Coleoptera in cereals. Annals of Applied Biology 108:461-74.

Crist, T. O., J. A. Veech, J. C. Gering, and K. S. Summerville. 2003. Partitioning species diversity across landscapes and regions: a hierarchical analysis of $\alpha, \beta$, and $\gamma$ diversity. The American Naturalist 162:734-743.

Dauber, J., M. Hirsch, D. Simmering, R. Waldhardt, A. Otte, and V. Wolters. 2003. Landscape structure as an indicator of biodiversity: matrix effects on species richness. Agriculture, Ecosystems and Environment 98:321329.

Duelli, P. 1997. Biodiversity evaluation in agricultural landscapes: an approach at two different scales. Agriculture, Ecosystems and Environment 62:81-91.

FAOSTAT. 2005. FAO Statistical Databases. Rome: Food and Agriculture Organization of the United Nations. http://faostat.fao.org (accessed Oct 2005)

Fleishman, E., C. J. Betrus, and R. B. Blair. 2003. Effects of spatial scale and taxonomic group on partitioning of butterfly and bird diversity in the Great Basin, USA. Landscape Ecology 18:675-685.

Fuller, R. J., L. R. Norton, R. E. Feber, P. J. Johnson, D. E. Chamberlain, A. C. Joys, F. Mathews, R. C. Stuart, M. C. Townsend, W. J. Manley, M. S. Wolfe, D. W. Macdonald, and L. G. Firbank. 2005. Benefits of organic farming to biodiversity vary among taxa. Biology Letters. In press.

Gabriel, D., C. Thies, and T. Tscharntke. 2005. Local diversity of arable weeds increases with landscape complexity. Perspectives in Plant Ecology, Evolution and Systematics 7:85-92.

Gathmann, A., and T. Tscharntke. 1999. Landschafts-Bewertung mit Bienen und Wespen in Nisthilfen: Artenspektrum, Interaktionen und Bestimmungsschlüssel. Naturschutz und Landschaftspflege BadenWürttemberg 73:277-305.

Gering, J. C., T. O. Crist, and J. A. Veech. 2003. Additive partitioning of species diversity across multiple spatial scales: implications for regional conservation of biodiversity. Conservation Biology 17:488-499. 
Grafen, A., and J. Schramek. 2000. Germany: complex agri-environmental policy in a federal system. Pages 119-143 in H. Buller, G. A. Wilson, and A. Höll, editors. Agri-environmental policy in the European Union, Ashgate, Aldershot, UK

Heltshe, J. F., and N. Forrester. 1983. Estimating species richness using the jackknife procedure. Biometrics 39:1-11.

Hole, D. G., A. J. Perkins, J. D. Wilson, I. H. Alexander, P. V. Grice, and A. D. Evans. 2005. Does organic farming benefit biodiversity? Biological Conservation 122:113-130.

Jeanneret, Ph., B. Schüpbach, L. Pfiffner, and Th. Walter. 2003. Arthropod reaction to landscape and habitat features in agricultural landscapes. Landscape Ecology 18:253-263.

Kiflawi, M., and M. Spencer. 2004. Confidence intervals and hypothesis testing for beta diversity. Ecology 85:2895-2900.

Koleff, P., K. J. Gaston, and J. J. Lennon. 2003. Measuring beta diversity for presence-absence data. Journal of Animal Ecology 72:367-382.

Kleijn D., R. A. Baquero, Y. Clough, M. Díaz, J. De Esteban, F. Fernández, D. Gabriel, F. Herzog, A. Holzschuh, R. Jöhl, E. Knop, A. Kruess, E. J. P. Marshall, I. Steffan-Dewenter, T. Tscharntke, J. Vehulst, T. M. West, and J. L. Yela. (in press) European agri-environment schemes promote general biodiversity but rarely benefit endangered species. Ecology Letters.

Kleijn, D., and L. A. C.van der Voort. 1997. Conservation headlands for rare arable weeds: the effects of fertilizer application and light penetration on plant growth. Biological Conservation 81: 57-67.

Krebs, J. R., J. D. Wilson, R. B. Bradbury, and G. M. Siriwardena. 1999. The second Silent Spring? Nature 400:611-612.

Lande, R. 1996. Statistics and partitioning of species diversity, and similarity among multiple communities. Oikos 76:5-13.

Legendre, P., D. Borcard, and P. R. Peres-Neto. 2005. Analyzing beta diversity: partitioning the spatial variation of community composition data. Ecological Monographs 75: 435-450

Lindroth, C.H. 1992. Ground beetles (Carabidae) of Fennoscandia. A zoogeographic study. Part I. Specific knowledge regarding the species. Intercept, Andover.

Loreau, M., and N. Mouquet. 1999. Immigration and the maintenance of local species diversity. The American Naturalist 154:428-440.

Matson, P. A., P. J. Parton, A.G. Power, and M. J. Swift. 1997. Agricultural intensification and ecosystem properties. Science 277:504-509. 
Novotny, V., and G. D. Weiblen. 2005. From communities to continents: beta-diversity of herbivorous insects. Annales Zoologici Fennici 42:463-475.

Pinheiro, J. C., and D. M. Bates. 2000. Mixed-effects models in S and S-Plus, Springer, New York.

Purtauf, T., I. Roschewitz, J. Dauber, C. Thies, T. Tscharntke, and V. Wolters. 2005. Landscape context of organic and conventional farms: influences on carabid beetle diversity. Agriculture, Ecosystems and Environment 108:165-174.

R Development Core Team. 2005. R: A language and environment for statistical computing, Foundation for Statistical Computing, Vienna; URL: http://www.R-project.org.

Ribera, I., G. N. Foster, I. S. Downie, D. I. McCracken, and V.J. Abernethy. 1999. A comparative study on the morphology and life traits of Scottish ground beetles (Coleoptera, Carabidae). Annales Zoologici Fennici 36:2137.

Schmidt, M. H., Y. Clough, W. Schulz, A. Westphalen, and T. Tscharntke. 2005. Capture efficiency and preservation attributes of different fluids in pitfall traps. Journal of Arachnology, in press.

Soil Association. 2000. The biodiversity benefits of organic farming. Soil Association, Bristol, UK.

Topping, C. J. and K. D. Sunderland. 1992. Limitations in the use of pitfall traps in ecological studies exemplified by a study of spiders in a field of winter wheat. Journal of Applied Ecology 29:485-491.

Tylianakis, J., A. M. Klein, and T. Tscharntke. (in press) Temporally-dependent effects of habitat on spatially partitioned Hymenoptera diversity within a tropical mosaic landscape. Ecology.

Veech, J. A., K. S. Summerville, T. O. Crist, and J. C. Gering. 2002. The additive partitioning of species diversity: recent revival of an old idea. Oikos 99:3-9.

Wagner, H. H., O. Wildi, and K. C. Ewald. 2000. Additive partitioning of plant species diversity in an agricultural mosaic landscape. Landscape Ecology 15:219-227.

Westrich, P. 1996. Habitat requirements of central European bees and the problems of partial habitats. Pages 116 in A. Matheson, S. L. Buchmann, C. O'Toole, P. Westrich, and I. H. Williams, editors. The conservation of bees. Academic Press, New York, USA.

Whittaker, R. H. 1977. Species diversity in land communities. Evolutionary Biology 10:1-67. 


\section{Summary}

It is widely recognised that the intensification of agricultural practices in the second half of the twentieth century has not only substantially increased crop yields, but was part of a process which profoundly changed many aspects of the rural world, to the extent and on such a scale that from an ecological point of view this is a large part of what is now referred to as global change. From a spatial point of view, this intensification is a multi-scale process: at the field scale it is characterised by a high input load, high disturbance regimes and short crop rotations, at a larger scale it materialises through the concentration of similar land-uses, especially arable land, resulting in homogeneous landscapes. These profound modifications have taken their toll on biodiversity in agricultural landscapes, raising the concern that the functioning of the agroecosystem, which is hypothesised to depend on the diversity of species living in it, may be threatened.

In this study, we investigate whether certified organic agriculture can contribute to improve biodiversity in agroecosystems, and how these potential local improvements relate to the landscape context, which is independent of the local management. We focus on two groups of ground-dwelling arthropods, the spiders, which are predatory, and the staphylinids, which cover a range of different feeding groups including predators, detritivores and fungivores. In addition, we surveyed how experimental plots of a common weed, the creeping thistle Cirsium arvense, were colonised by herbivorous insects in the organic and conventional fields. In the last part of the work, patterns of $\beta$ diversity in the differently managed fields are investigated, and the importance of this diversity component for total diversity in the arable systems under study is highlighted.

Our investigations were conducted in 54 organic and conventional winter wheat fields in the vicinity of Göttingen, in the Soester Boerde and in the Lahn-Dill Bergland. These regions differ in many aspects and were chosen to provide some generality to the conclusions of the study. In each region we selected a number of organic and conventional field pairs, around which we mapped the landscape composition using geographical information systems. Biodiversity surveys were conducted in the centre and edge of the field because management effects can be expected to differ between these locations.

We found that the response to local and landscape factors strongly depended on the different arthropod groups. Species richness and activity-density of spiders were not affected by the management type, but strongly depended on the landscape context: more spiders and more spider species were caught in landscapes with a higher percentage of non-crop area. Similarly, 
activity-density and diversity was enhanced at the edges of the fields. Furthermore we could show that the composition of the spider fauna differs between edge and centre of the winter wheat fields, with lycosids concentrated near the perennial edge and erigonids making up the bulk of the spider fauna in the centre of the fields. The response of staphylinids was more complex: by separating species into feeding groups we could show that organic agriculture significantly enhances activity-density and species richness of the detritivorous guild, reflecting the importance of organic fertilisation through animal and green manure in these systems. Activity-density, but not species richness of the predatory staphylinids was higher in conventional fields, which is argued may be due to the higher density of aphids. Staphylinids were not affected by the landscape context, with the exception of one of the most common predators which was caught in higher numbers in heterogeneous landscapes at the beginning of the season.

The diversity of herbivorous insects colonising the experimental thistle plots was higher in organic fields than in conventional fields and increased with percentage non-crop habitat in the landscape, which shows that the effective isolation of weed patches from the higher trophic level depends on both local and landscape factors.

The analysis of $\beta$ diversity demonstrated that the species turnover is large between fields across all species groups, but that the relative importance of $\beta$ diversity depends on the group considered. Using the dichotomy between flightless and winged carabids, we could show that the importance of $\beta$ diversity in a collection of species depends on the dispersal ability: dispersal acts as a homogenising force which increases $\alpha$ diversity and decreases $\beta$ diversity. The analysis of management effects revealed that those groups for which organic fields had a higher $\alpha$ diversity (i.e. plot scale species richness), $\beta$ diversity was also higher, these "hidden" benefits of organic farming thus leading to a large difference in total diversity across samples. Our results show that organic fields harbour more arthropods and more arthropod species. This effect is not true for all groups, as larger scale factors may be more important than local management as was demonstrated for spiders. The results for the ground-dwelling arthropods as well as for the thistle herbivore community clearly show that landscape diversity as well as local management can complement each other. We thus suggest that the maintenance of important ecological functions such as weed herbivory, predation and saprophagy should be secured through a multi-scale approach to conservation in agricultural landscapes. 


\section{Zusammenfassung}

Die Intensivierung der landwirtschaftlichen Nutzung während der zweiten Hälfte des zwanzigsten Jahrhunderts hat nicht nur dazu geführt die Produktion erheblich zu steigern, sondern war Teil eines Prozesses, der zu vielseitigen Veränderungen im ländlichen Raum geführt hat. Durch das Ausmaß und die Verbreitung dieses Wandels auf der ganzen Welt ist es nun üblich, ihn als Teil des „Global Change“ wahrzunehmen, also der globalen Veränderung unserer Umwelt. Aus einer räumlichen Sicht muss diese Intensivierung auf verschiedenen Skalen betrachtet werden: auf der Ebene des Feldes zeichnet Sie sich durch erhöhten Pestizid- und Düngeraufwand aus, sowie durch eine höhere Störfrequenz durch Bodenbearbeitung und kürzeren Fruchtfolgen; auf der Landschaftsebene wiederum werden ähnliche Landnutzungsformen räumlich konzentriert, was $\mathrm{zu}$ einfacheren, homogenen Landschaften führt. Diese Veränderungen haben die Biodiversität stark in Mitleidenschaft gezogen, wodurch die Vermutung entstanden ist, dass funktionelle Aspekte der Agrarökosysteme, von denen man annehmen kann das Sie von der Artendiversität abhängen, gefährdet sind.

In dieser Studie wird untersucht, ob ökologischer Landbau zu einer Erhöhung der Biodiversität in Agrarökosystemen beitragen kann, und wie lokale Effekte im Zusammenhang mit dem Landschaftskontext stehen. Speziell untersuchen wir zwei Gruppen epigäischer Arthropoden, die Spinnen, die räuberisch leben, sowie die Staphyliniden, die ein breites Band an Ernährungsformen abdecken (u.a. Räuber, Saprophage, Pilzfresser). Zusätzlich wird ermittelt, welche Effekte lokale sowie Landschaftsfaktoren auf die Diversität der Herbivoren der Ackerkratzdistel Cirsium arvense haben. Im letzten Teil der Arbeit werden die $\beta$ Diversitätsmuster in den unterschiedlich bewirtschafteten Feldern analysiert, und die Wichtigkeit dieser räumlichen Diversitätskomponente in den Vordergrund gestellt.

Unsere Untersuchungen wurden in 54 ökologisch und konventionell bewirtschafteten Winterweizenfeldern bei Göttingen, in der Soester Boerde und im Lahn-Dill Bergland durchgeführt. Diese Regionen unterscheiden sich in einigen Aspekten und wurden ausgesucht, um den Ergebnissen der Studie eine breite Gültigkeit zu verleihen. In jeder Region wurden ökologisch-konventionelle Felderpaare ausgewählt, in deren Umfeld die Landschaftszusammensetzung aufgenommen und in ein geographisches Informationssystem übertragen wurde. Biodiversitätsaufnahmen wurden in der Mitte sowie am Rand der Felder durchgeführt, weil zu erwarten war, dass sich Bewirtschaftungseffekte in diesen beiden Bereichen unterschiedlich stark ausprägen. 
Wir fanden heraus, dass die verschiedenen Arthropodengruppen unterschiedlich auf lokale und Landschaftsfaktoren reagierten. Artenreichtum und Aktivitätsdichte von Spinnen waren in ökologisch und konventionellen Feldern ähnlich, hingen aber stark vom Landschaftkontext ab: mehr Spinnen sowie mehr Spinnenarten wurden in Landschaften mit einem hohen Anteil an perennierenden Habitaten gefangen. Aktivitätsdichte und Artenreichtum waren im Feldrand höher als in der Feldmitte, unabhängig von der Bewirtschaftung. Ferner konnte gezeigt werden, dass die Zusammensetzung der Spinnenfauna zwischen Rand- und Innenbereich unterschiedlich war, mit einer höheren Aktivitätsdichte der Lycosiden in der unmittelbaren Nähe zum perennierenden Randstreifen, und einer höheren Aktivitätsdichte der Erigoniden in der Feldmitte. Der ökologischen Heterogenität der Gruppe entsprechend fielen bei den Staphyliniden die Ergebnisse komplexer aus: indem wir die Arten Fraßgruppen zuordneten, konnten wir feststellen dass die ökologische Bewirtschaftung sich positiv auf die Aktivitätsdichte sowie auf den Artenreichtum der saprophagen Staphyliniden auswirkte, ein Ergebnis, das die Wichtigkeit des Einsatzes organischer Dünger in ökologischen Betrieben wiederspiegelt. Staphyliniden wurden vom Landschaftskontext nicht nachweislich beeinflusst, mit der Ausnahme eines häufigen Räubers, dessen Aktivitätsdichte am Anfang der Saison in Landschaften mit einem hohen Anteil an perennierenden Habitaten signifikant höher war.

Die Diversität der phytophagen Insekten an der Ackerkratzdistel war in ökologischen Feldern höher als in den konventionellen Kontrollfeldern, und stieg mit zunehmendem Anteil perennierender Habitate in der Landschaft an. Dies zeigt dass die effektive Isolation von Ackerwildkräutern sowohl von lokalen wie Landschaftsfaktoren abhängig ist.

Durch die Analyse der $\beta$ Diversität konnte nachgewiesen werden, dass das räumliche Artenturnover zwischen den Feldern sehr groß ist, aber dass die relative Größe der $\beta$ Diversität im Bezug zur Gesamtdiversität stark von der jeweiligen Artengruppe abhängig war. Anhand der separaten Auswertung der flugunfähigen, dimorphen und flugfähigen Carabiden konnte gezeigt werden, dass das Ausbreitungsvermögen hier eine wesentliche Rolle spielt, und dass Ausbreitung Artengemeinschaften homogenisiert, also die $\beta$ Diversität zugunsten der $\alpha$ Diversität abnehmen lässt. Die Bewirtschaftung wirkte sich innerhalb der verschiedenen Artengruppen ähnlich auf die $\beta$ Diversität aus wie auf die $\alpha$ Diversität. Dies führt zu zusätzlichen Diversitätsvorteilen in ökologischen und konventionellen Feldern bei Ackerwildkräutern und Bienen.

Die Ergebnisse dieser Studie zeigen dass ökologische Felder eine größere und diversere Arthropodenfauna beherbergen. Dies gilt nicht für alle Gruppen, da Landschaftsfaktoren eine wichtigere Rolle spielen können, wie es hier für die Spinnen nachgewiesen wurde. Die 
Analyse der epigäischen Fauna sowie der Distelherbivoren weist darauf hin, dass die Effekte der Landschaftsdiversität und der lokalen Bewirtschaftung sich gegenseitig ergänzen können. Wir ziehen die Schlussfolgerung, dass die Sicherung und die Förderung von wichtigen ökologischen Funktionen wie Herbivorie, Prädation und Saprophagie nur unter Einbeziehung der lokalen und der Landschaftsebene erfolgreich sein können. 


\section{Acknowledgements}

The past three years spent at the Agroecology in Göttingen have been extraordinarily enriching in many ways and I would like to seize the opportunity to thank those that contributed to the experience.

I would like to thank my supervisors Teja Tscharntke and Andreas Kruess for their precious time, help and guidance throughout the past three years. Many interesting discussions and constructive comments have hugely added to the work.

Carrying out my part of the EASY project would have been impossible without the fruitful cooperation with Andrea Holzschuh, who proved to be an invaluable co-worker and office roommate, regularly enabling the extension of working days with overly palatable carbohydrates.

David Kleijn coordinated the EASY project - I would like to thank him for the great leadership and all the project participants with whom we exchanged many ideas during the project - and especially Péter, Saci, Eva, Florian, Jort, Matthias, Josué, Elena and Rocio for lots of brilliant time, a number of lifers and many good laughs at formal and informal meetings!

Tobias Purtauf and Doreen Gabriel shared their data with me which was a great enrichment for the last part of my dissertation work. Thanks also to Tobi for his invaluable help in the field site selection and to Doreen for giving me a hand with the generation of the landscape data.

I am very grateful to Hella Grabe for all the work behind the screens and for helping to keep the red tape under control. Susanne Schiele knows how and when to pour oil into the motor of science to keep it turning, thank you for all the small things that make a big difference. I am similarly indebted to Mechthild Rittmeier and Magdi Weller for their assistance.

I would like to thank to the farmers in our study regions for allowing us to access their land, dig up things here and there, plant out noxious weeds, and for answering tons of questions without questioning our sanity.

Alejandro Acosta-Avila, Katharina Drzewiecki, Eva Völler, Britta Schäfer, Annett Reinhardt and Martin Malkmus and many other students spent hours looking through binocular microscopes or sorting pitfall samples, slicing open thistle stems, carrying buckets full of earth, planting thistles, watering thistles, digging up thistles roots and performing other chores essential for field-based ecological work. 
I thank Jochen, Andrea, Katrin, Indra, Melanie, Carsten, Alex, Dorthe, Katja, Doreen, Catrin, Martin, Christoph and Sabine for having integrated me so well into the group, with many barbecue and pub evenings and naturalist excursions that made the arrival in a new town so much more pleasurable!

Finally I would like to thank my mother, Ingrid, and my late father, John, for their love and trust and support in my endeavours, Jean Pierre for being so extremely helpful in difficult times, and Stéphanie with whom I shared countless great moments. 


\section{Publications}

Clough, Y., Kruess, A., Tscharntke, T. (submitted). Functional grouping helps understand staphylinid response to farming system.

Clough, Y., Gabriel, D., Holzschuh, A., Purtauf, T., Kruess, A., Steffan-Dewenter, I., Kleijn, D., Tscharntke, T. (submitted). $\alpha$ and $\beta$ diversity responses to crop management differ between species groups.

Clough Y., Kruess, A., Tscharntke, T. (submitted). Untangling local and landscape factors affecting the insect herbivore community of non-crop plants in arable fields.

Kleijn D., Baquero, R. A., Clough, Y., Díaz, M., De Esteban, J., Fernández, F., Gabriel, D., Herzog, F., Holzschuh, A., Jöhl, R., Knop, E., Kruess, A., Marshall, E. J. P., SteffanDewenter, I., Tscharntke, T., Verhulst, J., West, T. M., Yela, J. L. (in press) European agrienvironment schemes promote general biodiversity but rarely benefit endangered species. Ecology Letters.

Schmidt, M. H., Clough, Y., Schulz, W., Westphalen, A., Tscharntke, T. (in press) Capture efficiency and preservation attributes of different fluids in pitfall traps. Journal of Arachnology.

Clough, Y., Kruess, A., Kleijn, D., Tscharntke, T. (2005) Spider diversity in cereal fields: comparing factors at local, landscape and regional scales. Journal of Biogeography 32, 20072014.

Clough, Y., Kruess, A., Tscharntke, T. (2004) The insect community of Cirsium arvense benefits from landscape complexity and organic farming. Verhandlungen der Gesellschaft für Ökologie 35, 167.

Bukovinsky, T., Potting, R. P. J., Clough, Y., van Lenteren, J. C., Vet, L. E. M. (2005) The role of pre- and post- alighting detection mechanisms in the responses to patch size by specialist herbivores. Oikos 109, 435-446. 
Clough, Y., Kruess, A., Tscharntke, T. (2004) Spider abundance and diversity in winter wheat fields: no clear cut effects of organic management. Verhandlungen der Gesellschaft für Ökologie 34, 195.

Clough, Y., Bukovinsky, T., van Lenteren, J. C., Vet, L. E. M. (2002) Evaluating pest pressure in the Brussels sprout-barley intercropping system: influence of host plant patch size and surrounding vegetation. Proceedings Experimental and Applied Entomology 13, 123-126. 


\section{Curriculum vitae}

Yann Clough

born 22.12.1978 in Saint-Germain-en-Laye, France

2002-2006 PhD studies at the Agroecology Department of the Georg-August-University in Göttingen under the supervision of Prof. Dr. Teja Tscharntke and PD Dr. Andreas Kruess

2000-2002 MSc (Crop Science) Wageningen University, The Netherlands, 2002. Courses in entomology, nematology, phytopathology and integrated pest and vector management; Thesis: "Effects of resource patch size and surrounding vegetation on the pests of Brussels sprouts and their natural enemies" (Supervisors: Prof. Joop C. van Lenteren, Dr. Tibor Bukovinszky); Completed "with distinction".

1996-2000 Studies in agricultural and environmental sciences, Institut Supérieur d'Agriculture (ISA), Lille, France

1996 Completion of secondary education at the Lycée International, Saint-Germainen-Laye, France 